UNIVERSIDADE DE SÃO PAULO

ESCOLA DE ENGENHARIA DE SÃO CARLOS

TATIANA MATEUS GOMES

APLICAÇÃO DE MÉTRICAS DE CONFIABILIDADE PARA AVALIAÇÃO DA SETORIZAÇÃO DE SISTEMAS DE ABASTECIMENTO DE ÁGUA

VERSÃO CORRIGIDA

SÃO CARLOS, SP 2018 

TATIANA MATEUS GOMES

\section{APLICAÇÃO DE MÉTRICAS DE CONFIABILIDADE PARA AVALIAÇÃO DA SETORIZAÇÃO DE SISTEMAS DE ABASTECIMENTO DE ÁGUA}

Dissertação apresentada à Escola de
Engenharia de São Carlos da
Universidade de São Paulo como
parte dos requisitos para obtenção do
título de Mestre em Ciências:
Engenharia Hidráulica e Saneamento.

Orientadora: Prof. Tit. Luisa Fernanda Ribeiro Reis

VERSÃO CORRIGIDA

SÃO CARLOS, SP 2018 
AUTORIZO A REPRODUÇÃO TOTAL OU PARCIAL DESTE TRABALHO, POR QUALQUER MEIO CONVENCIONAL OU ELETRÔNICO, PARA FINS DE ESTUDO E PESQUISA, DESDE QUE CITADA A FONTE.

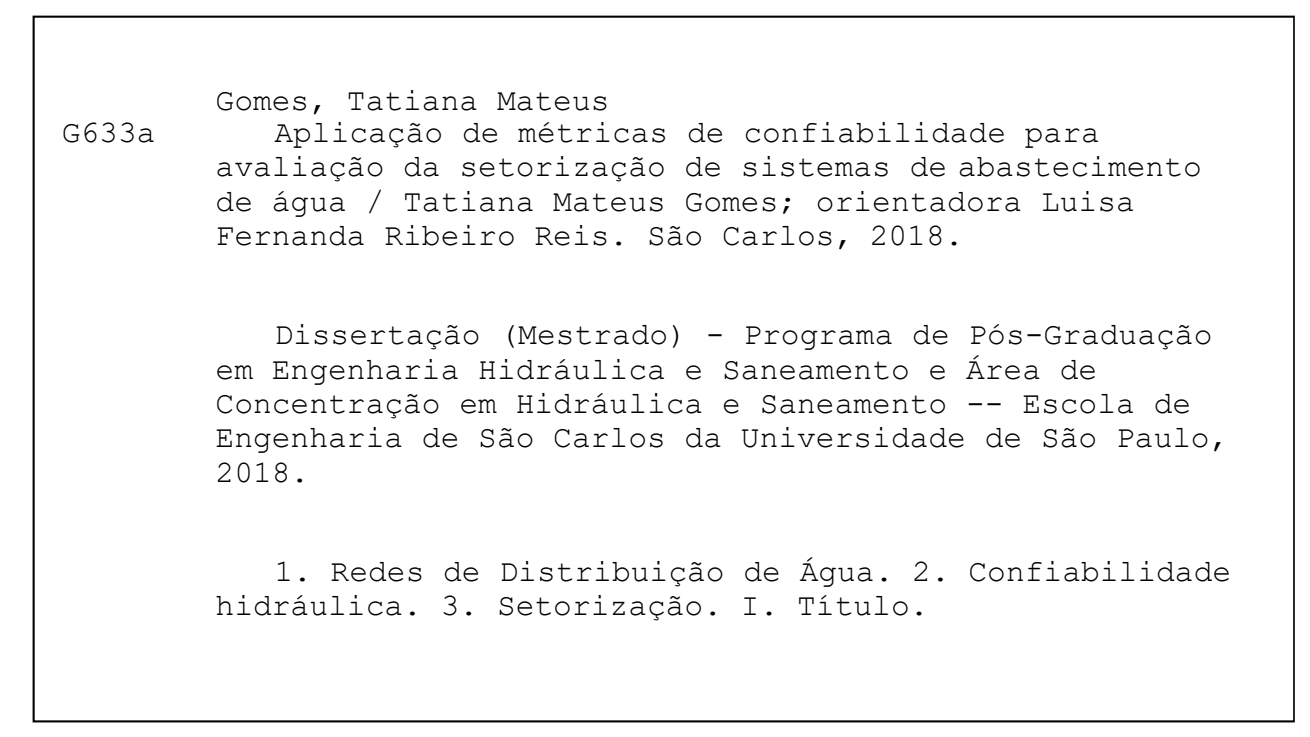




\section{FOLHA DE JULGAMENTO}

Candidata: Bacharela TATIANA MATEUS GOMES.

Título da dissertação: "Aplicação de métricas de confiabilidade para avaliação da setorização de sistemas de abastecimento de água".

Data da defesa: 08/10/2018.

Comissão Julgadora:

Profa. Titular Luisa Fernanda Ribeiro Reis

(Orientadora)

(Escola de Engenharia de São Carlos/EESC)

Prof. Dr. Erich Kellner

(Universidade Federal de São Carlos/UFSCar)

Profa. Dra. Cali Laguna Achon

(Universidade Federal de São Carlos/UFSCar)
Resultado:

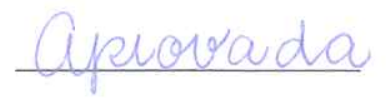

APROVADO

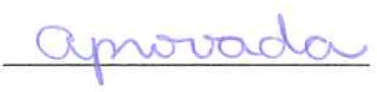

Coordenador do Programa de Pós-Graduação em Engenharia Hidráulica e Saneamento:

Prof. Dr. Eduardo Mario Mendiondo

Presidente da Comissão de Pós-Graduação:

Prof. Associado Luís Fernando Costa Alberto 



\section{AGRADECIMENTOS}

Quero agradecer primeiramente à minha família pelo apoio, em especial meus pais, Solange e Hélio, e meu irmão Bruno, pelo incentivo a todo o momento.

Agradecer, e muito, a minha orientadora Luisa Fernanda Ribeiro Reis por acreditar na minha capacidade, por todo o conhecimento e a experiência que me proporcionou, e principalmente pela paciência e suporte na reta final desta jornada.

Aos amigos incríveis que conquistei em São Carlos pelo companheirismo e pelos bons momentos que levarei para a minha vida, em especial Ana Cláudia e Alana Moura pela parceria e por sempre me darem abrigo quando precisei.

Aos amigos do LABSIN Arlan Scortegagna, Rafael Damiano e Maria Mercedes pelo convívio e pelos ensinamentos.

A todos os amigos de Vitória (ES), que apesar da distância sempre me apoiaram e entenderam a minha ausência nesta fase.

Ao SAAE São Carlos pela disponibilidade dos dados para a esta pesquisa.

À CAPES pelo apoio financeiro.

A todos que de alguma forma contribuíram com este trabalho. 



\section{RESUMO}

GOMES, Tatiana Mateus. Aplicação de métricas de confiabilidade para avaliação da setorização de sistemas de abastecimento de água. 2018. Dissertação (Mestrado) - Escola de Engenharia de São Carlos, Universidade de São Paulo, São Carlos, 2018.

Os avanços observados em Sistemas de Distribuição de Água vêm surgindo da necessidade de aumentar a eficiência, a qualidade e segurança do abastecimento de água aos consumidores. Dois desses avanços recentes que podem ser citados são a setorização e a quantificação da confiabilidade. O processo de setorização de um sistema de distribuição de água favorece a sua gestão, uma vez que possibilita maior controle da vazão distribuída e dos limites de fornecimento do serviço, entretanto pode implicar em restrições no abastecimento durante eventos de falhas ou emergências, sendo necessária a avaliação da confiabilidade. Diversos pesquisadores têm buscado uma metodologia coerente e adequada para quantificar a confiabilidade em sistemas de distribuição de água, muitos deles desenvolvendo métricas alternativas que visam simplificar esta definição. O presente trabalho visou investigar métricas alternativas de confiabilidade, propostas na literatura especializada, aplicando-as a estudos de caso para a rede original e após a setorização. Os resultados sugerem a viabilidade de utilização das métricas de confiabilidade como forma de avaliar diferentes níveis de setorização, no que diz respeito à vulnerabilidade do sistema.

Palavras-chave: Redes de Distribuição de Água; Confiabilidade hidráulica; Setorização. 



\begin{abstract}
GOMES, Tatiana Mateus. Usage of reliability measures for Water network Partitioning assessment. 2018. Master thesis - Escola de Engenharia de São Carlos, Universidade de São Paulo, São Carlos, 2018.

Improvements upon Water Distribution Systems have been made under the urge of increasing efficiency, quality and security of water supply to its customers. A couple of recent breakthroughs on Water Distribution Network are partitioning and reliability. Water network partitioning enhances operational management, once it enables higher control of supplied flow and awareness of boundaries regarding each partition. Nevertheless, it can lead to supply restrictions under emergency and failure events, what may require reliability assessment. Several researchers have pursued consistent approach to quantify reliability of Water Distribution Network, many of them proposed surrogate measures which focused on simplifying its measurement. The aim of this work is to look into surrogate reliability measures proposed in the literature and applying them on case studies for its original layout and after proposed partitioning. The results implies the usage feasibility for the reliability measures as a way of evaluating different stages of partitioning, regarding system's vulnerability.
\end{abstract}

Key word: Water Distribution Network; Hydraulic reliability; Partitioning. 



\section{LISTA DE FIGURAS}

Figura 1 - Composição das demandas no SDA (JUN; GUOPING, 2013). .29

Figura 2 - Fatores chave que influenciam a Confiabilidade Hidráulica em DAS (GHEISI; NASER, 2013).

Figura 3 - Fluxograma algoritmo do processo iterativo de cálculo do modelo de análises hidráulicas.

Figura 4 - Rede hipotética apresentada por Tucciarelli, Criminisi e Termini (1999).

Figura 5 - RDA de Pescara (WANG et al., 2015).

Figura 6 - RDA de Modena (WANG et al., 2015)

Figura 7 - RDA de Exeter - Universidade de Exeter - UK (Farmani, Savic e Walters, 2005)

Figura 8 - Localização do Setor Aracy. .54

Figura 9 - SDA do Aracy - São Carlos/SP. 55

Figura 10 - Vazão distribuída pelo Reservatório 1 (Zavaglia).................................56

Figura 11 - Vazão distribuída pelo Reservatório 2 (Antenor Garcia).......................56

Figura 12 - Vazão distribuída pelo Reservatório 3 (Aracy).

Figura 13 - Variação do fator multiplicativo $R_{i}$ dentro do range de pressão $P^{\min } \mathrm{e}$ $P^{\text {des. }}$

Figura 14 - Convergência dos modelos

Figura 15 - Variação do fator multiplicativo $R_{i}$ dentro do range de pressão $P$ min 10 mca e Pdes 20 mca.

Figura 16 - Variação da vazão distribuída pelo SDA com a pressão, variando-se a proporção de VDD e PDD.

Figura 17 - Pressão nos nós da RDA de Pescara considerando a total disponibilidade dos componentes do sistema (ausência de falha).

Figura 18 - Pressão nos nós da RDA de Modena considerando a total disponibilidade dos componentes do sistema (ausência de falha).

Figura 19 - Pressão nos nós da RDA de Exeter considerando a total disponibilidade dos componentes do sistema (ausência de falha).

Figura 20 - Pressão nos nós da RDA de Aracy considerando a total disponibilidade dos componentes do sistema (ausência de falha).

Figura 21 - Setores definidos a partir do algoritmo k-means para o Estudo de caso 1 - RDA de Pescara (a) nós da rede categorizados por DMC na localização geográfica e, (b) elevação dos nós da rede. 
Figura 22 - Setorização da RDA de Pescara com posicionamento dos fechamentos de setor.

Figura 23 - Setores definidos a partir do algoritmo $k$-means para o Estudo de caso 1 - RDA de Modena (a) nós da rede categorizados por DMC na localização geográfica e, (b) elevação dos nós da rede.

Figura 24 - Setorização da RDA de Modena com posicionamento dos fechamentos de setor.

Figura 25 - Resultados do número ótimo de clusters para cada um dos índices avaliados para o Estudo de caso 3 - RDA de Exeter.

Figura 26 - Setores definidos a partir do algoritmo k-means utilizando os índices GAP e Silhouette para o Estudo de caso 3 - RDA de Exeter (a) nós da rede categorizados por DMC na localização geográfica e, (b) elevação dos nós da rede.

Figura 27 - Setores definidos a partir do algoritmo k-means utilizando os índices Calinski-Harabasz e Davies-Bouldin para o Estudo de caso 3 - RDA de Exeter (a) nós da rede categorizados por DMC na localização geográfica e, (b) elevação dos nós da rede.

Figura 28 - Setorização da RDA de Exeter (2 setores) com posicionamento dos fechamentos de setor.

Figura 29 - Setorização da RDA de Exeter (12 setores) com posicionamento dos fechamentos de setor.

Figura 30 - Resultados do número ótimo de clusters para cada um dos índices avaliados para o Estudo de caso 4 - RDA de Aracy................................. 79

Figura 31 - Setores definidos a partir do algoritmo k-means utilizando os índices Silhouette e Davies-Bouldin para o Estudo de caso 4 - RDA de Aracy (a) nós da rede categorizados por DMC na localização geográfica e, (b) elevação dos nós da rede.

Figura 32 - Setores definidos a partir do algoritmo k-means utilizando os índices GAP e Calinski-Harabasz para o Estudo de caso 4 - RDA de Aracy (a) nós da rede categorizados por DMC na localização geográfica e, (b) elevação dos nós da rede.

Figura 33 - Setorização da RDA de Aracy (4 setores) com posicionamento dos fechamentos de setor.

Figura 34 - Setorização da RDA de Aracy (15 setores) com posicionamento dos fechamentos de setor.

Figura 35 - Relação entre a Confiabilidade Hidráulica e as métricas alternativas Inr e Ir e S. 


\section{LISTA DE TABELAS}

Tabela 1 - Equações para determinação do Ri para cálculo da PDD avaliadas.......43

Tabela 2 - Dados dos nós da rede de Tucciarelli, Criminisi e Termini (1999). .........45

Tabela 3 - Dados dos trechos da rede de Tucciarelli, Criminisi e Termini (1999).....46

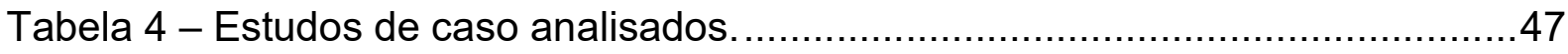

Tabela 5 - Resultados para cada modelo considerando $\mathrm{P}^{\min }=0 \mathrm{mca}$ e $\mathrm{P}^{\text {des }}=$

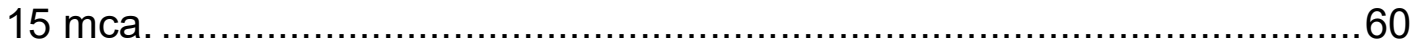

Tabela 6 - Resultados para cada modelo considerando $\mathrm{P}^{\mathrm{min}}=5 \mathrm{mca}$ e $\mathrm{P}^{\mathrm{des}}=$

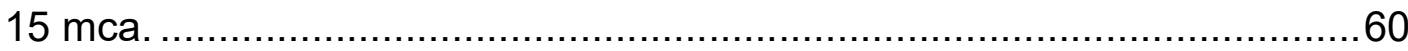

Tabela 7 - Resultados para cada modelo considerando $P^{\min }=10 \mathrm{mca}$ e $P^{\text {des }}=$ 20 mca.

Tabela 8 - Resultados para a rede hipotética variando a proporção VDD/PDD . ......63

Tabela 9 - Resultados das métricas de confiabilidade para os sistemas

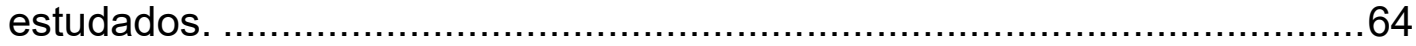

Tabela 10 - Valores das métricas de confiabilidade para o sistema original e o sistema após definição da setorização para o Estudo de caso 1 - RDA de Pescara.

Tabela 11 - Comparação entre as métricas de confiabilidade para o sistema original e o sistema após definição da setorização para o Estudo de caso 2 - RDA de Modena.

Tabela 12 - Comparação entre as métricas de confiabilidade para o sistema original e o sistema após definição da setorização para o Estudo de caso 3 - RDA de Exeter.

Tabela 13 - Comparação entre as métricas de confiabilidade para o sistema original e o sistema após definição da setorização para o Estudo de caso 4 - RDA de Aracy. 



\section{SUMÁRIO}

1 INTRODUCÃO

2 OBJETIVOS

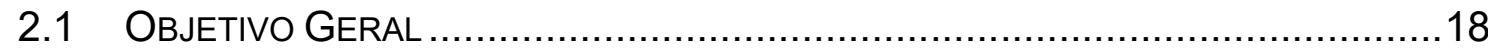

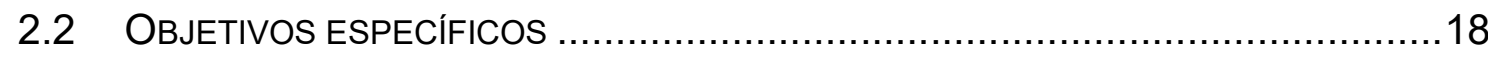

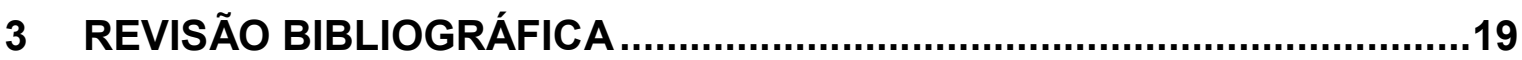

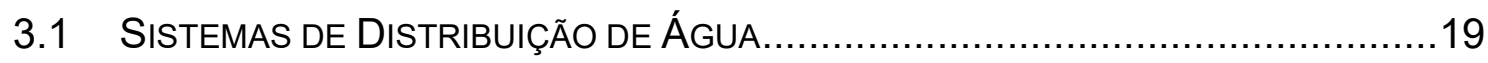

3.1.1 Formação de subsistemas para controle e gestão …………..............20

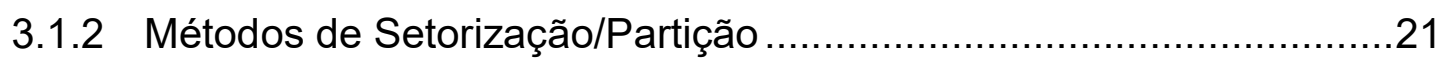

3.2 Modelos de SimulaçÃo para Sistemas de Distribuição de Água ............23

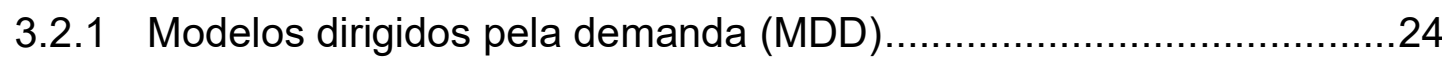

3.2.2 Modelos de demanda dirigidos pela pressão (MDDP) ........................25

3.3 COMPONENTES DA DEMANDA EM SISTEMAS DE DISTRIBUIÇÃo dE ÁGUA ..........25

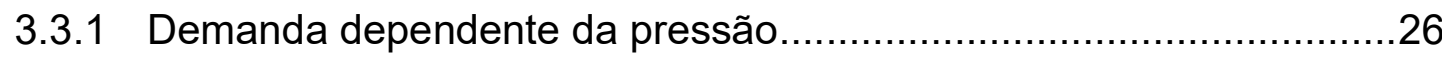

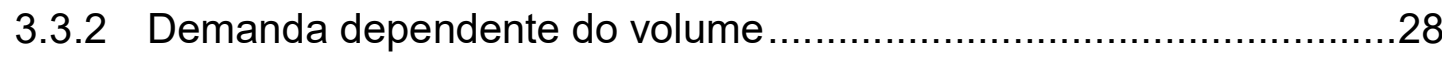

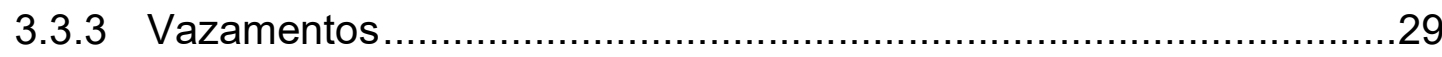

3.4 CONFIABILIDADE APLICADA A SISTEMAS DE DISTRIBUIÇÃo DE ÁGUA ................30

3.4.1 Confiabilidade Hidráulica ................................................................

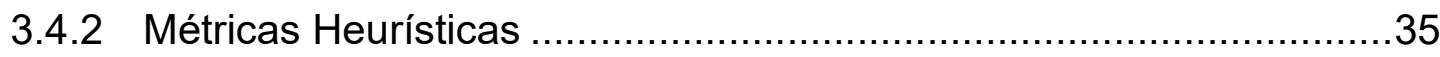

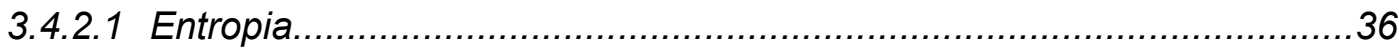

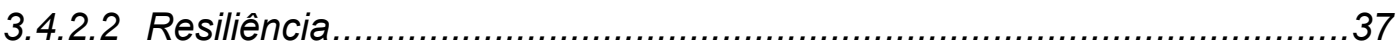

4 MATERIAIS E MÉTODOS

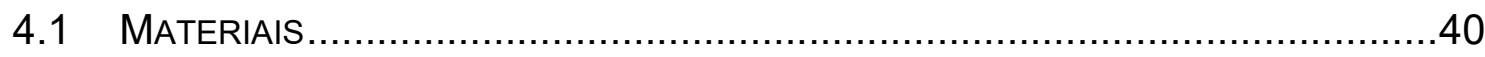

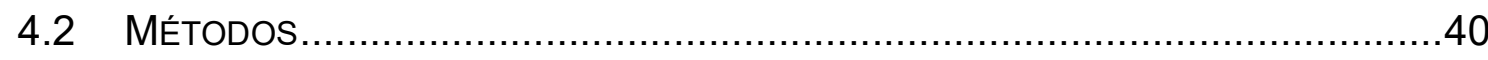

4.2.1 Fluxograma do Modelo de Simulação Hidráulica...............................40

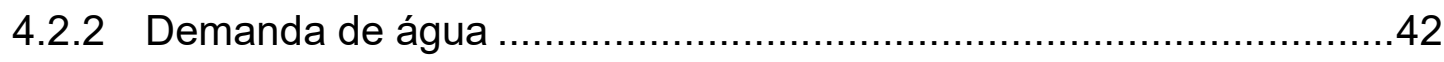

4.2.2.1 Demanda dependente da pressão (PDD).......................................... 43

4.2.2.2 Demanda dependente do volume (VDD) ...........................................4

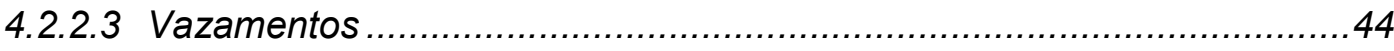


4.2.2.4 Rede hipotética análise previa.................................................... 44

4.2.3 Métricas de confiabilidade ..................................................... 46

4.2.4 Setorização de Sistemas de Distribuição de Água......................... 48

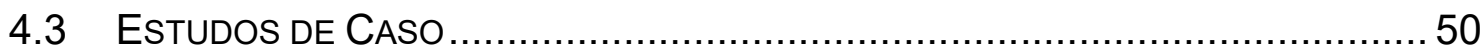

4.3.1 Estudo de caso 1 - RDA de Pescara............................................ 50

4.3.2 Estudo de caso 2 - RDA de Modena ............................................51

4.3.3 Estudo de caso 3 - RDA de Exeter ....................................... 52

4.3.4 Estudo de caso 4 - RDA de Aracy............................................ 53

$5 \quad$ RESULTADOS E DISCUSSÃO .......................................................... 58

5.1 AVALIAÇÃO DOS MODELOS DE DEMANDA DIRIGIDA PELA PRESSÃO ................. 58

5.2 IMPACTO DA PROPORÇÃO VDD/PDD NA VAZÃO DISTRIBUÍDA ....................... 62

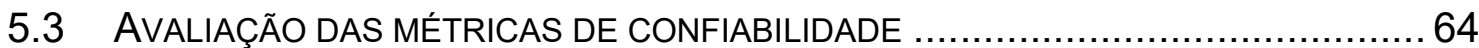

6 CONCLUSÕES .............................................................................. 87

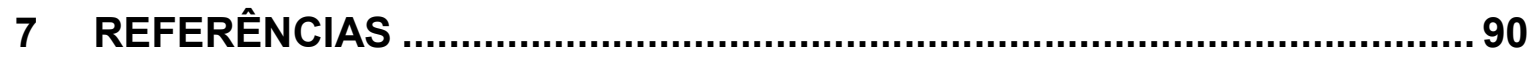




\section{INTRODUCÃO}

Se, por um lado, a adequada concepção de um Sistema de Abastecimento de Água (SAA) é de vital importância para a sociedade moderna, por outro, o crescimento das zonas urbanas e principalmente das grandes metrópoles, vem tornando os Sistemas de Distribuição de Água (SDA) cada vez maiores e mais complexos, exigindo maior atenção para o seu funcionamento e sua qualidade.

Atualmente, as principais questões que envolvem os SDA referem-se à garantia desses sistemas operarem de maneira adequada a satisfazer a demanda da população abastecida, além de manter a qualidade do seu produto, que é a água potável, e minimizar custos tanto de implantação como de operação/manutenção desses sistemas.

Costumeiramente, tanto o projeto como a operação dos sistemas são realizados por tentativa e erro. O projetista elabora um modelo hidráulico e altera suas características e parâmetros para uma configuração que aparenta atender suas expectativas e condições preestabelecidas em normas técnicas especializadas.

Porém, considerando-se a dimensão dos sistemas atuais, esta pode ser uma metodologia inadequada, uma vez que diversas são as possibilidades para um mesmo sistema (FORMIGA; CHAUDHRY; VIERIA, 2006).

Modelos de otimização, voltados tanto para a etapa de implantação como para manutenção das redes de distribuição de água, pode ser utilizados de modo a produzir a solução mais adequada para dado sistema. Porém, frequentemente esses modelos estão focados na minimização dos custos, não considerando a vulnerabilidade do sistema a falhas.

A confiabilidade do abastecimento, do ponto de vista do consumidor, é o grau de confiança que ele tem de que água de qualidade desejada esteja disponível para seu consumo, o que significa que níveis de pressão adequados devem ser mantidos na rede. Tradicionalmente, esta confiança é atribuída pelos projetistas à redundância do sistema de distribuição, através das redes malhadas (CESARIO, 1995).

Há algumas décadas vem sendo adotada como metodologia para aumentar a eficiência na gestão e no controle de SDA, a divisão desses em subsistemas menores, 
delimitados por válvulas de isolamento e com auxílio de medidores de vazão. Esses subsistemas tornam-se setores controlados para os quais são conhecidas as entradas e possíveis saídas de água. Deste modo, é possível ter maior controle operacional, e inclusive das perdas por possibilitar a medição da vazão distribuída no subsistema e seu confronto com valores micro medidos.

No entanto, a delimitação desses subsistemas promove o corte de alguns anéis de rede, alterando sua configuração, que passa a apresentar mais trechos ramificados. Tal processo pode reduzir a redundância na distribuição, causando problemas durante situações de emergência, como ocorrência de falhas em trechos da rede limitando o abastecimento da população. Dessa forma, se faz necessária uma metodologia capaz de definir subsistemas mais confiáveis de acordo com suas características.

Para Goulter et al. (2000) a principal questão é tornar a confiabilidade do abastecimento uma medida quantificável, de modo que possa ser utilizada por gestores, projetistas e operadores de SDA para melhoria do abastecimento. $\mathrm{Na}$ literatura, diversos índices são propostos pelos autores, visando uma avaliação quantitativa da confiabilidade para redes de distribuição de água, que se baseiam em parâmetros tais como a carga hidráulica mínima exigida, vazão demandada, excedente de pressão no sistema, entre outros.

Para Wang e Chen (2016) o estudo da confiabilidade em redes de distribuição de água deve ser embasado na análise de falha dos componentes da rede. Essa afirmação evidencia a complexidade da análise, uma vez que redes de distribuição são formadas de inúmeros componentes, mesmo aquelas consideradas de médio porte. Adicionalmente, as incertezas sobre o fluxo hidráulico da fonte de abastecimento até os consumidores, aumentam a complexidade do problema.

Até o presente momento, nenhum dos índices propostos ao longo dos anos por pesquisadores é aceito universalmente como uma metodologia prática e adequada de representação da confiabilidade em redes de distribuição de água.

Assim, o presente trabalho foi proposto no sentido de promover a análise hidráulica de sistemas de distribuição de água, aliada a uma metodologia simples e promissora de setorização/partição de redes proposta mais recentemente na literatura 
especializada, com vistas à avaliação dos impactos da setorização segundo métricas de confiabilidade. 


\section{OBJETIVOS}

\subsection{Objetivo Geral}

O presente trabalho visa investigar e verificar métricas de confiabilidade aplicadas à avaliação da setorização/partição de Sistemas de Distribuição de Água (SDA) através de técnica simples e promissora. Para tanto, alguns sistemas de médio e grande porte foram avaliados antes e após a implementação da setorização.

\subsection{Objetivos específicos}

- Avaliar e definir modelos para cálculo da demanda dirigida pela pressão e do vazamento necessários à simulação hidráulica dos sistemas de distribuição de água para abastecimento;

- Eleger métricas de confiabilidade para avaliação de desempenho dos sistemas submetidos à técnica simples e promissora de setorização/partição de sistemas de distribuição de água para abastecimento proposta recentemente;

- Aplicar o ferramental escolhido a sistemas de médio e grande porte, de maneira a possibilitar análises de desempenho tanto da setorização/partição como das métricas em representar indicadores de confiabilidade reconhecidos na literatura especializada. 


\section{REVISÃO BIBLIOGRÁFICA}

\subsection{Sistemas de Distribuição de Água}

Em se tratando de SDA, diversas são as incertezas que influenciam tanto o seu dimensionamento como a sua operação. A definição do projeto de uma rede, para que esta opere adequadamente, deve levar em consideração, por exemplo, as variações de demanda de seus consumidores uma vez que elas influenciam a operação de seus diversos componentes, tais como reservatórios, bombas, válvulas e tubulações (ALPEROVITS; SHAMIR, 1977).

Grande parte dos SDA projetados no século XIX se baseava em uma rede tronco de diâmetro maior, que se ramificava em diversas tubulações de diâmetros menores, como afirma Todini (2000). O custo de implantação dos sistemas baseava-se somente nos custos diretos para promover o abastecimento de determinado sistema, como custos construtivos de reservatórios e tubulações.

A implantação de anéis de rede, formando a rede malhada, passou a ser considerada em atendimento ao critério da redundância do abastecimento. Tal concepção de projeto tem o objetivo de garantir que haja fornecimento adequado aos consumidores caso haja falha em algum ponto da rede (GOULTER, 1995).

Desse modo, o sistema possui caminhos alternativos para o fornecimento de água, podendo evitar a interrupção do serviço. Porém, é necessário observar que redes em anéis não garantem que o abastecimento de água ocorra quando sobre elas incidirem mudanças e/ou falhas no sistema (TODINI, 2000).

Para garantir que a água potável seja entregue ao usuário, a rede de distribuição de água deve ser projetada de modo a suportar condições de emergência, que podem ser classificadas em três grupos: falha na tubulação (ruptura, vazamentos, etc.), demandas para combate a incêndios e possíveis cortes de energia (LANSEY; MAYS; TUNG, 2002).

No entanto, a existência de inúmeras conexões entre as tubulações de um SDA implica em dificuldades na resolução de alguns problemas importantes na gestão de sistemas como, definição do balanço hídrico e, consequente, diferenciação das 
perdas por região, além da otimização das pressões visando redução do vazamento sem comprometer os padrões mínimos de abastecimento aos usuários (CIAPONI; MURARI; TODESCHINI, 2016).

Com a evolução da tecnologia dos dispositivos de monitoramento em SDA, abriu-se a possibilidade de instalação de válvulas e medidores de vazão e pressão remotamente controlados. Di Nardo et al. (2013) afirmam que essa realidade proporcionou melhoria e simplificação na gestão dos sistemas, com a implantação de subsistemas menores internamente aos grandes SDA.

\subsubsection{Formação de subsistemas para controle e gestão}

A segmentação é uma prática, iniciada nos anos 80 , utilizada para aprimorar o controle operacional e, consequentemente, a gestão de SDA. Esta prática implica na definição de subsistemas que podem ser completa ou parcialmente isolados através das válvulas de fechamento (novas ou já implantadas), e até mesmo do capeamento de tubulações existentes (CAMPBELL et al., 2015).

Di Nardo, Di Natale e Santonastaso (2014) classificam esta prática a partir de dois conceitos distintos. Quando os subsistemas de um SDA estão completamente isolados, de modo que cada setor possui sua fonte de abastecimento, está é considerada uma Setorização. No entanto, quando são formados subsistemas que apresentem interligações com subsistemas vizinhos, denomina-se Particionamento.

Visto que o objetivo inicial da delimitação de subsistemas foi a possibilidade de obter o balanço hídrico desses sistemas, é imprescindível que se conheçam as entradas e saídas e que estas possam ser medidas e controladas através de instrumentação adequada. Por este motivo, os subsistemas foram então denominados Distritos de Medição e Controle (DMC) (CIAPONI; MURARI; TODESCHINI, 2016).

Os DMC permitem realizar uma série de ações de controle, como: análise de consumo não faturado e/ou perdas aparentes e consequente planejamento de investimentos para subsistemas que possuem tais índices elevados; definição da curva de consumo de cada região; identificação de vazamentos e possíveis erros de medição; possibilidade de isolamento de setores para proteção contra contaminação; além de auxiliar no controle das pressões (DI NARDO et al., 2015). 
Vale ressaltar que, em sistemas pré-concebidos sem esta prática, a definição dos DMC pressupõe desfazer alguns anéis de rede, formando ramificações, se opondo ao critério de projeto de redes relativo à redundância. Ao formar subsistemas, reduzemse os caminhos alternativos para abastecimento, o que pode modificar o desempenho da rede em caso de falhas ou emergências. (DI NARDO; DI NATALE, 2011; SCARPA; LOBBA; BECCIU, 2016).

Por esses e outros motivos, a reestruturação de um SDA é considerado um problema complexo, que, se não for tratado de maneira cuidadosa pode levar a interrupções no abastecimento, redução da qualidade da água e diminuição da confiabilidade no sistema (FERRARI; SAVIC; BECCIU, 2014).

\subsubsection{Métodos de Setorização/Partição}

A busca pela formação de subsistemas adequados é desafiadora e vem sendo objeto de estudo dentro de análises de gestão e planejamento de SDA. Giustolisi e Ridolfi (2014) afirmam que a definição otimizada dos subsistemas se relaciona com algumas razões técnicas importantes como análise do desempenho do sistema, calibração dos modelos hidráulicos, planejamento de sistemas de medição eficientes, determinação dos pontos de fechamento dos setores, controle de pressão e consequentemente controle de perdas por vazamento.

Os principais critérios que devem ser considerados na segmentação de um SDA são as características do sistema, podendo ser indicadores hidráulicos ou topológicos, e os critérios econômicos ligados ao custo de implantação das ações necessárias para delimitação dos setores (LIU et al., 2018). Os autores afirmam que indicadores topológicos são de mais fácil aplicação computacional.

Laucelli et al. (2017) relatam, no entanto, que a definição da localização para os dispositivos de controle e de fechamento (medidores de vazão e válvulas de bloqueio) que além de delimitar os setores possa satisfazer os requisitos hidráulicos do sistema pode se tornar computacionalmente custoso.

Os autores ressaltam ainda que para ser efetivamente possível avaliar o desempenho hidráulico da segmentação proposta, se faz necessário utilizar modelos de demanda dirigida pela pressão além de considerar as variações de demanda que ocorrem no 
sistema, para todos os possíveis arranjos de setores. Se considerada ainda a aplicação em SDA de médio a grande porte o problema pode ter o seu grau de dificuldade ampliado.

Visto isso, Di Nardo et al. (2018) dividem o processo de segmentação de RDA em duas fases: (a) formação de clusters, com o objetivo de definir a quantidade, o tamanho e a forma dos subsistemas, e (b) divisão, dedicada a definir os locais de instalação dos dispositivos de controle, fechamento e medição.

A formação de clusters pode ser definida como o processo de divisão um conjunto em grupos cujos elementos integrantes apresentem padrões similares entre si, enquanto grupos distintos apresentem características diferentes (GÜNTER; BUNKE, 2003).

Sela Perelman et al. (2015) compararam três metodologias de formação de clusters: clustering global, estrutura de comunidades e partição em grafos. Tais métodos estão relacionados entre si na aplicação e análise de sistemas complexos e foram largamente estudados nos últimos anos.

Os grafos são estruturas formadas por vértices e arestas, em SDA, estas representam os nós e os trechos da rede. Di Nardo et al. (2018) investigaram a viabilidade de aplicação de dois dos métodos de partição em grafos mais adotados, segundo os autores, são eles o "Metis" e o "N Cut".

Já Liu et al. (2018) avaliaram outros dois métodos de partição de RDA nomeadamente "Fast Greedy" e "Random Walk", que são métodos focados em detectar a estrutura da comunidade. Além disso, avaliaram também a metodologia do algoritmo "Metis" já citado anteriormente.

O clustering global é um dos métodos mais tradicionais quando se trata de algoritmos de segmentação. Estes necessitam ter como dado de entrada o número de clusters desejado para o resultado final (GÜNTER; BUNKE, 2003).

Para Maulik e Bandyopadhyay (2002) duas questões são fundamentais quando se fala de formação de clusters em qualquer sistema: a) quantos clusters estão presentes nos dados e, b) a qualidade da configuração que se obtém como consequência.

Com vistas a solucionar tais questões, alguns índices de validação foram propostos na literatura, tais como, Davies-Bouldin, Dunn, C e Goodman-Kruskal. Estes índices 
determinam a qualidade da configuração obtida para determinado número de clusters, assim é possível identificar o número que otimiza o resultado (GÜNTER; BUNKE, 2003).

Novarini et al. (2017) propuseram um método de clustering global utilizando o algoritmo k-means para definição dos subsistemas que é considerado pelos autores um algoritmo de fácil implementação e, por isso, aplicável a muitas áreas de conhecimento. Para definição do número ótimo de clusters para o sistema estudado os autores utilizaram como índice de validação o índice GAP, o Silhouette, o índice Calinski-Harabasz, além do índice Davies-Bouldin citado anteriormente.

Quando se trata de avaliar a performance dos algoritmos de segmentação, Sela Perelman et al. (2015) expõem que se trata de uma tarefa complexa principalmente porque o resultado adequado é desconhecido, dependem dos dados de entrada e de uma seleção de parâmetros que reflitam os critérios a serem considerados. Os autores acrescentam ainda, que, mesmo com as diversas métricas quantitativas propostas ao longo dos anos, a tomada de decisão ainda demanda análise qualitativa e considerações subjetivas.

Di Nardo et al. (2015) afirmam que o particionamento de RDA é amplamente utilizado, mas não foram desenvolvidos indicadores específicos para comparar diferentes configurações de partições para auxiliar na tomada de decisão entre todas as possibilidades.

\subsection{Modelos de Simulação para Sistemas de Distribuição de Água}

O problema correspondente à análise de RDA é definido como a determinação do comportamento hidráulico do sistema, de modo a definir as vazões nos trechos e pressões nos nós da rede. Devido à não linearidade das equações que governam esses sistemas relacionando vazão e perda de carga nas tubulações, estas não podem ser solucionadas diretamente, sendo necessária a utilização de métodos iterativos que geram soluções parciais e convergem para uma solução final (FORMIGA; CHAUDHRY, 2008; ROSSMAN, 2000a).

Formiga e Chaudhry (2008) classificam estes métodos iterativos em cinco categorias: Gradiente local, Newton-Raphson, Linearização, Minimização numérica e Métodos 
híbridos. Cada um deles apresenta vantagens e desvantagens que devem ser analisadas previamente à sua aplicação.

A união dos métodos de minimização numérica e de Newton-Raphson resultou no Método do Gradiente (TODINI; PILATI, 1987), um algoritmo utilizado na maior parte dos simuladores hidráulicos disponíveis e muito utilizado atualmente, como EPANET e WATERCAD.

De acordo com Giustolisi e Walski (2012), quando se trata da demanda do sistema, modelos de simulação hidráulica são comumente divididos em duas categorias, sendo elas, modelos dirigidos pela demanda (MDD) ou modelos de demanda dirigida pela pressão (MDDP).

Muranho et al. (2014) argumentam que ambas as abordagens de modelagem hidráulica possuem importância inquestionável quando se trata de planejamento, dimensionamento e, até mesmo, diagnóstico e operação de SDA. Porém, os MDD são mais precisos quando o sistema apresenta condições normais de abastecimento (pressões satisfatórias), enquanto o MDDP é ideal para sistemas com pressões deficitárias.

\subsubsection{Modelos dirigidos pela demanda (MDD)}

Os MDD representam uma metodologia clássica de modelagem em SDA, na qual a demanda é considerada conhecida para que então se determine a pressão nos nós e vazões nos trechos da rede. Para Wu et al. (2009), essa metodologia só pode ser considerada válida caso as pressões nos nós da rede tenham valor desejável para que o abastecimento seja adequado, uma vez que demandas são supostamente atendidas.

Modelos de simulação hidráulica tradicionais não levam em consideração a variação da demanda do sistema dada qualquer variação da condição de pressão disponibilizada, o que representa uma limitação importante para esses modelos (CONEJOS; ALZAMORA; ALONSO, 2017).

Tanyimboh, Tahar e Templeman (2002) questionam a aplicabilidade dos MDD, uma vez que, São baseados na presunção da existência de carga hidráulica na rede 
suficiente para que a demanda requerida pelo consumidor seja satisfeita por completo. Como consequência disso, calculam-se as pressões na rede de distribuição.

Na prática, como afirmam Formiga e Chaudhry (2008), caso a pressão disponibilizada na rede não seja adequada à completa satisfação da demanda requerida, esta será fornecida em quantidade reduzida, promovendo um fornecimento de água parcial não nulo. A maneira adequada de introduzir tal comportamento nos modelos hidráulicos consiste em considerar a análise de demanda dirigida pela pressão (MDDP), segundo a qual a demanda é uma variável dependente da pressão em cada nó de consumo.

\subsubsection{Modelos de demanda dirigidos pela pressão (MDDP)}

Metodologias de análise de redes baseadas em MDDP preestabelecem valores limites de pressão de serviço para definição da quantidade de demanda passível de ser atendida. Para que a demanda seja satisfeita por completo, a pressão em dado nó deve ser igual ou superior a um valor desejável (CHEUNG; VAN ZYL; REIS, 2005).

Cheung, Van Zyl e Reis (2005) afirmam, ainda, que a demanda não será satisfeita e o abastecimento será nulo caso a disponibilidade de pressão seja inferior à pressão mínima estabelecida. Para valores de pressão disponível intermediários, considerase uma relação de proporção entre pressão e demanda para definição da quantidade de água fornecida.

Desde os anos 80, muitas foram as propostas de MDDP, no entanto, para Mahmoud, Savic e Kapelan (2017) grande parte das formulações não é ideal devido às dificuldades de implementação e ineficiência computacional, com difícil utilização em SDA maiores e principalmente avaliações em período estendido.

\subsection{Componentes da demanda em Sistemas de Distribuição de Água}

Giustolisi e Walski (2012) classificam as demandas encontradas em um SDA em quatro tipos: a) demanda dependente da pressão (PDD) - controlada pelo consumidor; b) demanda dependente do volume (VDD); c) demanda de combate a incêndios; e d) vazamentos. 


\subsubsection{Demanda dependente da pressão}

Em um SDA real, a vazão distribuída aos nós de consumo da rede está atrelada à pressão disponível para o atendimento da demanda. A demanda requerida pela rede será plenamente satisfeita uma vez que a pressão disponibilizada seja igual ou maior que a desejada Da mesma maneira, o abastecimento será nulo caso a pressão disponibilizada seja menor que uma pressão mínima (PACCHIN; ALVISI; FRANCHINI, 2017).

As condições para determinação da vazão efetivamente distribuída nos nós de consumo são definidas como:

$$
\left\{\begin{array}{lr}
q_{i}^{\text {PDD disp }}=q_{i}^{\text {PDD req }} & \text { se } P_{i} \geq P_{i}^{\text {des }} \\
q_{i}^{\text {PDD disp }}=q_{i}^{\text {PDD req }} \cdot R_{i} & \text { se } P_{i}^{\min }<P_{i}<P_{i}^{\text {des }} \\
q_{i}^{\text {PDD disp }}=0 & \text { se } P_{i} \leq P_{i}^{\min }
\end{array}\right.
$$

Sendo: Ri o coeficiente que define a porcentagem da demanda satisfeita para uma dada pressão; $q_{i}^{\text {PDD req }}$ a parcela de demanda dependente da pressão requerida pelo no $i ; q_{i}^{P D D ~ d i s p ~ a ~ p a r c e l a ~ d e ~ d e m a n d a ~ d e p e n d e n t e ~ d a ~ p r e s s a ̃ o ~ d i s p o n i ́ v e l ~ p a r a ~ o ~ n o ́ ~ i ; ~}$ $\mathrm{P}_{\mathrm{i}}, \mathrm{P}_{\mathrm{i}}^{\mathrm{min}}$ e $\mathrm{P}_{\mathrm{i}}^{\text {des }}$ as pressões disponível, mínima e desejável, respectivamente, no nó i.

Dadas as condições apresentadas anteriormente, diversos autores apresentaram propostas para a determinação do coeficiente $\mathrm{R}_{\mathrm{i}}$.

Wagner, Shamir e Marks (1988) propuseram a seguinte equação para determinar o coeficiente $R_{i}$.

$R_{i}=\left(\frac{P_{i}-P_{i}^{\min }}{P_{i}^{\text {des }}-P_{i}^{\min }}\right)^{1 / 2}$

Tanyimboh, Tabesh e Burrows (2001) propuseram uma equação similar à apresentada anteriormente para coeficiente $R_{i}$.

$\mathrm{R}_{\mathrm{i}}=\left(\frac{\mathrm{P}_{\mathrm{i}}-\mathrm{P}_{\mathrm{i}}^{\min }}{\mathrm{P}_{\mathrm{i}}^{\text {des }}-\mathrm{P}_{\mathrm{i}}^{\min }}\right)^{1 / e_{i}}$

Neste caso $e_{i}$ é um expoente que deve ser determinado para cada nó e pode variar entre 1,5 a 2. Este é comumente admitido como dois o que se igualaria à equação de 
Wagner, Shamir e Marks (1988). Para esta proposição, admite-se que a pressão mínima para que parte da demanda seja satisfeita deve ser igual a 5 mca.

Já Fujiwara e Li (1998) propuseram uma equação distinta, conforme apresentado a seguir.

$R_{i}=\frac{\left(P_{i}-P_{i}^{\text {min }}\right)^{2} \cdot\left(3 P_{i}^{\text {des }}-2 P_{i}-P_{i}^{\min }\right)}{\left(P_{i}^{\text {des }}-P_{i}^{\text {min }}\right)^{3}}$

Da mesma maneira que Tanyimboh, Tabesh e Burrows (2001), esta proposição admite uma pressão mínima igual a igual a 5 mca.

Tucciarelli, Criminisi e Termini (1999) propuseram outra equação que limita a pressão mínima estabelecida para a satisfação da demanda em zero.

$R_{i}=\sin ^{2}\left(\frac{P_{i}}{2 P_{i}^{\text {des }}} \cdot \pi\right)$

Esta equação foi posteriormente reformulada por Jun e Guoping (2013) para incorporar situações nas quais a $\mathrm{P}_{\mathrm{i}}^{\min }$ é maior que zero.

$R_{i}=\sin ^{2}\left[\frac{P_{i}-P_{i}^{\min }}{2\left(P_{i}^{d e s}-P_{i}^{\min }\right)} \cdot \pi\right]$

Tanymboh e Templeman (2010) propuseram uma equação que se baseia em dois coeficientes alfa e beta, os quais, na ausência de dados de campo para determinalos, podem ser definidos como segue.

$\mathrm{R}_{\mathrm{i}}=\frac{\exp \left[\alpha_{i}+\beta_{i}\left(P_{i}+h_{i}\right)\right]}{1+\exp \left[\alpha_{i}+\beta_{i}\left(P_{i}+h_{i}\right)\right]}$

Sendo: $h_{i}$ é a elevação do nó (m).

$\alpha_{i}=\frac{-4,595\left(P_{i}^{\text {des }}+h_{i}\right)-6,907\left(P_{i}^{\text {min }}+h_{i}\right)}{\left(P_{i}^{\text {des }}-P_{i}^{\text {min }}\right)}$

$\beta_{i}=\frac{11,502}{\left(P_{i}^{\text {des }}-P_{i}^{\text {min }}\right)}$ 


\subsubsection{Demanda dependente do volume}

Esta pode ser considerada uma parcela fixa da demanda, causada por dispositivos automáticos que se utilizam de determinado volume de água cada vez que seu funcionamento é ativado. (CONEJOS; ALZAMORA; ALONSO, 2017).

Segundo Ghorbanian, Karney e Guo (2015), VDD são basicamente vasos sanitários, banheiras, lavadoras de roupa e louça e estas praticamente não são afetadas pela variação de pressão disponibilizada uma vez que dependem de um volume de água predefinido.

A metodologia utilizada por Jun e Guoping (2013) também considera que uma parcela da demanda é dependente do volume que deve satisfazer as seguintes condições:

$$
\begin{cases}q_{i}^{\text {VDD disp }}=q_{i}^{\text {VDD req }} & \text { se } P_{i}>0 \\ q_{i}^{\text {VDD disp }}=0 & \text { se } P_{i} \leq 0\end{cases}
$$

Sendo: $q_{i}^{V D D \text { req }}$ a parcela de demanda dependente do volume requerida pelo no $i$; $q_{i}^{V D D}$ disp a parcela de demanda dependente do volume disponível para o nó i; e $P_{i}$, a pressão disponível no nó i.

A Figura 1 apresenta o comportamento dessas demandas com a variação da pressão no sistema, o que ilustra o pleno atendimento da demanda VDD qualquer que seja a pressão acima de 0 mca. 
Figura 1 - Composição das demandas no SDA (JUN; GUOPING, 2013).

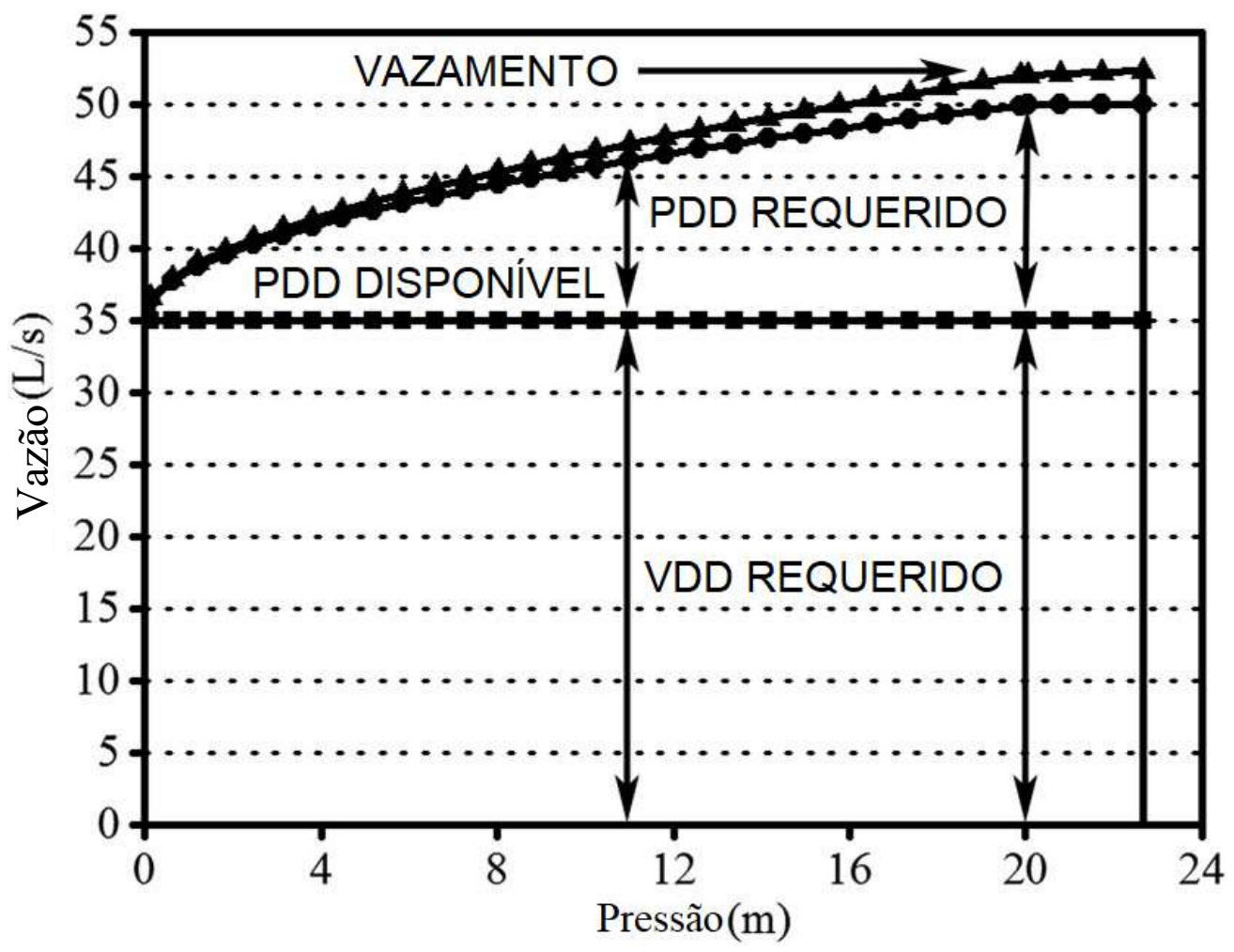

Também é possível observar na Figura 1 a característica de dependência da pressão para os vazamentos da RDA, não apenas para a demanda PDD.

\subsubsection{Vazamentos}

É notório que os vazamentos em uma RDA estão diretamente relacionados com a pressão de serviço do sistema. Jowitt e Xu (1990) afirmam que pressão e vazamento possuem uma relação não linear e que a vazão perdida aumenta proporcionalmente com o aumento da pressão média de serviço.

De modo a incorporar a relação entre vazamentos e pressão nas análises de RDA e em modelos de simulação, Germanopoulos (1985) propôs uma equação capaz de quantificar a vazão perdida em cada nó do sistema. Esta proposição relaciona ainda, o volume vazado com comprimento da tubulação e determinada constante que depende das características da RDA.

$\mathrm{q}_{\mathrm{i}}^{\mathrm{vaz}}=\frac{1}{2} \sum_{j} \mathrm{CL}_{\mathrm{j}} \mathrm{P}_{\mathrm{j}}^{1,18}$ 
Sendo: $P_{\mathrm{j}}$ igual à média das pressões nos nós a montante e a jusante do trecho j; Ljigual ao comprimento do trecho ligado ao nó j;

Tucciarelli, Criminisi e Termini (1999) propuseram outro equacionamento para a determinação dos vazamentos na RDA incluindo como parâmetro o diâmetro da tubulação, abrangendo toda a área útil da tubulação.

$q_{i}^{v a z}=P_{i}^{a} \sum_{j} \frac{\pi}{2} D_{j} L_{j} C$

Sendo: $P_{j}$ igual à pressão no nó $i ; D_{j}$ igual ao diâmetro do trecho $j ; L_{j}$ igual ao comprimento do trecho ligado ao nó j; e $\mathrm{C}$ é a taxa de vazamento por unidade de superfície do trecho j.

Neste caso o expoente de perdas (a) ao qual se submete a pressão pode variar de 0,5 a 1,18 .

\subsection{Confiabilidade aplicada a Sistemas de Distribuição de Água}

Confiabilidade em SDA é definida por GOULTER (1995) como a habilidade em satisfazer as demandas requeridas, atendendo aos limites de pressão necessários ao abastecimento adequado, mesmo em condições de operação atípicas.

Esta definição é amplamente atribuída ao conceito de confiabilidade por diversos autores. No entanto, ainda não há uma definição aceita universalmente quando se trata da melhor maneira de quantificar a confiabilidade em redes de distribuição de água (LANSEY; MAYS; TUNG, 2002; XU; GOULTER, 1999).

Apesar de não haver consenso quanto à medida de confiabilidade em Redes de Distribuição de Água (RDA), Tanyimboh e Templeman (1993a) citam alguns parâmetros que podem compor tal conceito, como: a confiabilidade mecânica de todos os componentes da rede, a diminuição do consumo na ocorrência de falhas no sistema, a resiliência da rede em condições de operação variadas e a probabilidade de ocorrência de falhas.

Giustolisi e Walski (2012) afirmam que qualquer que seja a causa de uma falha esta pode promover uma queda de pressão para níveis inferiores ao desejável para que 
haja o abastecimento adequado dos consumidores, considerada uma condição de pressão deficitária.

Diversas são as formas de ocorrência de falhas em redes de distribuição de água, muitas vezes de forma combinada. Trata-se de um entrave na gestão de redes que estimula a busca por medidas simples e eficazes para caracterizar a confiabilidade de um sistema, seja para definir seu projeto ou a sua manutenção (LANSEY; MAYS; TUNG, 2002).

Goulter (1995) definiu as seguintes categorias de abordagens para avaliação da confiabilidade em SDA:

- Simulação;

- Analítica;

- Heurística.

Esta classificação também é proposta por Gheisi, Forsyth e Naser (2016), os quais afirmam que o método analítico leva em consideração apenas os componentes principais de um SDA e a conectividade entre eles, de modo que um nó da rede esteja ligado ao menos a um que o abasteça (nó fonte).

Os autores ainda criticam o método afirmando que a conexão entre os componentes da rede não garante o fluxo de água de um nó a outro, e sugerem que a abordagem analítica seja empregada como uma análise inicial da confiabilidade aplicando-se modelos de simulação na sequência.

De acordo com Goulter (1995), os métodos que se utilizam de modelos de simulação para definição da confiabilidade, utilizam os resultados das condições operacionais impostas à rede de distribuição. O autor afirma, ainda, que devem ser feitas simulações para cada caso e todas as condições de operação, considerando as falhas nos componentes da rede, o que torna o método desvantajoso devido a seu requisito computacional.

\subsubsection{Confiabilidade Hidráulica}

Tanyimboh e Templeman (1995), baseados em modelos de simulação, propuseram uma métrica de confiabilidade para sistemas considerada direta, realista e de simples 
aplicação. Os autores afirmam que existem duas formas de falha em SDA que devem ser consideradas ao se definir a confiabilidade do abastecimento, são elas as falhas mecânica e hidráulica.

A confiabilidade mecânica está relacionada com a disponibilidade operacional dos componentes do sistema e a tolerância à falha nas tubulações. Já a confiabilidade hidráulica, apesar de ser dependente da primeira, está diretamente relacionada com o desempenho hidráulico da rede e sua capacidade de satisfazer as variações de demanda com a carga hidráulica requerida (TANYIMBOH; TEMPLEMAN, 1995).

O conceito aplicado à função de confiabilidade hidráulica, em linhas gerais, associa a falha em uma tubulação e a probabilidade de ocorrência da falha com o resultado de vazão demandada pelo sistema nessas condições. A função da confiabilidade é apresentada a seguir (GARGANO; PIANESE, 1998; TANYIMBOH; TEMPLEMAN, 1995).

$R^{(0)}=\frac{1}{T}\left(p(0) Q(0)+\sum_{m}^{M} p(m) Q(m)+\sum_{m}^{M-1} \sum_{m+1}^{M} p(m, n) Q(m, n)+\ldots\right)$

$+\frac{1}{2}\left(1-p(0)-\sum_{m}^{M} p(m)-\sum_{m}^{M-1} \sum_{m+1}^{M} p(m, n)-\ldots\right)$

sendo: $\mathrm{M}$ o número de trechos na rede; $\mathrm{p}(0)$ a probabilidade de nenhum trecho da rede sofrer falha; $p(m)$ a probabilidade de somente o trecho $m$ falhar; $p(m, n)$ a probabilidade dos trechos $\mathrm{m}$ e $\mathrm{n}$ falharem simultaneamente; $\mathrm{Q}(0)$ vazão fornecida para o sistema quando nenhum trecho falhar, $Q(m)$ vazão fornecida para o sistema quando o trecho $m$ falhar; $Q(m, n)$ vazão fornecida para o sistema quando os trechos $\mathrm{m}$ e $\mathrm{n}$ falharem simultaneamente; $\mathrm{T}$ é a vazão total requerida pelo sistema em pleno funcionamento.

Os fatores chave que afetam diretamente o resultado da confiabilidade em SDA são apresentados na Figura 2 (GHEISI; NASER, 2013). 
Figura 2 - Fatores chave que influenciam a Confiabilidade Hidráulica em DAS (GHEISI; NASER, 2013).

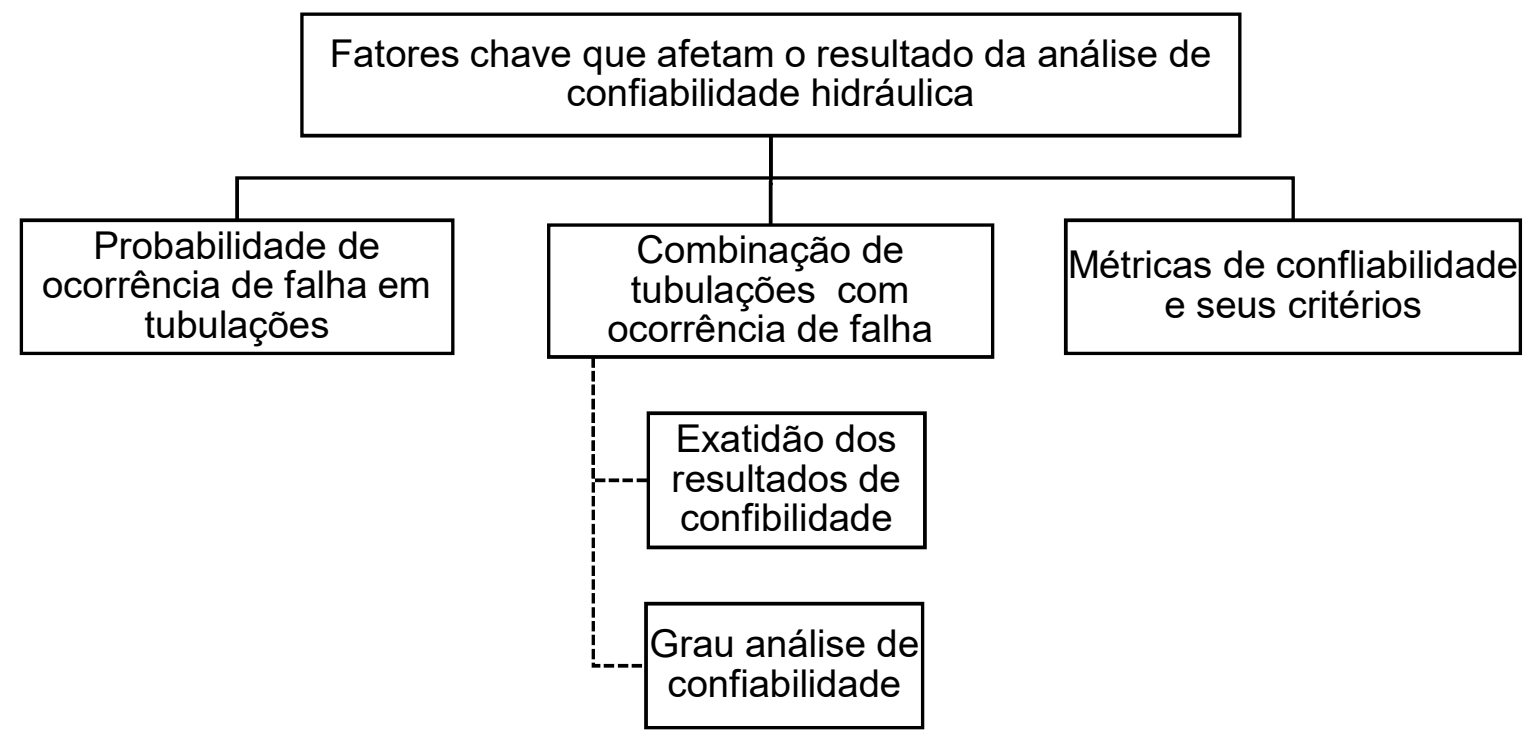

Tanyimboh et al. (2016) aplicaram a equação truncada, considerando a combinação das ocorrências de falha restrita a uma tubulação em cada momento, o que é justificado pelos autores devido à baixa probabilidade de ocorrência de múltiplas falhas.

A função de confiabilidade supracitada também foi aplicada por Gargano e Pianese (2000) considerando falha em apenas um trecho por vez. Os autores alegam que esta ponderação diminui consideravelmente o tempo computacional sem perda significativa de precisão.

Gheisi e Naser (2014) discordam da afirmação sobre a baixa probabilidade de ocorrência de falhas múltiplas em redes de distribuição de água. No entanto, confirmam que o esforço computacional de tal análise é significativo mesmo para um sistema pequeno, uma vez que é necessário incluir todas as combinações de trechos, que devido à falha, estejam indisponíveis no sistema de distribuição.

A problemática da combinação de tubulações com ocorrência de falha é abordada por Tanyimboh e Templeman (1998) como "estado de confiabilidade". O estado da confiabilidade é relativo à quantidade de componentes indisponíveis no sistema. Desta forma, quando se considera a possibilidade de todos os componentes do sistema estarem disponíveis, a confiabilidade é denominada "estado zero". 
Mais tarde, Tanyimboh, Tabesh e Burrows (2001) estenderam este conceito introduzindo o que denominaram como a tolerância do sistema à indisponibilidade de seus componentes. Gheisi e Naser (2015) utilizaram este mesmo conceito que foi então considerado como a confiabilidade de "primeiro estado".

$R^{(1)}=\frac{R^{(0)}-\frac{p(0) Q(0)}{T}}{1-p(0)}$

A probabilidade de falha de cada trecho pode ser obtida através da proposição de Fujiwara e Tung (1991) que discorrem sobre disponibilidade (A) e indisponibilidade (U) das tubulações do sistema, dado que U=1-A. Desta maneira, a probabilidade de que não ocorra falha em nenhum trecho do sistema é dada como:

$$
p(0)=\prod_{j=1}^{J} A_{j}
$$

sendo: j cada um dos trechos do sistema e $A_{j}$ a disponibilidade do trecho j.

Para determinação da disponibilidade de cada trecho da rede, Gheise e Naser (2015) se basearam na definição elaborada por Cullinane, Lansey e Mays (1992) que determina a disponibilidade $(A)$ como:

$A_{j}=\frac{45,60858 \cdot D_{j}^{1,462131}}{0,00211 \cdot D_{j}^{0,285}+45,60858 \cdot D_{j}^{1,462131}}$

Sendo: $D_{j}$ o diâmetro do trecho j.

Fujiwara e Tung (1991) definiram, ainda, a probabilidade de falha em um trecho por vez e a probabilidade de falha em mais de um trecho por vez segue como:

$p(j)=p(0) \cdot \frac{U_{j}}{A_{j}}$

$p\left(j, j^{\prime}\right)=p(0) \cdot \frac{U_{j} \cdot U_{j^{\prime}}}{A_{j} \cdot A_{j^{\prime}}}$

Baseado nos conceitos de confiabilidade hidráulica apresentadas até então, Gheisi e Naser (2014) propuseram a aplicação destes para os conceitos de confiabilidade em "estados superiores", podendo atingir k estados.

Gheisi e Naser (2013) avaliaram a significância do número de componentes em falha simultânea a ser considerado para o cálculo da confiabilidade hidráulica e concluíram 
que este parâmetro tem maior impacto em RDA menores (número de trechos menor que 100). Já nas RDA maiores, a disponibilidade tem maior influência na precisão dos resultados.

Tanyimboh e Templeman (1998) afirmam que, tão importante quanto a disponibilidade dos componentes do sistema, apresentada na Equação (14), em determinado período para o cálculo da confiabilidade, é a demanda imposta para este mesmo período. Os autores ressaltam que a demanda varia com o seu padrão diário típico, mas que a incorporação desse fator nas medidas de confiabilidade é um problema complexo.

Isso pode ser observado em publicações de diversos autores. Creaco, Franchini e Todini (2016), por exemplo, afirmam que a análise sobre a confiabilidade que elaboraram foi realizada através de simulações instantâneas, não considerando uma simulação em período estendido.

Quanto à condição de operação do sistema, Jung et al. (2016) fizeram uso da demanda média, atribuída a partir de uma densidade populacional e consumo per capita relativo à área de estudo. Di Nardo et al. (2015), por sua vez, empregaram a demanda de pico, ou seja, aquela que representa a pior condição de operação do sistema.

Vale ressaltar que a análise da confiabilidade hidráulica em SDA, via métodos de simulação, se baseia na avaliação do desempenho do sistema dada a ocorrência de falhas que podem causar déficit de pressão no sistema e que, devido a isso, demandam a utilização de uma abordagem MDDP. (GHEISI; FORSYTH; NASER, 2016).

Uma vez que se utiliza de uma abordagem MDDP e de imposição de falhas simultâneas no sistema, a análise da confiabilidade hidráulica demanda muito tempo e esforço computacional. Por isso, a aplicação de métricas alternativas mais práticas vem se tornando frequente (GHEISI; NASER, 2014b).

\subsubsection{Métricas Heurísticas}

A terceira abordagem de análise da confiabilidade é o desenvolvimento de métricas heurísticas. Gheisi, Forsyth e Naser (2016) consideram que estas são atalhos para 
produzir um resultado rápido e satisfatório de confiabilidade em sistemas, mas que podem não representar a melhor alternativa.

Para Jung et al. (2016), tais métricas são índices de desempenho que têm o intuito de representar o grau da confiabilidade de forma simplificada. De acordo com o autor, muitas são as métricas alternativas de confiabilidade em SDA que vêm sendo propostas nas últimas décadas.

\subsubsection{Entropia}

A métrica alternativa de confiabilidade mais difundida na literatura é a entropia e diversos autores encontraram forte correlação entre esta e a confiabilidade. A função de entropia elaborada por Shannon (1948) trata originalmente do conceito de um sistema de comunicação que, de modo geral, envolve a fonte, o transmissor, um possível ruído e o receptor.

Em 1991, Awumah, Goulter e Bhatt promoveram modificações nesta função, de modo a adaptá-la à configuração de um Sistema de Distribuição de Água, como uma medida adimensional de redundância e flexibilidade em Rede de Distribuição de Água (RDA).

$\widehat{S}=\sum_{j}^{N}\left(\frac{q_{j}}{Q_{0}}\right) S_{j}-\sum_{j}^{N}\left(\frac{q_{j}}{Q_{0}}\right) \ln \left(\frac{q_{j}}{Q_{0}}\right)$

$S_{j}=\sum_{i}^{N}\left(\frac{q_{i j}}{Q_{i}}\right) \ln \left(\frac{q_{i j}}{Q_{i}}\right)$

sendo: $\widehat{S}$ a entropia; $q_{j}$ a demanda no nó $j\left(\mathrm{~m}^{3} / \mathrm{s}\right) ; Q_{0}$ a soma das vazões afluentes ao sistema $\left(\mathrm{m}^{3} / \mathrm{s}\right) ; \mathrm{S}_{\mathrm{j}}$ a entropia do nó $\mathrm{j} ; \mathrm{Q}_{\mathrm{i}}$ a soma das vazões afluentes ao nó $\mathrm{i}\left(\mathrm{m}^{3} / \mathrm{s}\right) ; q_{i j}$ a vazão no trecho que liga os nós i e j $\left(\mathrm{m}^{3} / \mathrm{s}\right)$.

Mais tarde, Tanyimboh e Templeman (1993b), tomando a mesma base proposta por Shannon (1948), propuseram um novo modelo para a entropia. Para os autores, em redes malhadas, todos os nós podem ser abastecidos por mais de um caminho e, uma vez que não se tem informação sobre tais caminhos, a probabilidade de tomar cada um deles deve ser igual.

$\bar{K}=-\sum_{i}^{1} \frac{Q_{i}}{Q_{0}} \ln \left(\frac{Q_{i}}{Q_{0}}\right)-\frac{1}{Q_{0}} \sum_{j}^{J} Q_{j}\left[\frac{q_{j}}{Q_{j}} \ln \left(\frac{q_{j}}{Q_{j}}\right)+\sum_{i j \in N_{j}} \frac{q_{i j}}{Q_{j}} \ln \left(\frac{q_{i j}}{Q_{j}}\right)\right]$ 
sendo: $\mathrm{S}$ a entropia; $\mathrm{K}$ uma constante arbitrária positiva; $\mathrm{Q}_{0}$ a vazão total fornecida pelo reservatório ( $\left.\mathrm{m}^{3} / \mathrm{s}\right)$; $\mathrm{Q}_{\mathrm{j}}$ a vazão afluente ao nó j $\left(\mathrm{m}^{3} / \mathrm{s}\right)$; $\mathrm{Q}_{\mathrm{i}}$ a vazão afluente ao nó $\mathrm{i}$ $\left(\mathrm{m}^{3} / \mathrm{s}\right) ; q_{\mathrm{j}}$ a demanda no nó $\mathrm{j}\left(\mathrm{m}^{3} / \mathrm{s}\right) ; \mathrm{q}_{\mathrm{ij}}$ a vazão entre os nós i e j $\left(\mathrm{m}^{3} / \mathrm{s}\right) ; \mathrm{I}$ o total de nós fonte; J é o total de nós de demanda; $N_{j}$ todos os trechos com vazão para o nó j.

Visando complementar esta abordagem, Liu et al. (2014) afirmam que o diâmetro da tubulação tem impacto significativo na confiabilidade da rede e que a função de entropia proposta por Tanyimboh e Templeman (1993b) são insensíveis às variações deste parâmetro. Dessa forma, os autores propuseram a alteração da função de entropia de modo a considerar as velocidades do fluido nas tubulações.

$\overline{\mathrm{K}}=-\sum_{i}^{1} \frac{Q_{i}}{Q_{0}} \ln \left(\frac{Q_{i}}{Q_{0}}\right)-\frac{1}{Q_{0}} \sum_{j}^{J} Q_{j}\left[\frac{q_{j}}{Q_{j}} \ln \left(\frac{q_{j}}{Q_{j}}\right)+\sum_{i j \in N_{j}} \frac{C}{V_{i j}} \frac{q_{i j}}{Q_{j}} \ln \left(\frac{q_{i j}}{Q_{j}}\right)\right]$

sendo: $V_{\mathrm{ij}}$ a velocidade no trecho entre os nós i e j e $C$ uma constante de velocidade arbitrária $(1 \mathrm{~m} / \mathrm{s})$, que mantém a entropia como um índice adimensional.

Tanyimboh et al. (2016) avaliaram a relação entre a entropia e a confiabilidade hidráulica e encontraram forte correlação entre as duas, concluindo que a entropia apresenta propriedades de uma métrica alternativa plausível.

Resultado similar foi obtido por Gheisi e Naser (2015), uma vez que os autores chegaram a uma correlação forte entre a métrica e a confiabilidade em "estados maiores", não tendo o mesmo sucesso para a confiabilidade estado zero.

Raad, Sinske e Van Vuuren (2010) aplicaram diversas métricas alternativas de confiabilidade para dimensionamento ótimo de redes. Diferente dos autores citados anteriormente obteve para a entropia uma correlação baixa apresentando o pior desempenho em geral.

Os autores citados aplicaram em seus trabalhos a equação proposta por Tanyimboh e Templeman (1993b) que foi descrita como uma métrica para avaliar sistemas com fonte de abastecimento única.

\subsubsection{Resiliência}

Outra métrica alternativa proposta para representar a confiabilidade é a resiliência. A função proposta por Todini (2000), denominada Índice de Resiliência, pode ser 
definida como o excesso de pressão a ser disponibilizado nos nós da rede de distribuição de água, de modo que esse excedente seja dissipado na forma de perda de carga em caso de falha, mantidos os padrões de abastecimento mínimos exigidos para o sistema.

$$
\mathrm{I}_{\mathrm{r}}=\frac{\sum_{i}^{\mathrm{n}_{\mathrm{n}}} \mathrm{q}_{\mathrm{i}}\left(\mathrm{H}_{\mathrm{i}}-\mathrm{H}_{\mathrm{i}}^{\text {req }}\right)}{\sum_{\mathrm{k}}^{\mathrm{n}_{\mathrm{r}}} \mathrm{Q}_{\mathrm{k}} \mathrm{H}_{\mathrm{k}}+\sum_{\mathrm{j}}^{\mathrm{n}_{\mathrm{p}} \mathrm{P}_{\mathrm{j}}}-\sum_{\mathrm{i}}^{\mathrm{n}_{\mathrm{n}}} \mathrm{q}_{\mathrm{i}} \mathrm{H}_{\mathrm{i}}^{\text {req }}}
$$

sendo: $q_{i}$ a demanda no nó $i\left(m^{3} / s\right) ; H_{i}$ a carga hidráulica no nó i $(m) ; H_{i}^{\text {req }}$ a carga hidráulica mínima requerida pelo nó $\mathrm{i}(\mathrm{m}) ; \mathrm{Q}_{\mathrm{k}}$ a vazão fornecida pelo reservatório $\left(m^{3} / s\right), n_{r}$ o total reservatórios no sistema; $H_{k}$ a carga hidráulica no reservatório $k(m)$; $P_{j}$ a potência da bomba $\mathrm{j}(\mathrm{N} \cdot \mathrm{m} / \mathrm{s}), \mathrm{n}_{\mathrm{p}}$ o total de bombas existentes no sistema; $\gamma$ o peso específico da água $\left(\mathrm{N} / \mathrm{m}^{3}\right)$.

Jayaram e Srinivasan (2008) consideram a definição do Índice de Resiliência como uma métrica simples e de aplicação prática. Porém, encontraram inconsistências na aplicação da métrica e, por isso, propuseram uma alteração a esta função como uma crítica à aplicabilidade a sistemas com mais de um reservatório como fonte de abastecimento.

$\mathrm{MI}_{\mathrm{r}}=\frac{\sum_{\mathrm{i}}^{\mathrm{l}} \mathrm{q}_{\mathrm{i}}\left(\mathrm{H}_{\mathrm{i}}-\mathrm{H}_{\mathrm{i}}^{\text {req }}\right)}{\sum_{\mathrm{i}}^{\mathrm{i}} \mathrm{q}_{\mathrm{i}} \mathrm{H}_{\mathrm{i}}^{\text {eq }}} \times 100$

Já Prasad e Park (2004) afirmam que redes ramificadas, mesmo possuindo energia excedente suficiente para o abastecimento adequado, podem produzir consequências operacionais negativas em determinados nós da rede em caso de falha na tubulação, uma vez que esta possui menos caminhos alternativos para o abastecimento.

Portanto, os autores propuseram um índice alternativo ao de resiliência de Todini (2000), denominado Resiliência da Rede, de modo a considerar o efeito da redundância na confiabilidade. Desse modo, a existência de anéis de rede pode ser observada quando as tubulações conectadas ao nó avaliado não possuírem variação de diâmetro muito grande.

$$
\mathrm{I}_{\mathrm{nr}}=\frac{\sum_{\mathrm{i}}^{\mathrm{l}} \mathrm{C}_{i} \mathrm{q}_{\mathrm{i}}\left(\mathrm{H}_{\mathrm{i}}-\mathrm{H}_{\mathrm{i}}^{\mathrm{req}}\right)}{\sum_{\mathrm{k}}^{\mathrm{n}_{\mathrm{r}}} \mathrm{Q}_{\mathrm{k}} \mathrm{H}_{\mathrm{k}}+\sum_{\mathrm{j}}^{\mathrm{J}} \frac{\mathrm{P}_{\mathrm{j}}}{\mathrm{V}}-\sum_{\mathrm{i}}^{\mathrm{q}} \mathrm{q}_{\mathrm{i}} \mathrm{H}_{\mathrm{i}}^{\text {req }}}
$$


sendo: $\mathrm{C}_{\mathrm{i}}$ um coeficiente de uniformidade dos diâmetros das tubulações conectadas ao nó i.

Raad, Sinske e Van Vuuren (2010) obtiveram resultados muito positivos, tanto para o Índice de Resiliência como para a Resiliência da Rede. No entanto, os autores ressaltam que não há consistência suficiente para afirmar a existência de uma relação linear entre essas métricas e a confiabilidade hidráulica.

Já Gheisi e Naser (2015) chegaram a resultados que apresentam correlação baixa desses indicadores com a confiabilidade em diferentes estados, chegando mesmo a apresentar correlação negativa.

Cimorelli et al. (2018) afirmam que o Índice de Resiliência proporciona bons resultados em termos de confiabilidade e satisfação de demanda uma vez que considera a pressão requerida pelo sistema para o cálculo da métrica. Os autores afirma que diversos trabalhos realizaram comparação entre as métricas alternativas de confiabilidade, e que os resultados contrastam entre si. 


\section{MATERIAIS E MÉTODOS}

\subsection{Materiais}

Neste trabalho foi utilizado o software simulador hidráulico EPANET 2 (ROSSMAN, 2000b) e rotinas desenvolvidas em MatLab para a avaliação dos parâmetros operacionais das redes (pressões e vazões). Para integração entre ambos, foi utilizada a "toolkit" desenvolvida pelo Centro de pesquisa KIOS, da Universidade do Chipre.

\subsection{Métodos}

A abordagem definida para este trabalho visou quantificar a confiabilidade em redes de distribuição de água através de métricas já propostas na literatura especializada. Para tal, foi realizada a revisão bibliográfica para identificar as diversas metodologias propostas por autores acerca do tema.

Previamente à análise dos parâmetros de confiabilidade em sistema de distribuição de água, foi necessário desenvolver um modelo de Simulação Hidráulica que viabilizasse a determinação da demanda dependente da pressão e vazão de perdas por vazamentos.

\subsubsection{Fluxograma do Modelo de Simulação Hidráulica}

Neste trabalho foi utilizado o software EPANET 2 (ROSSMAN, 2000b) como módulo simulador hidráulico auxiliar da rede de distribuição de água. Com o auxílio da "toolkit" citada anteriormente, são fornecidos os dados de entrada ao simulador hidráulico EPANET (em formato '.inp') que por sua vez deve reproduzir as pressões resultantes nos nós da rede com base nas perdas de carga geradas pela demanda previamente atribuída aos nós.

O fluxograma apresentado na Figura 3 representa o processo iterativo de cálculo do modelo de análises hidráulicas aplicado neste trabalho. A abordagem apresentada é baseada na metodologia proposta por Jun e Guoping (2013), que tem como objetivo determinar as vazões efetivamente demandadas pela rede de distribuição de água para a condição de pressão atuante no sistema. 
Figura 3 - Fluxograma algoritmo do processo iterativo de cálculo do modelo de análises hidráulicas.

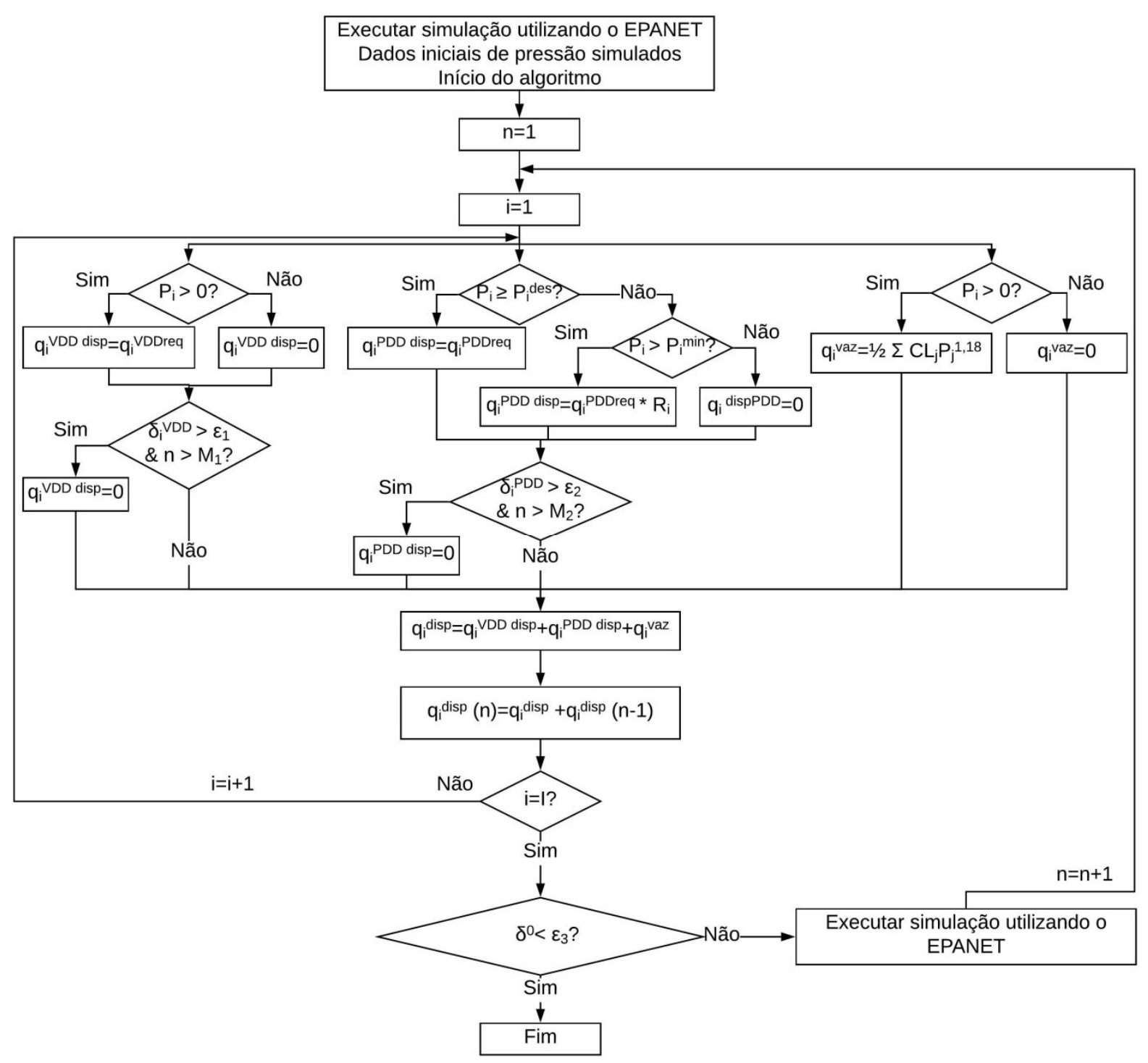

O processo iterativo representado no fluxograma da Figura 3 se inicia com a simulação hidráulica (dirigida pela demanda) da rede em estudo através do simulador hidráulico EPANET, tendo como conhecimento prévio as demandas dos nós, para produzir as pressões nos nós do sistema.

Uma vez obtidas as pressões para todos os nós, inicia-se o processo iterativo no qual se verificam as pressões disponíveis e as condições de pressão preestabelecidas para cálculo das demandas PDD e VDD e dos vazamentos.

O fluxograma do processo iterativo apresentado na Figura 3 apresenta diversas etapas de decisão, sendo três delas relacionadas à convergência das demandas 
efetivas do sistema. As duas primeiras referem-se à demanda VDD e à demanda PDD calculadas para cada nó após a verificação da pressão disponibilizada.

Calcula-se, então, as variáveis $\delta_{i}^{V D D ~ d i s p ~}$ e $\delta_{i}^{\text {PDD disp }}$ conforme equações (24) e (25).

$\delta_{i}^{\text {VDD disp }}=q_{i}^{\text {VDD disp }}(n)-q_{i}^{\text {VDD disp }}(n-1)$

$\delta_{i}^{P D D \text { disp }}=q_{i}^{\text {PDD disp }}(n)-q_{i}^{\text {PDD disp }}(n-1)$

sendo: $\mathrm{n}$ o número o número de iterações do modelo.

As variáveis $\delta_{i}^{\mathrm{VDD} \text { disp }}$ e $\delta_{i}^{\mathrm{PDD} \text { disp }}$ são confrontadas com as tolerâncias $\varepsilon_{1}$ e $\varepsilon_{2}$ que para este trabalho foram adotadas iguais a $0,1 \mathrm{l} / \mathrm{s}$.

Restringiu-se também número máximo de iterações ( $M_{1}=M_{2}=15$ iterações) para que as tolerâncias $\varepsilon_{1}$ e $\varepsilon_{2}$ fossem atingidas. Nota-se que para sistemas com grande deficiência de pressão os limites $\mathrm{M}_{1}$ e $\mathrm{M}_{2}$ podem ser úteis à flexibilização do modelo hidráulico.

Outra etapa de decisão importante do processo iterativo apresentado na Figura 3 refere-se à demanda total calculada para cada nó. Para isso avalia-se a variável $\delta^{0}$, que é definida através da seguinte relação:

$\delta^{\circ}=\max \left|\delta_{i}^{\text {disp }}(n)-\delta_{i}^{\text {disp }}(n-1)\right|$

Esta é confrontada com a tolerância $\varepsilon_{3}$ admitida para este trabalho igual a $0,05 \mathrm{l} / \mathrm{s}$.

\subsubsection{Demanda de água}

A demanda de água em um sistema pode ser dividida em duas parcelas: o consumo efetivo e os vazamentos. A primeira parcela é definida através do perfil de consumo dos usuários do sistema e pode ser considerada dependente da pressão ou do volume.

No presente trabalho, a condição mais crítica do sistema, no que diz respeito ao abastecimento, ou seja, a vazão máxima distribuída durante o dia de referência, foi utilizada para análise dos SDA 
A seguir são apresentadas as equações utilizadas para determinação da demanda dependente da pressão, da demanda dependente do volume e da parcela de vazamentos.

\subsubsection{Demanda dependente da pressão (PDD)}

As equações que visam definir a PDD, ou seja, a demanda que a rede de distribuição pode efetivamente disponibilizar para o consumidor, invariavelmente representam a relação pressão/demanda de modo similar. As proposições avaliadas neste trabalho estão apresentadas na Tabela 1.

Tabela 1 - Equações para determinação do Ri para cálculo da PDD avaliadas.

\begin{tabular}{|c|c|}
\hline Autores & Equação \\
\hline Wagner, Shamir e Marks (1988) & $R_{i}=\left(\frac{P_{i}-P_{i}^{\min }}{P_{i}^{\text {des }}-P_{i}^{\min }}\right)^{1 / 2}$ \\
\hline Tanyimboh, Tabesh e Burrows (2001) & $\mathrm{R}_{\mathrm{i}}=\left(\frac{\mathrm{P}_{\mathrm{i}}-\mathrm{P}_{\mathrm{i}}^{\min }}{\mathrm{P}_{\mathrm{i}}^{\text {des }}-\mathrm{P}_{\mathrm{i}}^{\min }}\right)^{1 / e_{i}}$ \\
\hline & Para $P_{i}^{\min }>=5 \mathrm{mca}$ \\
\hline Fujiwara e Li (1998) & $\mathrm{R}_{\mathrm{i}}=\frac{\left(\mathrm{P}_{\mathrm{i}}-\mathrm{P}_{\mathrm{i}}^{\min }\right)^{2} \cdot\left(3 \mathrm{P}_{\mathrm{i}}^{\text {des }}-2 \mathrm{P}_{\mathrm{i}}-\mathrm{P}_{\mathrm{i}}^{\min }\right)}{\left(\mathrm{P}_{\mathrm{i}}^{\text {des }}-\mathrm{P}_{\mathrm{i}}^{\min }\right)^{3}}$ \\
\hline Tucciarelli, Criminisi e Termini (1999) & $\mathrm{R}_{\mathrm{i}}=\sin ^{2}\left(\frac{\mathrm{P}_{\mathrm{i}}}{2 \mathrm{P}_{\mathrm{i}}^{\mathrm{des}}} \cdot \pi\right)$ \\
\hline Tanymboh e Templeman (2010) & $\mathrm{R}_{\mathrm{i}}=\frac{\exp \left[\alpha_{\mathrm{i}}+\beta_{\mathrm{i}}\left(\mathrm{P}_{\mathrm{i}}+\mathrm{h}_{\mathrm{i}}\right)\right]}{1+\exp \left[\alpha_{\mathrm{i}}+\beta_{\mathrm{i}}\left(\mathrm{P}_{\mathrm{i}}+\mathrm{h}_{\mathrm{i}}\right)\right]}$ \\
\hline
\end{tabular}

As diversas equações foram utilizadas na Literatura, apresentando resultados coerentes na maioria dos casos.

\subsubsection{Demanda dependente do volume (VDD)}

A segunda parcela que compõe a demanda, considerada neste estudo admite que parte desta deva ser suprida com base no volume e, caso a pressão seja superior a zero, esta será plenamente atendida.

A definição da proporção da demanda total, de um SDA, que é afetada por esta condição pode variar de acordo com as características da região de estudo. Foi avaliada a suscetibilidade da proporção VDD/PDD para as pressões no sistema de distribuição de água do que diz respeito à pressão geral do sistema. 


\subsubsection{Vazamentos}

Parcela importante da demanda de um SDA se refere aos vazamentos na rede. A literatura apresenta formulações elaboradas para a determinação mais assertiva da para a parcela da vazão efetivamente perdida por vazamentos no sistema.

Para o este trabalho foi utilizada a equação proposta por Tucciarelli, Criminisi e Termini (1999), devido a sua coerência em considerar toda a área útil da tubulação para o cálculo do vazamento inerente. Esta foi apresentada na equação (10) e reescrita a seguir.

$q_{i}^{v a z}=P_{i}^{a} \sum_{j} \frac{\pi}{2} D_{j} L_{j} C$

Neste trabalho o expoente de perdas, ao qual se submete a pressão, foi considerado igual a 1,18 e o coeficiente $C$ foi calculado, com base na pressão média do sistema, de modo que os vazamentos correspondessem a $10 \%$ da demanda total, uma vez que este trabalho se trata limita às análises hidráulicas para a condição horária de demanda máxima.

\subsubsection{Rede hipotética análise previa}

Uma vez identificados os principais modelos de PDD discutidos pela literatura especializada, observou-se a necessidade de avaliar tais equações utilizando-se a rede de distribuição de água hipotética proposta por Tucciarelli, Criminisi e Termini (1999), apresentada na Figura 4. 
Figura 4 - Rede hipotética apresentada por Tucciarelli, Criminisi e Termini (1999).

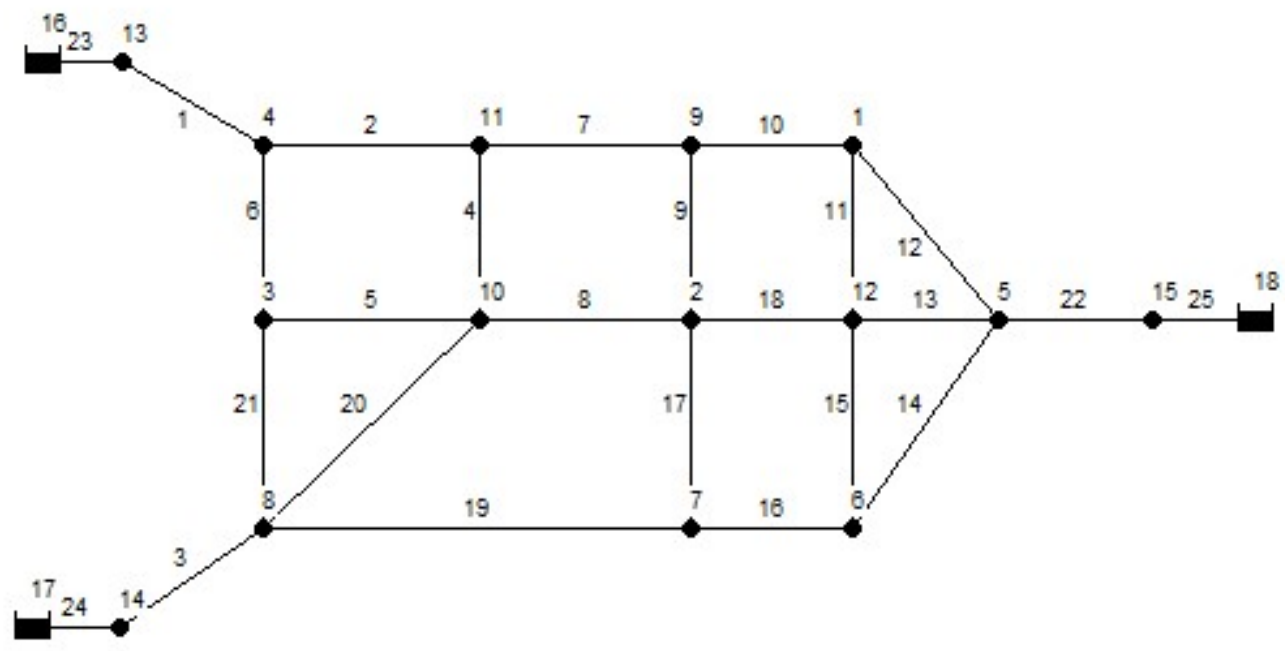

A rede é composta por 25 trechos de rede e 15 nós, sendo apenas quatro deles nós com demanda de água. As características de seus nós estão apresentadas na Tabela 2, enquanto as características das tubulações estão apresentadas na Tabela 3.

Tabela 2 - Dados dos nós da rede de Tucciarelli, Criminisi e Termini (1999).

\begin{tabular}{cc}
\hline Nós & Cota $(\mathrm{m})$ \\
\hline 1 & 25 \\
2 & 20 \\
3 & 22 \\
4 & 27 \\
5 & 30 \\
6 & 27 \\
7 & 22 \\
8 & 25 \\
9 & 25 \\
10 & 20 \\
11 & 22 \\
12 & 27 \\
13 & 25 \\
14 & 25 \\
15 & 30 \\
16 & 40 \\
17 & 40 \\
18 & 40 \\
\hline
\end{tabular}


Tabela 3 - Dados dos trechos da rede de Tucciarelli, Criminisi e Termini (1999).

\begin{tabular}{|c|c|c|c|}
\hline Trecho & $\begin{array}{l}\text { Comprimento } \\
(\mathrm{m})\end{array}$ & $\begin{array}{l}\text { Diâmetro } \\
(\mathrm{mm})\end{array}$ & $\begin{array}{r}\text { Coeficiente } \\
\text { de Perda }\end{array}$ \\
\hline 1 & 1000 & 500 & $1,0 \mathrm{E}-07$ \\
\hline 2 & 500 & 250 & $1,0 \mathrm{E}-07$ \\
\hline 3 & 1000 & 500 & $1,0 \mathrm{E}-07$ \\
\hline 4 & 500 & 150 & $1,0 \mathrm{E}-07$ \\
\hline 5 & 500 & 150 & $1,0 \mathrm{E}-07$ \\
\hline 6 & 500 & 250 & $1,0 \mathrm{E}-07$ \\
\hline 7 & 500 & 250 & 1,0E-07 \\
\hline 8 & 500 & 150 & 1,0E-07 \\
\hline 9 & 500 & 150 & $2,5 \mathrm{E}-07$ \\
\hline 10 & 500 & 250 & $2,5 \mathrm{E}-07$ \\
\hline 11 & 500 & 150 & $2,5 \mathrm{E}-07$ \\
\hline 12 & 560 & 250 & $2,5 \mathrm{E}-07$ \\
\hline 13 & 250 & 250 & $2,5 \mathrm{E}-07$ \\
\hline 14 & 560 & 250 & $2,5 \mathrm{E}-07$ \\
\hline 15 & 500 & 150 & $2,5 \mathrm{E}-07$ \\
\hline 16 & 500 & 250 & $2,5 \mathrm{E}-07$ \\
\hline 17 & 500 & 150 & 2,5E-07 \\
\hline 18 & 500 & 150 & $2,5 \mathrm{E}-07$ \\
\hline 19 & 500 & 250 & $2,5 \mathrm{E}-07$ \\
\hline 20 & 700 & 150 & $2,5 \mathrm{E}-07$ \\
\hline 21 & 500 & 250 & $2,5 \mathrm{E}-07$ \\
\hline 22 & 500 & 500 & 1,0E-07 \\
\hline 23 & 1 & 500 & 1,0E-07 \\
\hline 24 & 1 & 500 & 1,0E-07 \\
\hline 25 & 1 & 500 & $1,00 \mathrm{E}-07$ \\
\hline
\end{tabular}

Além disso, considera-se a equação de Darcy-Weisbach, para definição das perdas de carga no sistema e o coeficiente de rugosidade para todas as tubulações é igual a $3,15 \times 10^{-3} \mathrm{~mm}$. A demanda do sistema é igual a $180 \mathrm{l} / \mathrm{s}$, distribuída em apenas quatro dos nós da rede, sendo eles os nós 1, 2, 6 e 11.

\subsubsection{Métricas de confiabilidade}

As métricas apresentadas na revisão bibliográfica foram aplicadas a determinados sistemas, listados na Tabela 4 , de modo a avaliar a representatividade das mesmas em análises de SDA. 
Tabela 4 - Estudos de caso analisados.

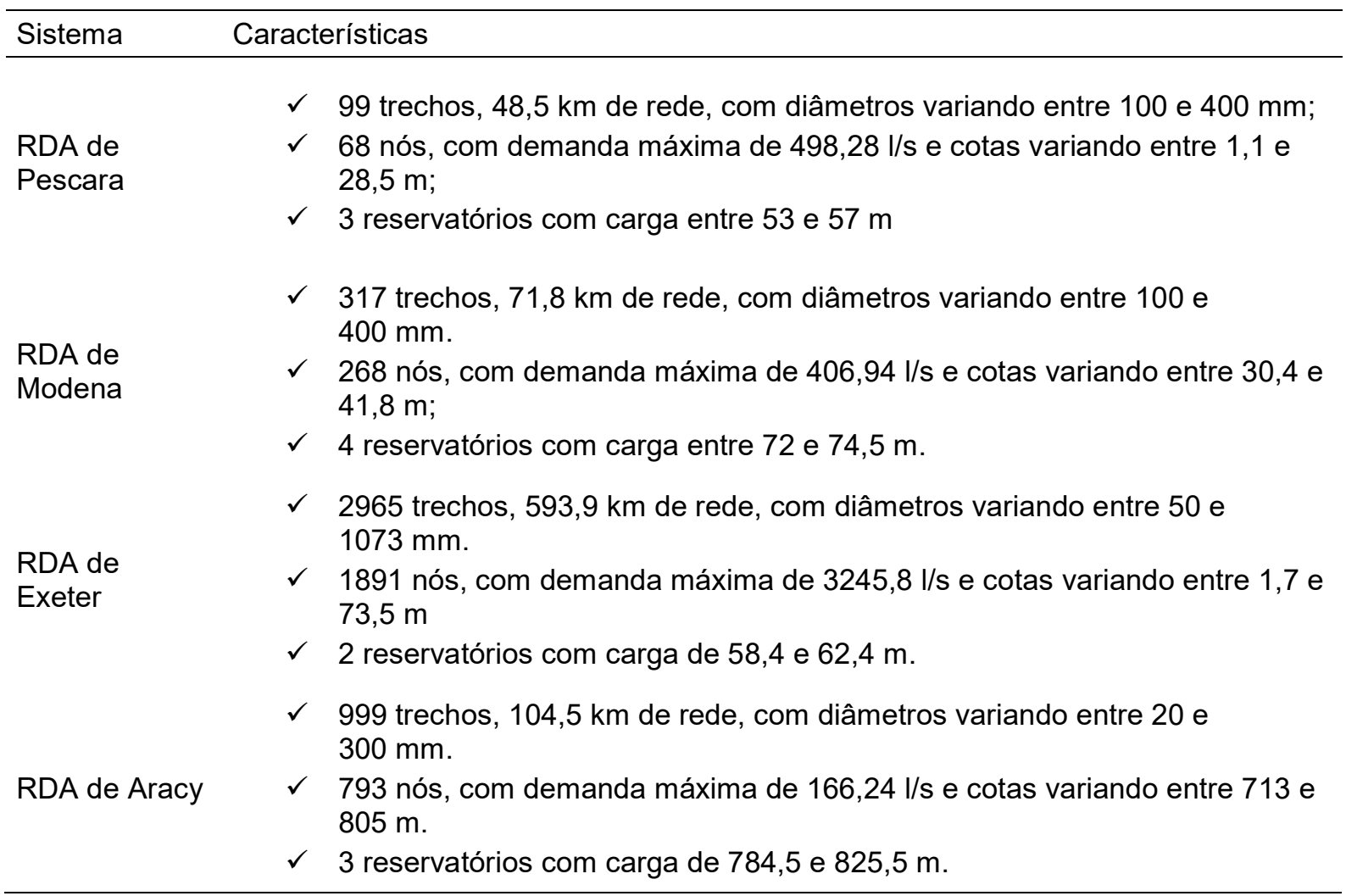

Para o cálculo da confiabilidade hidráulica, foi utilizada a equação (11) de Tanyimboh e Templeman (1995), reescrita a seguir.

$$
\begin{aligned}
& R=\frac{1}{T}\left(p(0) Q(0)+\sum_{m}^{M} p(m) Q(m)+\sum_{m}^{M-1} \sum_{m+1}^{M} p(m, n) Q(m, n)+\ldots\right) \\
& +\frac{1}{2}\left(1-p(0)-\sum_{m}^{M} p(m)-\sum_{m}^{M-1} \sum_{m+1}^{M} p(m, n)-\ldots\right)
\end{aligned}
$$

Nota-se que o uso da função de confiabilidade citada, necessita de resultados da simulação hidráulica do sistema através de modelo de PDD, segundo o qual a demanda requerida será atendida proporcionalmente à pressão no nó de demanda correspondente.

Para o cálculo da probabilidade de falha nos trechos da rede foram utilizadas as equações (15) e a equação (16).

Uma das métricas heurísticas de Resiliência, que foram utilizadas no presente trabalho, é o Índice de Resiliência ( $I_{r}$ ) de Todini (2000), apresentado na equação (21), reescrita a seguir. 


$$
\mathrm{I}_{\mathrm{r}}=\frac{\sum_{i}^{n_{n}} q_{i}\left(H_{i}-H_{i}^{\text {req }}\right)}{\sum_{k}^{n_{r}} Q_{k} H_{k}+\sum_{j}^{n_{p}} \frac{P_{j}}{\gamma}-\sum_{i}^{n_{n}} q_{i} H_{i}^{\text {req }}}
$$

Foi utilizada, também, a Resiliência da rede (Inr) proposta por Prasad e Park (2004) que promove o incremento de um coeficiente na função do Índice de Resiliência de Todini (2000), conforme equação (23) reescrita a seguir.

$$
\mathrm{I}_{n r}=\frac{\sum_{\mathrm{i}}^{l} \mathrm{C}_{\mathrm{i}} \mathrm{q}_{\mathrm{i}}\left(\mathrm{H}_{\mathrm{i}}-\mathrm{H}_{\mathrm{i}}^{\text {req }}\right)}{\sum_{\mathrm{k}}^{\mathrm{n}_{\mathrm{r}}} \mathrm{Q}_{\mathrm{k}} \mathrm{H}_{\mathrm{k}}+\sum_{\mathrm{j}}^{\mathrm{J}} \frac{\mathrm{P}_{\mathrm{j}}}{\mathrm{Y}}-\sum_{\mathrm{i}}^{\prime} \mathrm{q}_{\mathrm{i}} \mathrm{H}_{\mathrm{i}}^{\text {req }}}
$$

A entropia também foi considerada como métrica alternativa de confiabilidade, utilizando-se a equação (20) proposta por Awumah, Goulter e Bhatt (1991), uma vez que esta a equação proposta por Tanyimboh e Templeman (1993b) é destinada a sistemas que apresentam uma única fonte de abastecimento, o que não é fato nos estudos de caso apresentado neste trabalho.

$\widehat{S}=\sum_{j}^{N}\left(\frac{q_{j}}{Q_{0}}\right) S_{j}-\sum_{j}^{N}\left(\frac{q_{j}}{Q_{0}}\right) \ln \left(\frac{q_{j}}{Q_{0}}\right)$

\subsubsection{Setorização de Sistemas de Distribuição de Água}

Para a Setorização/Partição dos sistemas estudados neste trabalho foi aplicado o algoritmo $k$-means, devido à sua rapidez e facilidade de aplicação. Os dados utilizados como entrada do algoritmo k-means foram: a posição geográfica (coordenadas $\mathrm{x}$ e $\mathrm{y}$ ), a cota altimétrica e a pressão simulada em cada um nós das RDA estudadas.

Como índices de validação, para a determinação do número ótimo de clusters para a setorização ou partição, foram utilizados os índices: GAP, Silhouette, CalinskiHarabasz, Davies-Bouldin utilizados por Novarini et al. (2017).

Para isso, o algoritmo $k$-means é executado múltiplas vezes, variando-se o número de clusters atribuído a ele. Esta variação foi imposta considerando o limite superior de 15 clusters e o limite inferior igual ao número de reservatórios existentes em cada sistema. É apresentado para cada número total de clusters o resultado do índice de validação e, assim, verifica-se o número que otimiza cada índice. 
O GAP se baseia no conceito de dispersão das observações dentro de cada cluster através da seguinte equação (TIBSHIRANI; WALTHER; HASTIE, 2001).

$W_{r}=\sum_{r=1}^{k} \frac{1}{2 n_{r}} D_{r}$

sendo: $W_{r}$ o valor de GAP, $n_{r}$ o numero de pontos em cada cluster $r$, e $D_{r}$ a soma da distância euclidiana de todos os pontos pertencentes a o cluster $\mathrm{r}$.

O número de clusters estimado será aquele para o qual $\mathrm{GAP}_{\mathrm{n}}(\mathrm{k})$ é maximizado

$\operatorname{GAP}_{\mathrm{n}}(\mathrm{k})=\mathrm{E}_{\mathrm{n}}^{*}\left\{\log \left(\mathrm{W}_{\mathrm{k}}\right)\right\}-\log \left(\mathrm{W}_{\mathrm{k}}\right)$

O Silhouette pode ser obtido através da análise de similaridade de cada ponto em relação aos demais pertencentes ao mesmo cluster. (ROUSSEEUW, 1987)

$\mathrm{S}_{\mathrm{i}}=\left(\mathrm{a}_{\mathrm{i}}-\mathrm{b}_{\mathrm{i}}\right) / \max \left(\mathrm{a}_{\mathrm{i}}, \mathrm{b}_{\mathrm{i}}\right)$

sendo: $a_{i}$ a média das distâncias do ponto i em relação aos demais pertencentes ai mesmo cluster, e $b_{i}$ é a menor distância deste mesmo grupo.

O índice de Calinski-Harabasz se baseia no conceito dos "vizinhos mais próximos" para determinar a separação entre os clusters aplicando o critério da distância mínima em os pontos e entre os clusters (CALIÑSKI; HARABASZ, 1974)

$\operatorname{VRC}_{K}=\frac{\sum_{i}^{k} n_{i}\left\|m_{i}-m\right\|^{2}}{\sum_{i}^{k} n_{i}\left\|x-m_{i}\right\|^{2}} \cdot \frac{(N-k)}{(k-1)}$

sendo: $\mathrm{k}$ o número de clusters, $\mathrm{m}_{\mathrm{i}} \mathrm{o}$ centróide do setor $\mathrm{i}, \mathrm{m}$ a média de todos os pontos, $\mathrm{x}$ um ponto do setor $\mathrm{i}$.

Já o índice Davies-Bouldin busca o valor mínimo da relação entre as distâncias existentes dentro de um cluster e as distâncias entre os clusters, de acordo com a equação a seguir (DAVIES; BOULDIN, 1979).

$D_{i, j}=\frac{\left(\bar{d}_{i}+\bar{d}_{j}\right)}{d_{i, j}}$

sendo: $\bar{d}_{\mathrm{i}}$ a média das distâncias entre cada ponto do cluster i e o seu centroide, $\overline{\mathrm{d}}_{\mathrm{j}} \mathrm{a}$ média das distâncias entre cada ponto do cluster j e o seu centroide, $\mathrm{d}_{\mathrm{i}, \mathrm{j}}$ a distância euclidiana entre os centroides dos clusters i e j. 
Após a definição dos DMC para cada um dos sistemas, foram reavaliadas as métricas de confiabilidade para fins de comparação dos resultados e avaliação do impacto da setorização sobre tais quesitos.

No que diz respeito à comparação entre os resultados foi considerada a proposição de Di Nardo et al. (2015) de se calcular o desvio para ambas as métricas de Resiliência, Ir e In.

$I_{r d}=\left(1-\frac{I_{r}^{*}}{I_{r}}\right) \cdot 100$

$I_{\text {nrd }}=\left(1-\frac{I_{n r}^{*}}{I_{n r}}\right) \cdot 100$

A definição das entradas (pontos de abastecimento) de cada setor de abastecimento, nos casos em que não se trata de setorização (individualização dos reservatórios e suas áreas de abastecimento), foi realizada com base nos critérios de maior diâmetro e maior carga hidráulica disponível nas tubulações localizadas nos limites de cada setor.

\subsection{Estudos de Caso}

\subsubsection{Estudo de caso 1-RDA de Pescara}

A RDA de Pescara (WANG et al., 2015), localizada na Itália, contém 99 tubulações, 68 nós e 3 reservatórios com carga hidráulica variando de 53,08 m a 57,00 m. Toda a rede tem como material ferro fundido, com diâmetro mínimo de $100 \mathrm{~mm}$ e para tanto se considera a equação de Hazen-Williams, para definição das perdas de carga no sistema, com coeficiente de rugosidade igual a 130 . O coeficiente $C$, utilizado para cálculo da vazão de vazamentos, considerado para este sistema foi $0,25 \times 10^{-9}$. A Figura 5 contém a representação esquemática do sistema de Pescara. 
Figura 5 - RDA de Pescara (WANG et al., 2015).

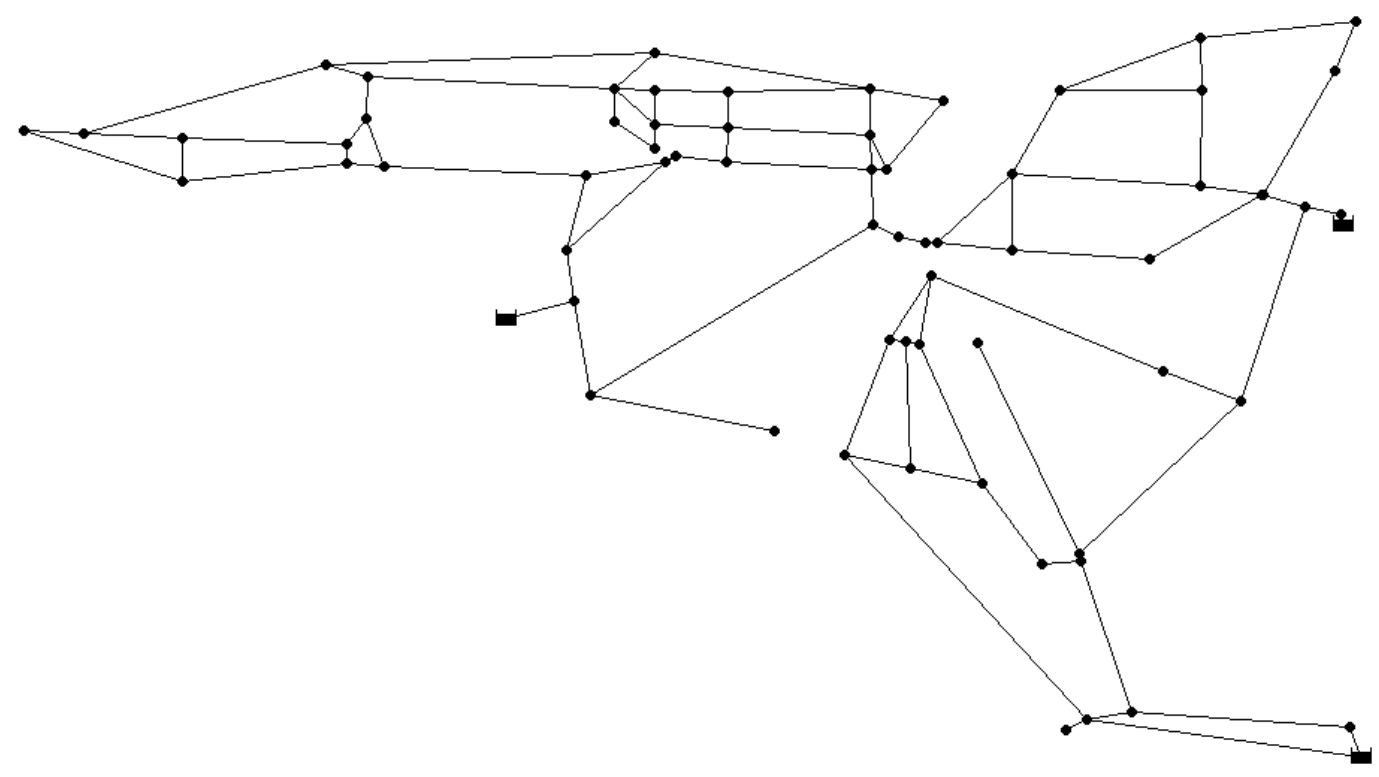

\subsubsection{Estudo de caso 2-RDA de Modena}

A RDA de Modena (WANG et al., 2015), localizada na Itália, contém 317 tubulações, 268 nós e quatro reservatórios com carga hidráulica entre 72,0 m e 74,5 m. O material da rede é ferro fundido, com diâmetro mínimo de $100 \mathrm{~mm}$ e para tanto se considera a equação de Hazen-Williams, para definição das perdas de carga no sistema, com coeficiente de rugosidade igual a 130. O coeficiente $C$, utilizado para cálculo da vazão de vazamentos, considerado para este sistema foi $1,05 \times 10^{-10}$. A Figura 6 contém a representação esquemática da rede descrita. 
Figura 6 - RDA de Modena (WANG et al., 2015).

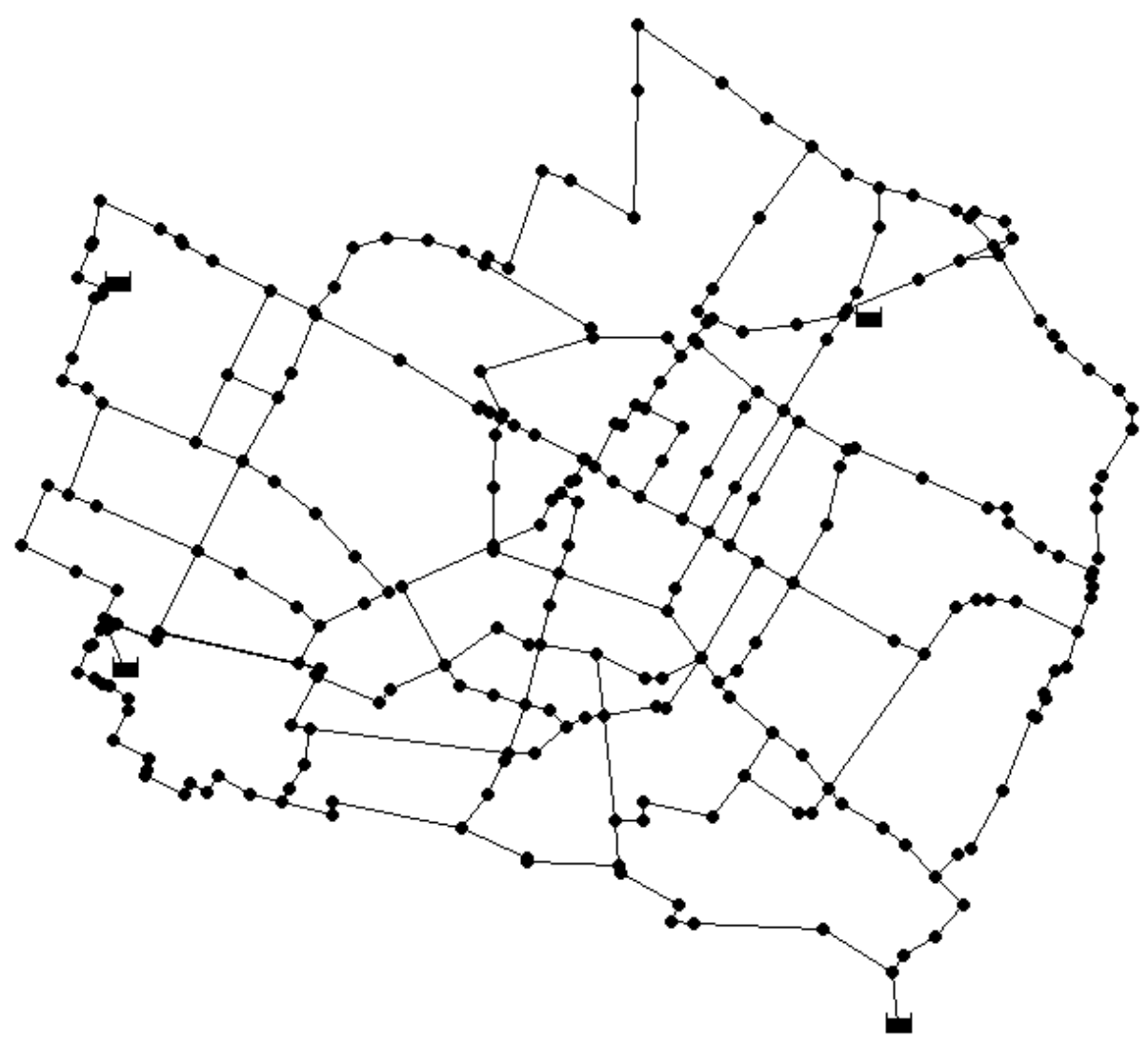

\subsubsection{Estudo de caso 3-RDA de Exeter}

A RDA de Exeter é um modelo de Sistema de abastecimento desenvolvido pelo Centre for Water Systems da universidade de Exeter no Reino Unido. A RDA abastece uma população de aproximadamente 400.000 habitantes e é constituída de tubulações de diâmetros menores com poucas adutoras, consequentemente apresentando uma perda de carga elevada no transporte de água. O diâmetro mínimo observado na rede é de $50 \mathrm{~mm}$ e para tanto se considera a equação de Darcy-Weisbach, para definição das perdas de carga no sistema, e os coeficientes para os trechos variam entre 0,02 e $30 \mathrm{~mm}$. Esta RDA foi estudada inicialmente por Farmani, Savic e Walters (2005) e pode ser visualizada na Figura 7. 
Figura 7 - RDA de Exeter - Universidade de Exeter - UK (Farmani, Savic e Walters, 2005).

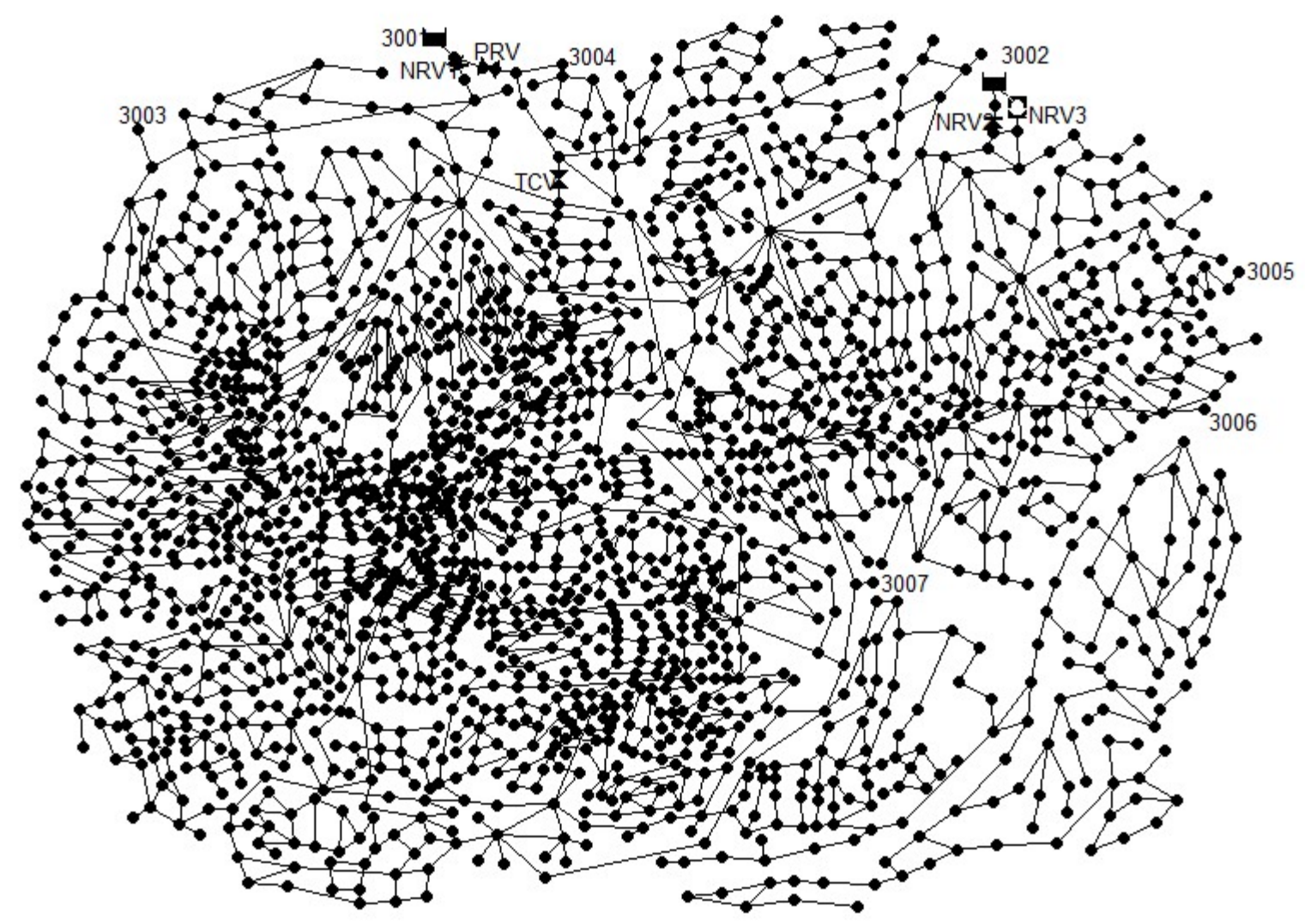

A rede apresentada é abastecida por dois reservatórios e sistemas adjacentes através dos nós 3003, 3004, 3005, 3006 e 3007. O coeficiente C, utilizado para cálculo da vazão de vazamentos, considerado para este sistema foi $0,58 \times 10^{-9}$.

\subsubsection{Estudo de caso 4 - RDA de Aracy}

A RDA de Aracy faz parte do SAA do município de São Carlos-SP. Os dados utilizados neste trabalho foram fornecidos pelo Serviço Autônomo de Água e Esgoto (SAAE) de São Carlos. A Figura 8 possibilita a visualização da delimitação do sistema estudado. 
Figura 8 - Localização do Setor Aracy.

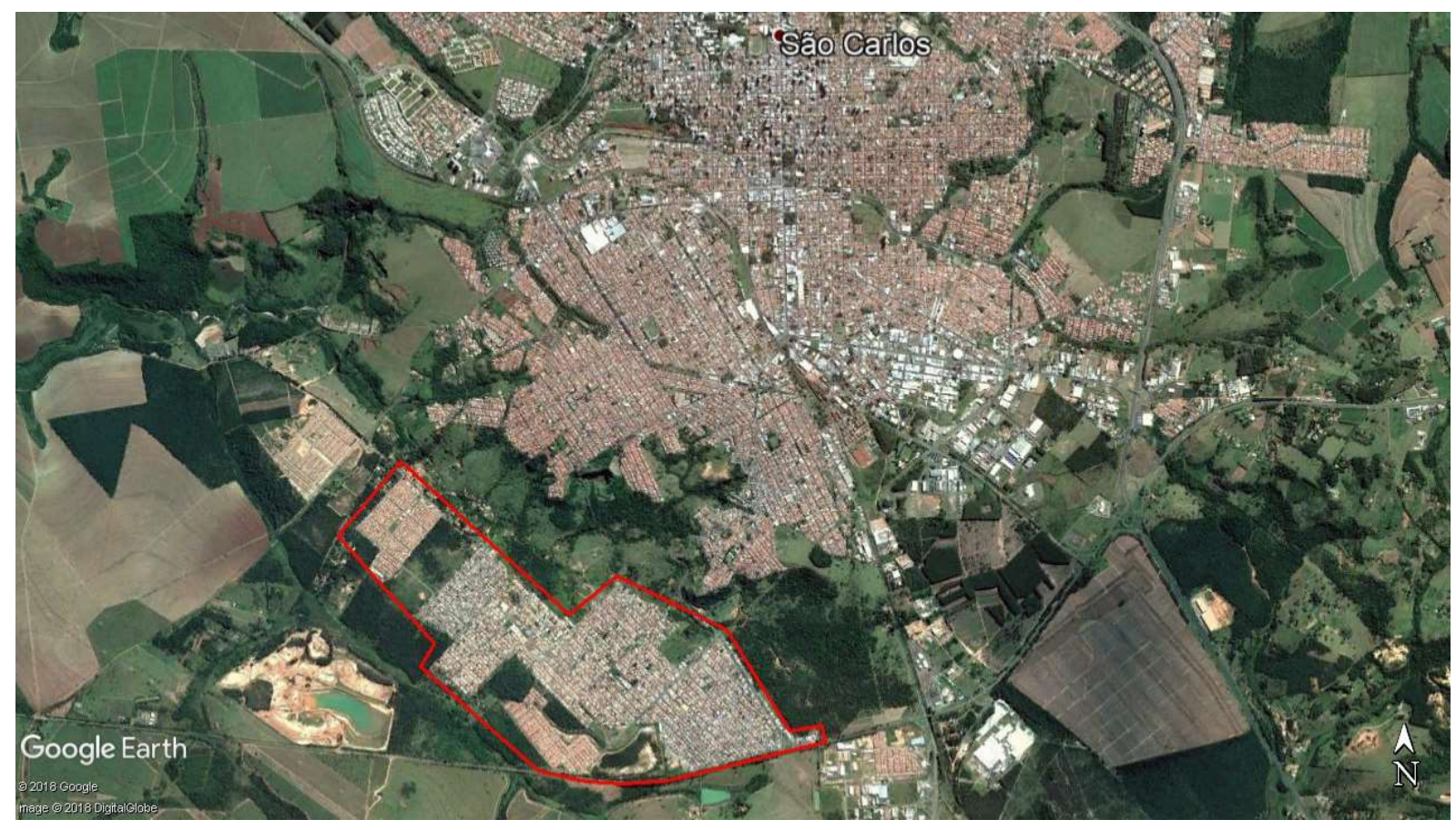

A região, denominada de setor Aracy, compreende os bairros Cidade Aracy, Presidente Collor, Antenor Garcia, o conjunto habitacional Planalto Verde e o Residencial Deputado José Zavaglia.

O modelo hidráulico que representa este sistema é composto de três reservatórios de nível fixo, 792 nós e 998 trechos de rede totalizando 104,528 km de rede. A Figura 9 é apresentada a representação esquemática do sistema empregado no modelo hidráulico EPANET utilizado neste trabalho. 
Figura 9 - SDA do Aracy - São Carlos/SP.

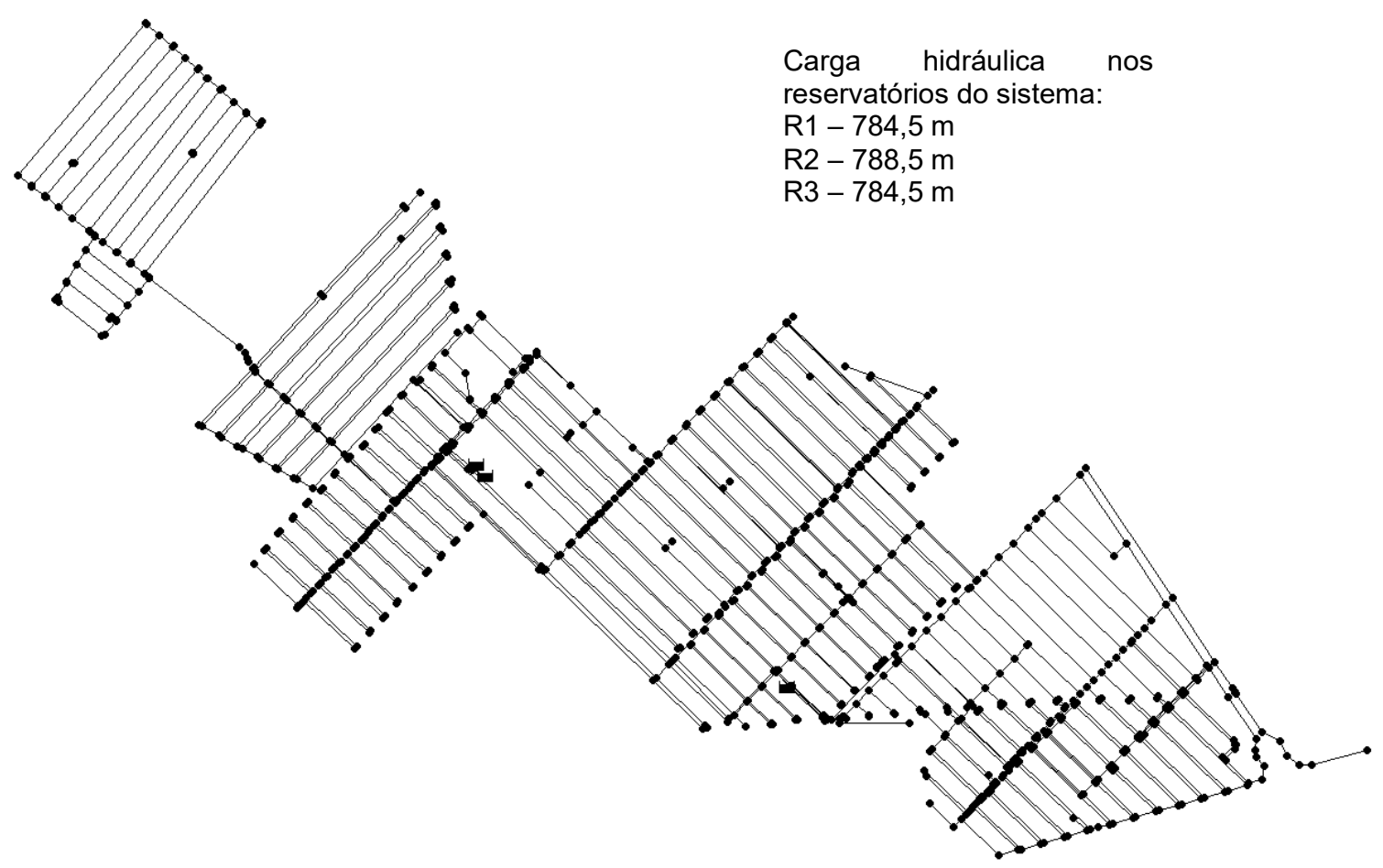

Os três reservatórios do sistema apresentam áreas de influência delimitadas e, para tanto, as vazões medidas na saída de cada um deles foi distribuída por seus nós com base na extensão de rede em cada uma dessas áreas.

O diâmetro mínimo observado na rede é de $20 \mathrm{~mm}$ e para tanto se considera a equação de Darcy-Weisbach, para definição das perdas de carga no sistema, e o coeficientes adotados para toda a RDA que tem como material das tubulações o PVC foi de $0,0056 \mathrm{~mm}$.

Os dados relativos às vazões distribuídas pelos reservatórios do sistema foram cedidos pelo SAAE para alguns dias consecutivos e para a utilização no modelo foi escolhido um dia em especifico. Os gráficos das vazões consideradas estão apresentados na Figura 10, Figura 11 e Figura 12. 
Figura 10 - Vazão distribuída pelo Reservatório 1 (Zavaglia).

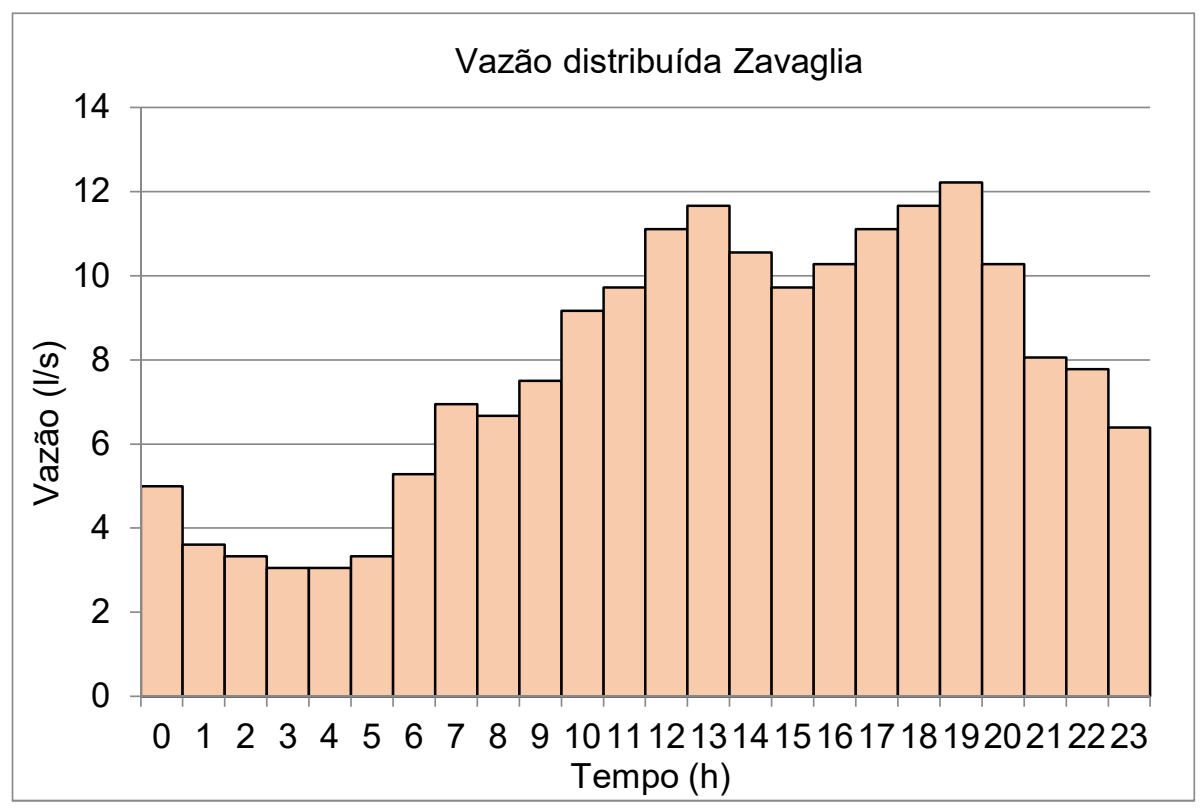

Figura 11 - Vazão distribuída pelo Reservatório 2 (Antenor Garcia).

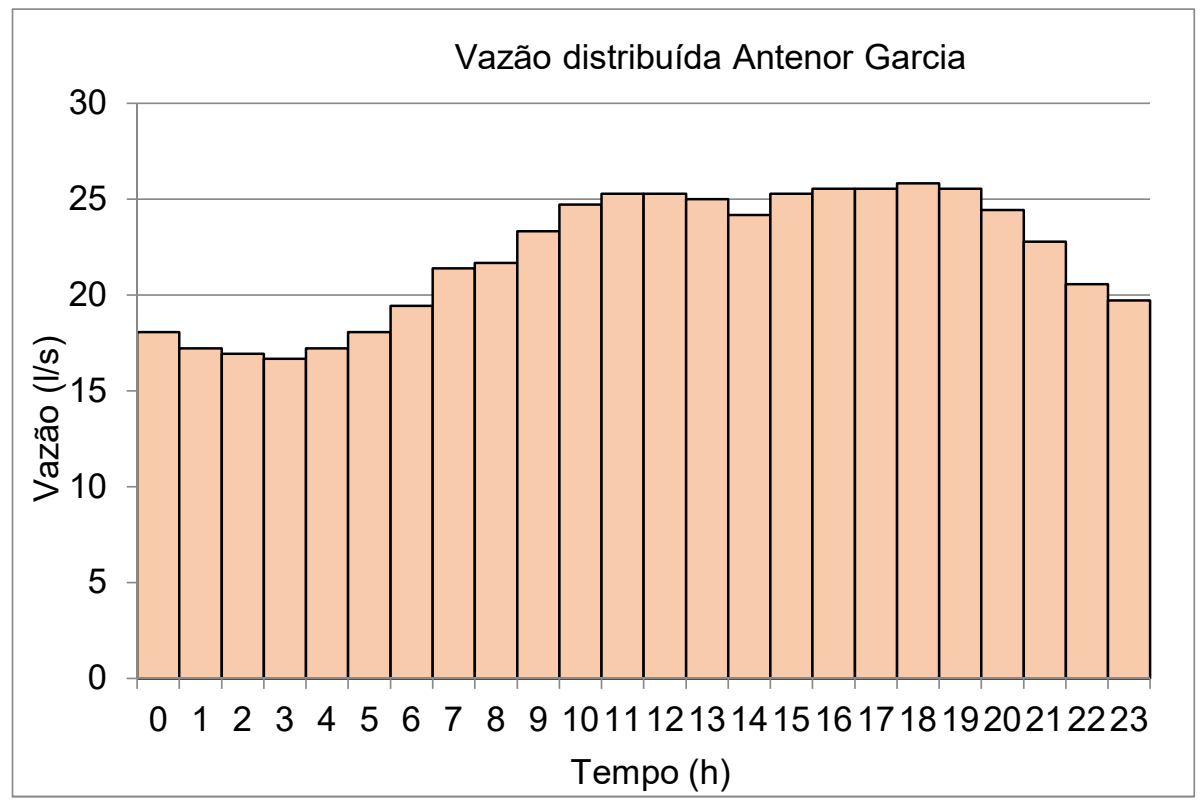


Figura 12 - Vazão distribuída pelo Reservatório 3 (Aracy).

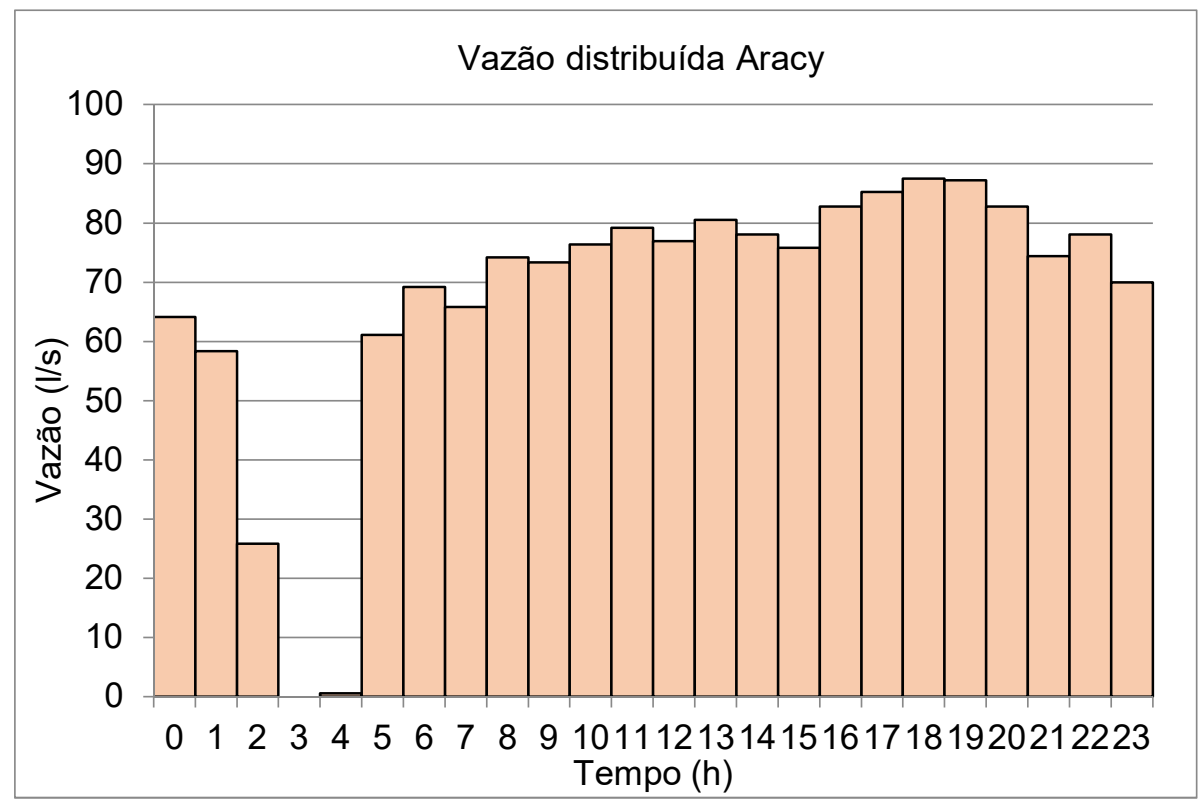

Como se tem os dados de vazão medida na saída de cada um dos reservatórios do sistema foram calculados os coeficientes $C$, para cálculo da vazão de vazamentos, individualizados por setor, são eles $C_{1}$ igual a $0,80 \times 10^{-8}, C_{2}$ igual a $2,98 \times 10^{-8}$ e $C_{3}$ igual a $1,50 \times 10^{-8}$. 


\section{RESULTADOS E DISCUSSÃO}

Nesta seção são apresentados os resultados produzidos e tecidos comentários pertinentes.

Na subseção 5.1 são apresentados os resultados da avaliação dos modelos de PDD desenvolvidos e apresentados na literatura.

$\mathrm{Na}$ subseção 5.2 são apresentados os resultados obtidos na avaliação da sensibilidade da variação da proporção PDD/VDD em relação às pressões do sistema de distribuição de água.

Na subseção 5.3 são apresentados os resultados obtidos através da análise das métricas de confiabilidade aplicadas aos estudos de caso.

\subsection{Avaliação dos modelos de demanda dirigida pela pressão}

Os diferentes modelos de PDD apresentam comportamentos diferentes dentro do range de pressão entre pressão mínima e pressão desejável. A Figura 13 apresenta as curvas de variação do fator multiplicativo Ri para os valores de pressão nodal dentro dos limites estabelecidos ( $P^{\text {min }}=0$ mca e $P^{\text {des }}=15 \mathrm{mca}$ ) para cada um dos modelos analisados deste trabalho.

Figura 13 - Variação do fator multiplicativo $R_{i}$ dentro do range de pressão $P^{\min }$ e $P^{\text {des }}$.

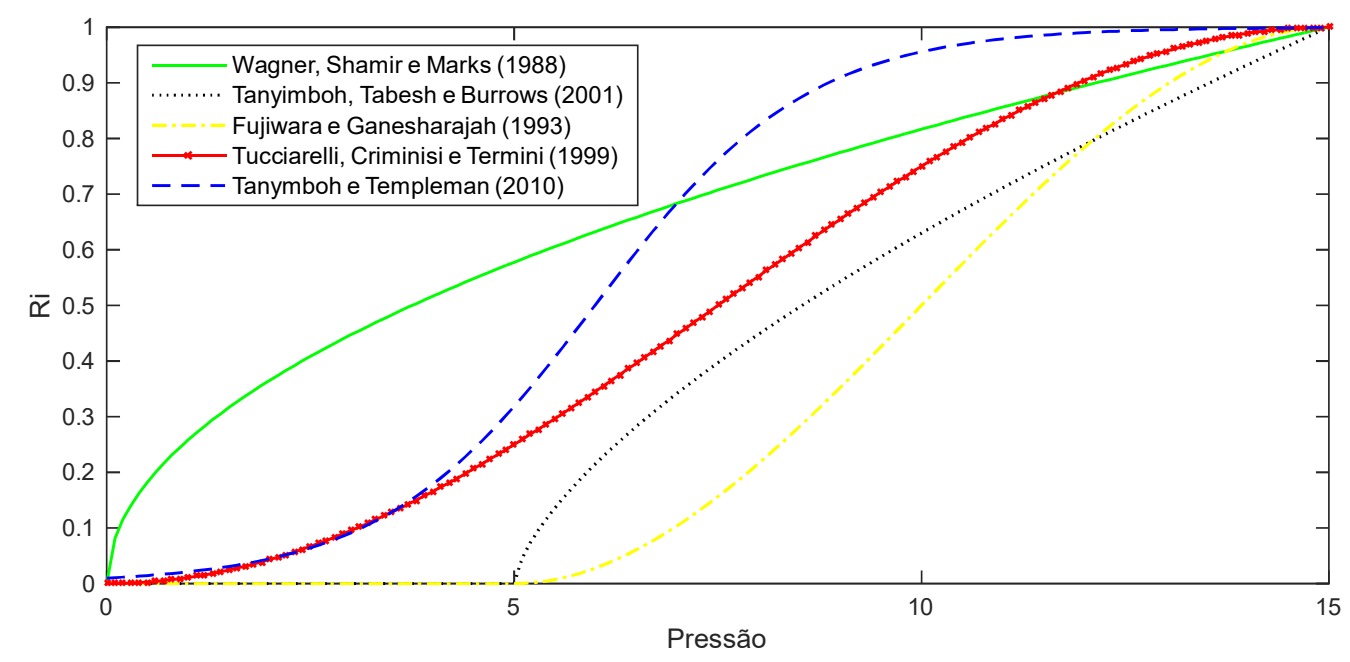

Observa-se que os modelos apresentados por Tanyimboh, Tabesh e Burrows (2001) e Fujiwara e Li (1998) iniciam o cálculo de valores de Ri apenas quando a pressão 
atinge à mínima preestabelecida (neste caso $5 \mathrm{mca}$ ), apresentando até este instante o fator multiplicador igual a zero.

Ainda, é possível observar que a equação proposta por Wagner, Shamir e Marks (1988) favorece o imediato crescimento do fator multiplicativo mesmo em pressões consideravelmente baixas. Já o modelo de Tanymboh e Templeman (2010) tem grande incremento no multiplicador entre as pressões de 5 e $7 \mathrm{mca}$, favorecendo um atendimento mais próximo do pleno para em pressões mais baixas.

Com vistas à análise da convergência dos modelos de PDD para definição da metodologia mais adequada à utilização neste trabalho, analisou-se a rede hipotética apresentada por Tucciarelli, Criminisi e Termini (1999) (Figura 4).

A Figura 14 apresenta as curvas de convergência dos modelos analisados no que diz respeito à diferença entre as vazões distribuídas ao sistema, calculadas a cada iteração, aqui denominada balanço hídrico.

Figura 14 - Convergência dos modelos

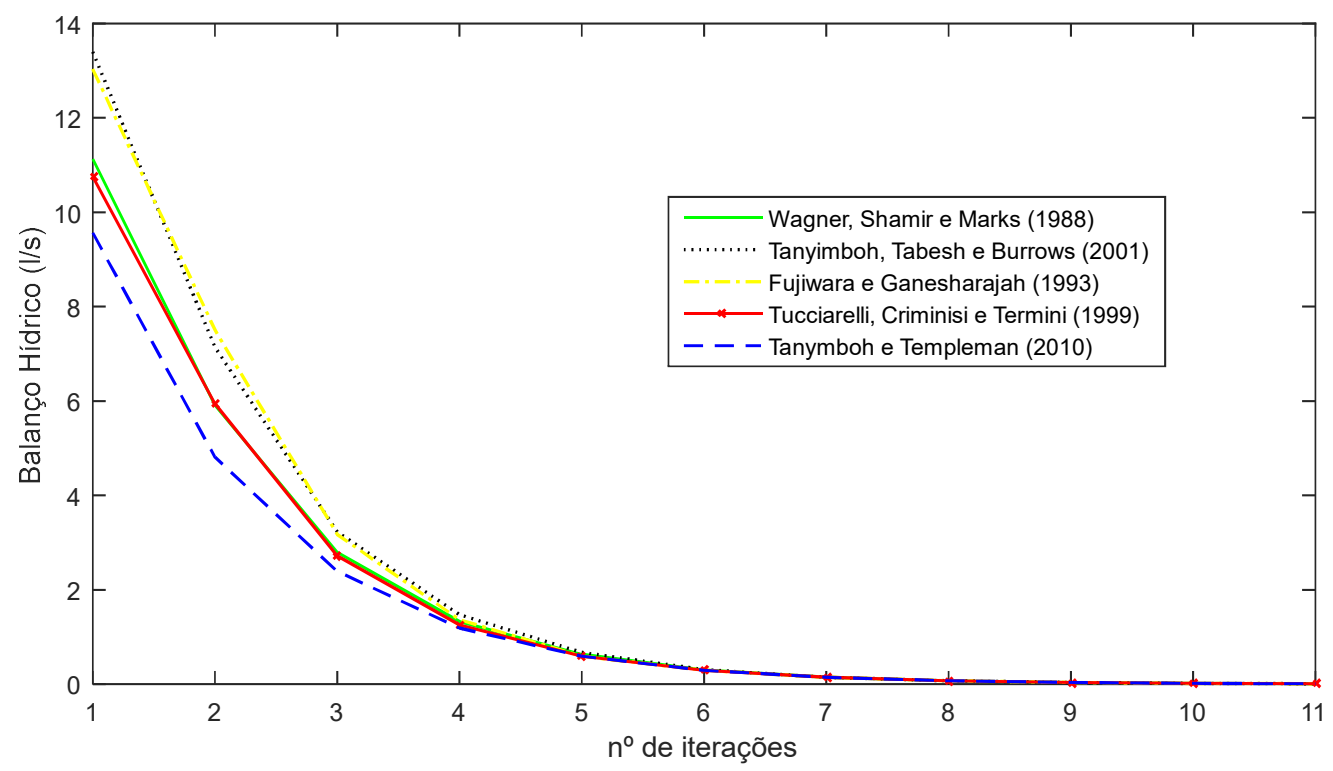

Como pode ser observado na Figura 14, os quatro modelos de PDD apresentaram desempenhos simulares no que diz respeito à velocidade de convergência ao longo das iterações.

A Tabela 5 apresenta os resultados das vazões obtidas para cada modelo, bem como o coeficiente $R_{i}$ médio e as pressões médias nos nós da rede. Ressalta-se que para 
esta avaliação não foi considerada a parcela de VDD sendo, portanto $100 \%$ da demanda requerida pelo sistema composta por PDD. Esta metodologia será tratada na subseção 5.2 .

Tabela 5 - Resultados para cada modelo considerando $\mathrm{P}^{\min }=0$ mca e $\mathrm{P}^{\mathrm{des}}=15 \mathrm{mca}$.

\begin{tabular}{|c|c|c|c|c|c|}
\hline & $\begin{array}{c}\text { Vazão } \\
\text { distribuída (1/s) }\end{array}$ & $\begin{array}{l}\text { Demanda } \\
\quad(1 / \mathrm{s})\end{array}$ & $\begin{array}{c}\text { Perdas por } \\
\text { vazamentos } \\
(1 / \mathrm{s})\end{array}$ & $\begin{array}{l}\text { Pressão média } \\
\text { nos nós (mca) }\end{array}$ & $\begin{array}{l}\mathrm{Ri} \\
\text { médio }\end{array}$ \\
\hline $\begin{array}{c}\text { Wagner, Shamir e Marks } \\
\text { (1988) }\end{array}$ & 210,60 & 173,27 & 37,33 & 12,066 & 0,950 \\
\hline $\begin{array}{l}\text { Tanyimboh, Tabesh e } \\
\text { Burrows (2001) }\end{array}$ & 204,44 & 167,01 & 37,42 & 12,090 & 0,902 \\
\hline $\begin{array}{c}\text { Fujiwara e } \\
\text { Ganesharajah (1993) }\end{array}$ & 206,51 & 169,13 & 37,38 & 12,080 & 0,893 \\
\hline $\begin{array}{l}\text { Tucciarelli, Criminisi e } \\
\text { Termini (1999) }\end{array}$ & 212,35 & 175,05 & 37,30 & 12,057 & 0,948 \\
\hline $\begin{array}{c}\text { Tanymboh e } \\
\text { Templeman }(2010)\end{array}$ & 216,67 & 179,44 & 37,23 & 12,041 & 0,992 \\
\hline
\end{tabular}

Observa-se que o modelo de Tanymboh e Templeman (2010) apresenta o maior fator Ri dentre os demais e, portanto, resulta em vazões distribuída e demandada maiores no sistema, mesmo apresentando pressão média similar.

Os valores de perdas por vazamento resultantes apresentam pouca variação entre os modelos por se tratarem da mesma equação e apenas serem influenciados por alterações das pressões esperadas na rede.

$\mathrm{Na}$ Tabela 6 apresentam-se os resultados para os modelos considerando-se a pressão mínima para todos eles igual a 5 mca.

Tabela 6 - Resultados para cada modelo considerando $\mathrm{P}^{\mathrm{min}}=5 \mathrm{mca}$ e $\mathrm{P}^{\text {des }}=15 \mathrm{mca}$.

\begin{tabular}{|c|c|c|c|c|c|}
\hline & $\begin{array}{c}\text { Vazão } \\
\text { distribuída (I/s) }\end{array}$ & $\begin{array}{l}\text { Demanda } \\
\quad(\mathrm{l} / \mathrm{s})\end{array}$ & $\begin{array}{c}\text { Perdas por } \\
\text { vazamentos (I/s) }\end{array}$ & $\begin{array}{l}\text { Pressão média } \\
\text { nos nós (mca) }\end{array}$ & $\begin{array}{l}\mathrm{Ri} \\
\text { médio }\end{array}$ \\
\hline $\begin{array}{c}\text { Wagner, Shamir e Marks } \\
\text { (1988) }\end{array}$ & 207,26 & 169,88 & 37,38 & 12,079 & 0,923 \\
\hline $\begin{array}{l}\text { Tanyimboh, Tabesh e } \\
\text { Burrows (2001) }\end{array}$ & 204,44 & 167,01 & 37,42 & 12,090 & 0,902 \\
\hline $\begin{array}{c}\text { Fujiwara e } \\
\text { Ganesharajah (1993) }\end{array}$ & 206,51 & 169,13 & 37,38 & 12,080 & 0,893 \\
\hline $\begin{array}{c}\text { Tucciarelli, Criminisi e } \\
\text { Termini (1999) }\end{array}$ & 212,35 & 175,05 & 37,30 & 12,057 & 0,948 \\
\hline $\begin{array}{c}\text { Tanymboh e } \\
\text { Templeman (2010) }\end{array}$ & 215,78 & 178,54 & 37,24 & 12,044 & 0,960 \\
\hline
\end{tabular}

Tanyimboh, Tabesh e Burrows (2001) e Fujiwara e Li (1998) não apresentam alteração quando comparado aos resultados obtidos para Pmin igual a 0 mca, uma vez 
que a $\mathrm{P}^{\mathrm{min}}$ para estes modelos é sempre igual 5 mca. Tucciarelli, Criminisi e Termini (1999) também não com a alteração da $P^{\min }$ de 0 para 5, isso se deve ao fato de este modelo não considerar pressões mínimas no calculo do coeficiente multiplicador da demanda.

Os dois demais modelos apresentaram diminuição em suas vazões distribuídas e demandas com a alteração da Pmin. Pressões até 5 mca passaram a ser consideradas insuficientes para a demanda PDD. Consequentemente foram observados reflexos nas pressões e nas perdas por vazamentos, mesmo que pouco significativos.

Considerando-se um sistema mais restritivo à satisfação plena das demandas pelo sistema e estabelecendo a pressão mínima igual a 10 mca e a pressão desejável igual a 20, apresentam-se os resultados da Tabela 7 .

Tabela 7 - Resultados para cada modelo considerando $P^{\min }=10$ mca e $P^{\text {des }}=20$ mca.

\begin{tabular}{|c|c|c|c|c|c|}
\hline & $\begin{array}{c}\text { Vazão } \\
\text { distribuída (I/s) }\end{array}$ & $\begin{array}{l}\text { Demanda } \\
(\mathrm{I} / \mathrm{s})\end{array}$ & $\begin{array}{c}\text { Perdas por } \\
\text { vazamentos (I/s) }\end{array}$ & $\begin{array}{l}\text { Pressão média } \\
\text { nos nós (mca) }\end{array}$ & $\begin{array}{l}\mathrm{Ri} \\
\text { médio }\end{array}$ \\
\hline $\begin{array}{c}\text { Wagner, Shamir e Marks } \\
\text { (1988) }\end{array}$ & 167,54 & 129,52 & 38,02 & 12,256 & 0,626 \\
\hline $\begin{array}{l}\text { Tanyimboh, Tabesh e } \\
\text { Burrows (2001) }\end{array}$ & 177,54 & 139,66 & 37,88 & 12,219 & 0,739 \\
\hline $\begin{array}{c}\text { Fujiwara e } \\
\text { Ganesharajah (1993) }\end{array}$ & 172,45 & 134,53 & 37,92 & 12,228 & 0,684 \\
\hline $\begin{array}{l}\text { Tucciarelli, Criminisi e } \\
\text { Termini (1999) }\end{array}$ & 189,32 & 151,64 & 37,67 & 12,160 & 0,736 \\
\hline $\begin{array}{c}\text { Tanymboh e } \\
\text { Templeman (2010) }\end{array}$ & 157,87 & 119,82 & 38,05 & 12,256 & 0,585 \\
\hline
\end{tabular}

Observa-se que todos os modelos apresentam queda das vazões distribuídas com a alteração da $P^{\text {min }}$ de 5 para 10 mca e $P^{\text {des }}$ de 15 para 20 mca, mas o impacto mais significativo observado vem a ser do modelo de Tanymboh e Templeman (2010), que resultou nas maiores vazões para as condições apresentadas na Tabela 6 $\left(\mathrm{P}^{\mathrm{min}}=5 \mathrm{mca}\right.$ e $\left.\mathrm{P}^{\text {des }}=15 \mathrm{mca}\right)$ e passou a produzir as menores vazões para condições apresentadas na Tabela $7\left(P^{\min }=10\right.$ mca e $\left.P^{\text {des }}=20 \mathrm{mca}\right)$.

Se analisarmos novamente o gráfico de variação do fator multiplicativo, estabelecendo novos valores de pressão para o range de pressão admitido, é possível observar, dadas as pressões médias do sistema, os resultados observados na Tabela 7. A Figura 15 apresenta os mesmos resultados de forma gráfica. 
Figura 15 - Variação do fator multiplicativo $R_{i}$ dentro do range de pressão $P^{\min } 10$ mca e $P^{\text {des }}$ 20 mca.

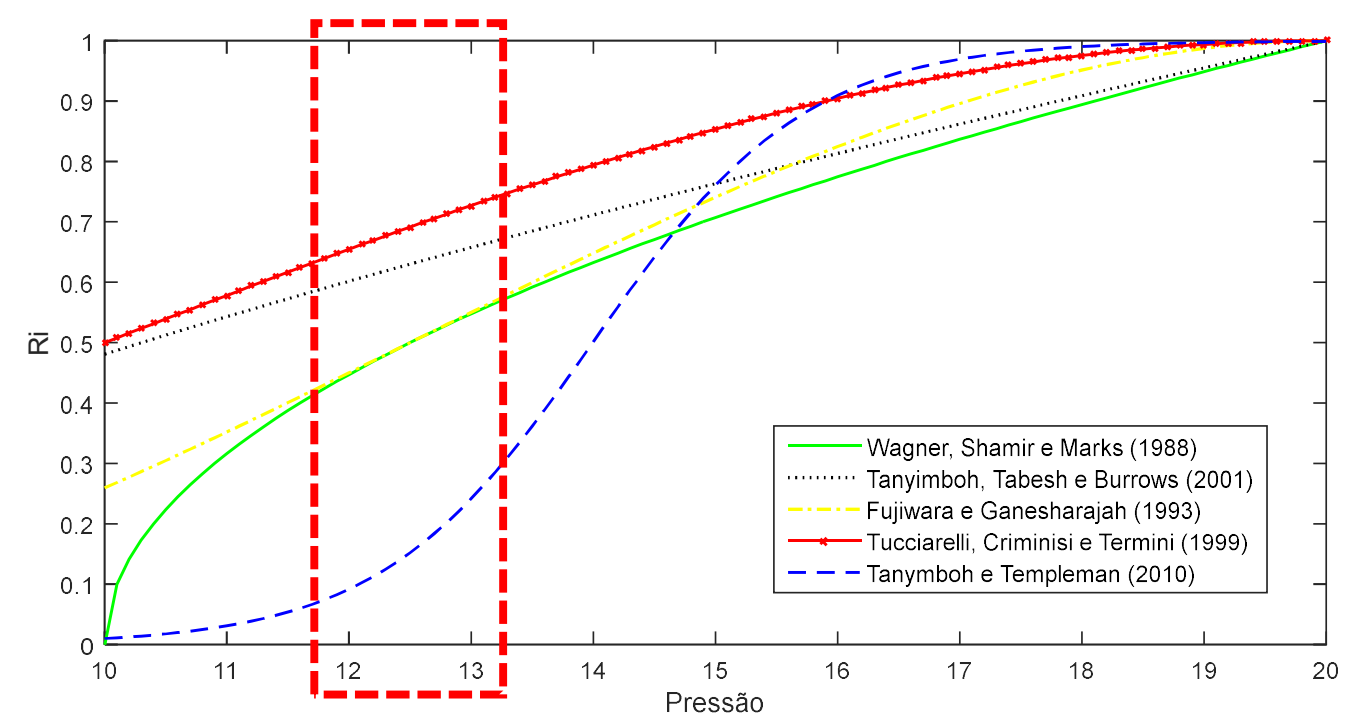

A região em que se encontram as pressões médias no sistema apresentam os menores valores para a o modelo de Tanymboh e Templeman (2010), assim como se pode observar que os maiores valores correspondem aos resultantes do modelo de Tucciarelli, Criminisi e Termini (1999).

Avalia-se, portanto, que o modelo de Tanymboh e Templeman (2010) mostra-se mais coerente, uma vez que a alteração dos limites de pressão preestabelecidos devem influenciar os resultados. Portanto, seguiu-se o trabalho utilizando este modelo para as demandas PDD.

\subsection{Impacto da proporção VDD/PDD na vazão distribuída}

Para analisar o impacto da implementação da metodologia proposta por Jun e Guoping (2013) foram avaliados alguns fatores de proporção entre VDD e PDD considerando-se as demandas da rede hipotética de Tucciarelli, Criminisi e Termini (1999), apresentada na Figura 4 cujos resultados são resumidos no gráfico apresentado na Figura 16. 
Figura 16 - Variação da vazão distribuída pelo SDA com a pressão, variando-se a proporção de VDD e PDD.

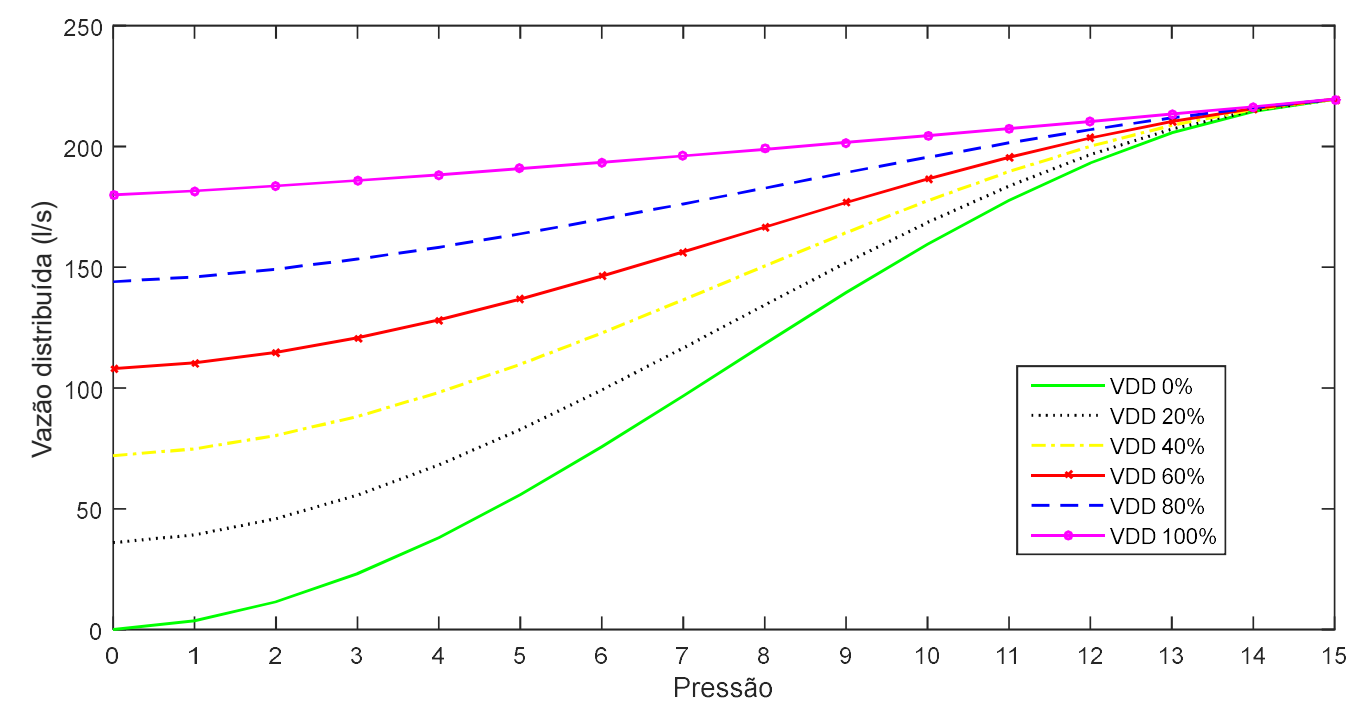

A Figura 16 permite a constatação de que o maior impacto, sobre a vazão total distribuída, da proporção entre VDD e PDD é observado quando ocorrem pressões mais baixas no sistema, uma vez que todo o volume avaliado como VDD é suprido mesmo com pressões mais baixas, superiores a zero.

Ressalta-se que foi considerada como pressão mínima para PDD igual a zero, o que faz a curva verde ( $0 \%$ VDD) subir assim que a pressão começa a aumentar. Na Tabela 8 são apresentados os resultados para o sistema da rede hipotética da Figura 4.

Tabela 8 - Resultados para a rede hipotética variando a proporção VDD/PDD.

\begin{tabular}{cccc}
\hline & $0 \%$ VDD & $60 \%$ VDD & $100 \%$ VDD \\
\hline Vazão distribuída (I/s) & 212,35 & 215,21 & 217,22 \\
Demanda (I/s) & 175,05 & 177,96 & 180,00 \\
Perdas por vazamentos (I/s) & 37,30 & 37,25 & 37,22 \\
Pressão média nos nós (mca) & 12,06 & 12,05 & 12,04 \\
\hline
\end{tabular}

Como observado no gráfico, quando a pressão se aproxima daquela observada na rede hipotética em estudo (média de aproximadamente $12 \mathrm{mca}$ ) a vazão distribuída apresenta pouca variação, conforme os resultados apresentados na Tabela 8.

Como foi observada influência pouco significativa na adoção da porcentagem de VDD sobre a demanda total, para o propósito desta análise adotou-se que $50 \%$ da demanda total será tratada como VDD e $50 \%$ como PDD para todos os estudos de caso, assim como considerado Jung et al. (2016). 


\subsection{Avaliação das métricas de confiabilidade}

Para cada um dos estudos de caso descritos no item anterior foi realizado o cálculo da confiabilidade hidráulica e das métricas heurísticas de confiabilidade. Os resultados são apresentados na Tabela 9

Tabela 9 - Resultados das métricas de confiabilidade para os sistemas estudados.

\begin{tabular}{cccccc}
\hline & \multicolumn{2}{c}{ Confiabilidade } & \multicolumn{2}{c}{ Resiliência } & \\
& $\begin{array}{c}\text { Estado zero } \\
\left(\mathrm{R}^{0}\right)\end{array}$ & $\begin{array}{c}1^{\circ} \text { estado } \\
\left(\mathrm{R}^{1}\right)\end{array}$ & $\begin{array}{c}\text { Resiliência da } \\
\text { rede }\left(\mathrm{I}_{\mathrm{nr}}\right)\end{array}$ & $\begin{array}{c}\text { Índice de } \\
\text { Resiliência }\left(\mathrm{I}_{\mathrm{r}}\right)\end{array}$ & Entropia (S) \\
\hline RDA de Modena & 0,992 & 0,575 & 0,41 & 0,43 & 4,92 \\
RDA de Pescara & 0,998 & 0,525 & 0,36 & 0,42 & 3,54 \\
RDA de Exeter & 0,800 & 0,654 & 0,18 & 0,19 & 6,77 \\
RDA de Aracy & 0,841 & 0,673 & 0,67 & 0,72 & 6,14 \\
\hline
\end{tabular}

É possível observar que os sistemas com indicador de confiabilidade "Estado Zero" mais baixos dentre os estudados foram a RDA de Exeter e a RDA de Aracy. Tal comportamento se deve ao fato de tais sistemas já apresentarem pressões abaixo da desejável em condições normais de operação (ausência de falha) o que pode ser observado nas Figura 19 e Figura 20.

Figura 17 - Pressão nos nós da RDA de Pescara considerando a total disponibilidade dos componentes do sistema (ausência de falha).

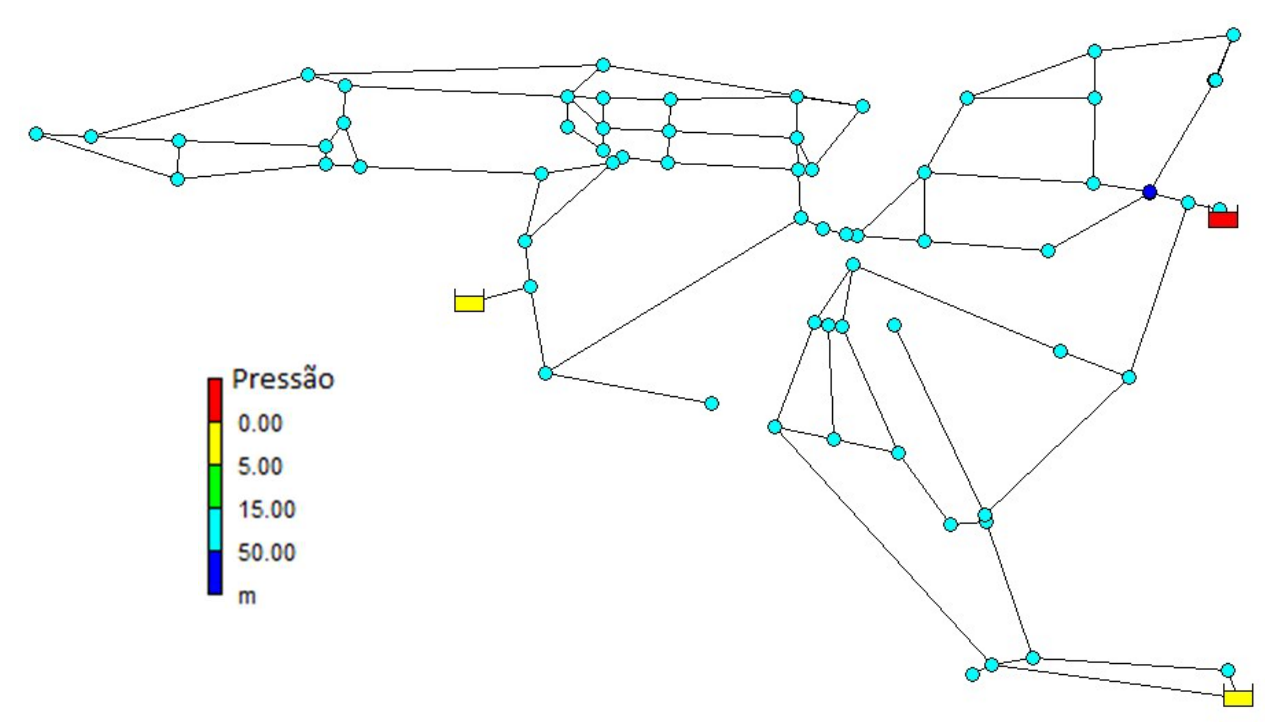


Figura 18 - Pressão nos nós da RDA de Modena considerando a total disponibilidade dos componentes do sistema (ausência de falha).

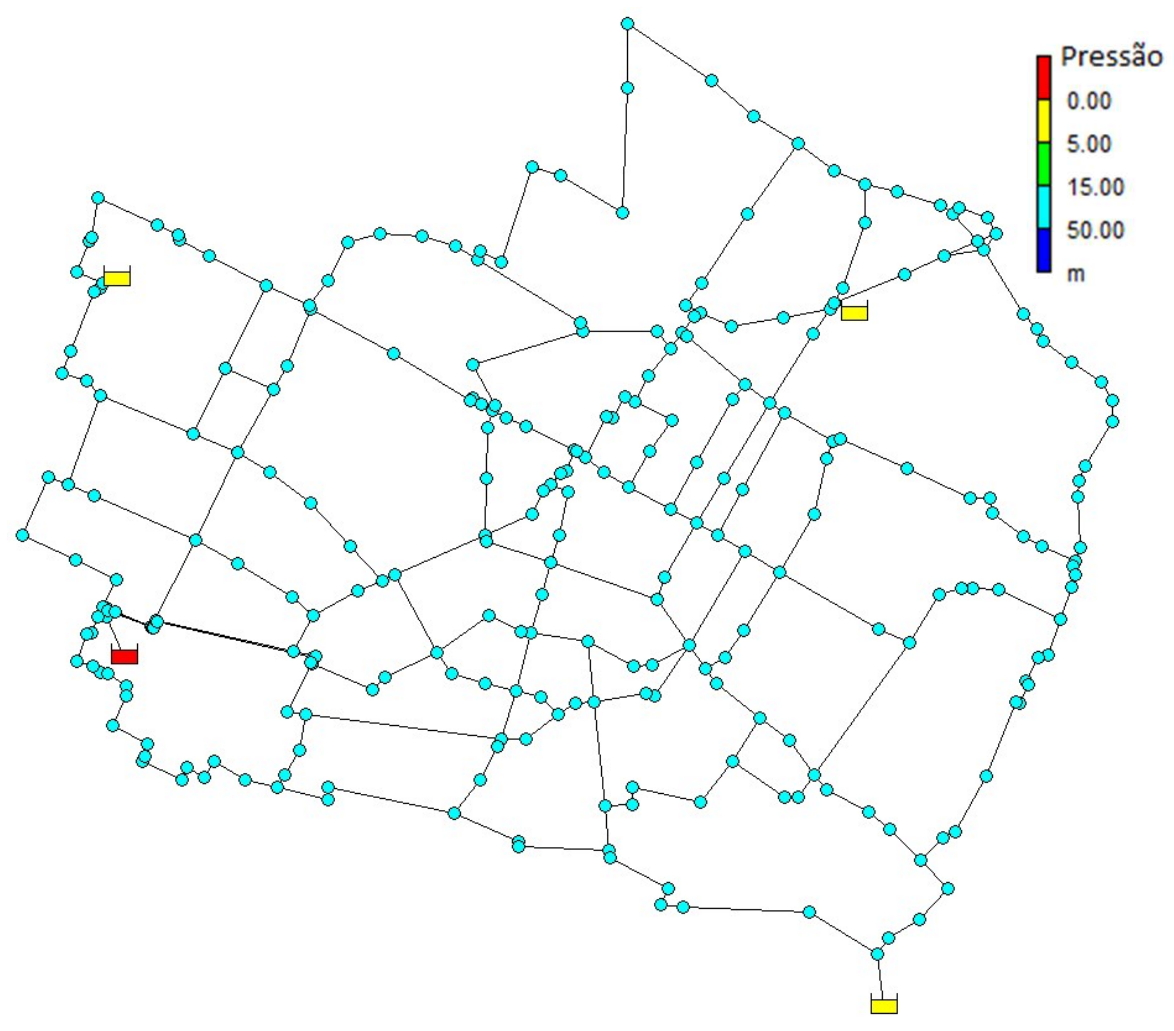

Figura 19 - Pressão nos nós da RDA de Exeter considerando a total disponibilidade dos componentes do sistema (ausência de falha).

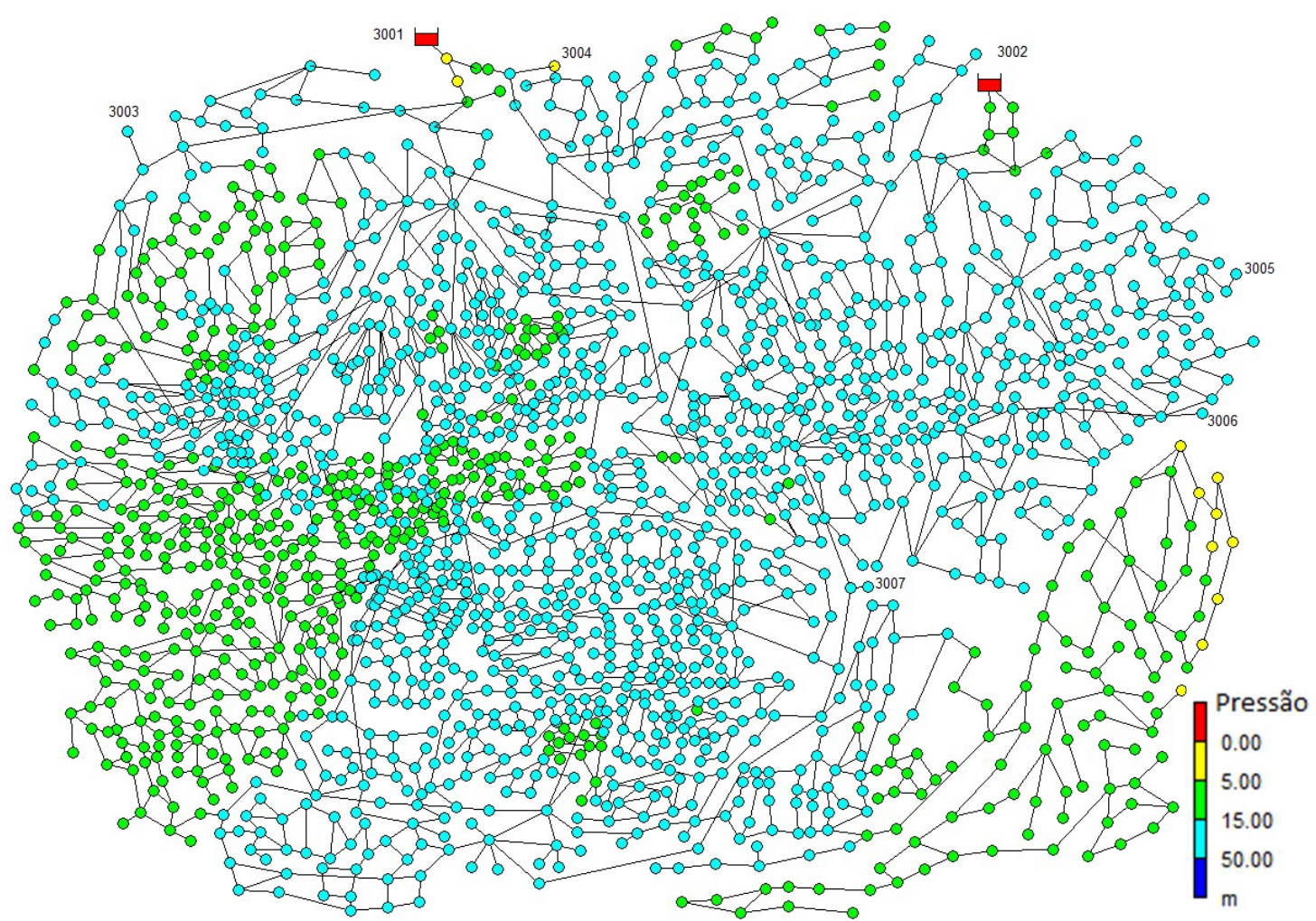


Figura 20 - Pressão nos nós da RDA de Aracy considerando a total disponibilidade dos componentes do sistema (ausência de falha).

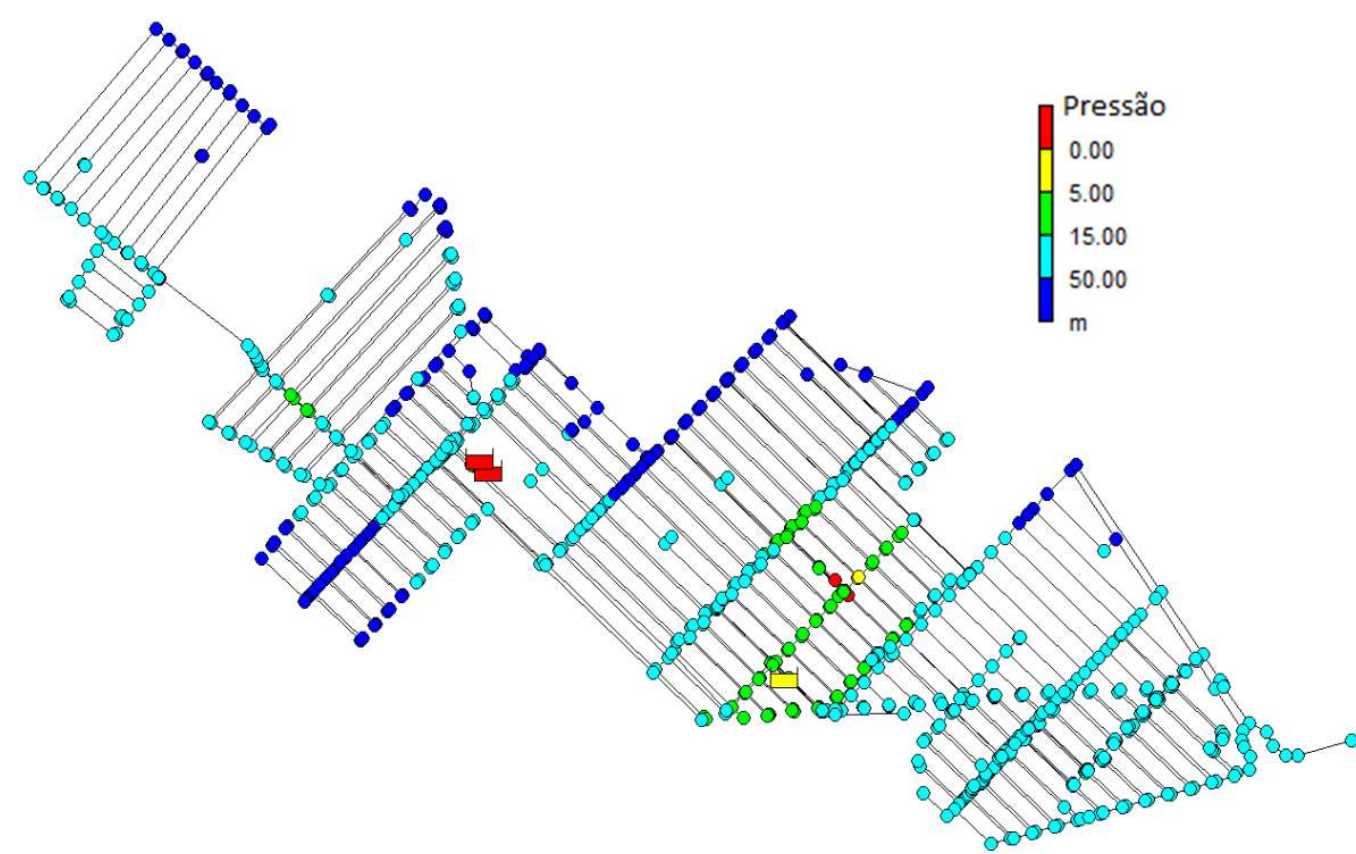

Para cada um dos estudos de caso foi proposto um ou mais possíveis arranjos de setores, para melhoria do controle e da gestão de pressões, e foi avaliado o impacto da segmentação de redes segundo as métricas de confiabilidade aqui apresentadas.

Para a RDA de Pescara, por ser um sistema de médio porte, com três reservatórios existentes como fonte de abastecimento, foi executado o algoritmo k-means considerando a formação de três clusters, de modo que cada DMC criado possuísse alimentação independente e única. A setorização resultante pode ser vista na Figura 21. 
Figura 21 - Setores definidos a partir do algoritmo k-means para o Estudo de caso 1 - RDA de Pescara (a) nós da rede categorizados por DMC na localização geográfica e, (b) elevação dos nós da rede.

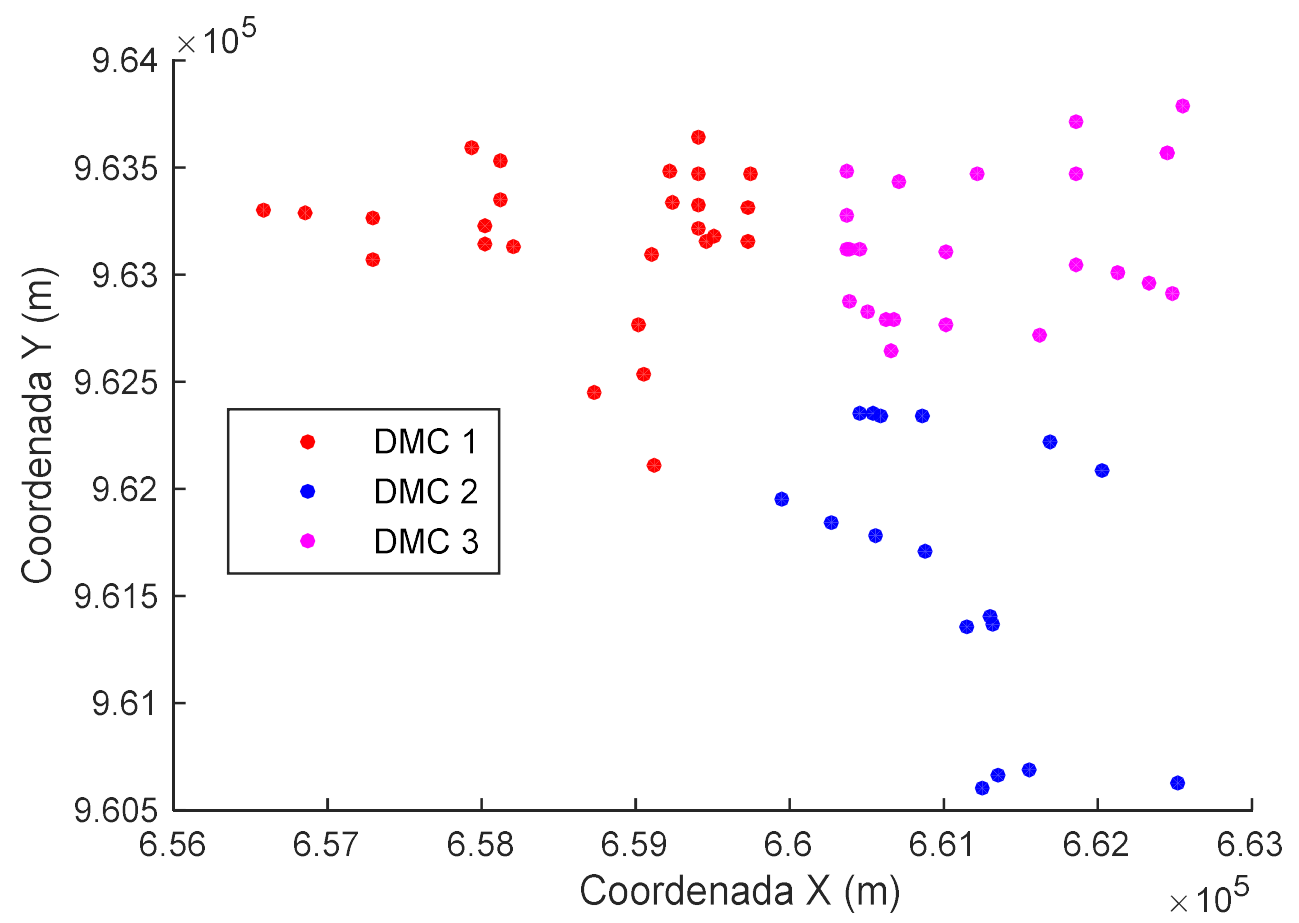

(a)

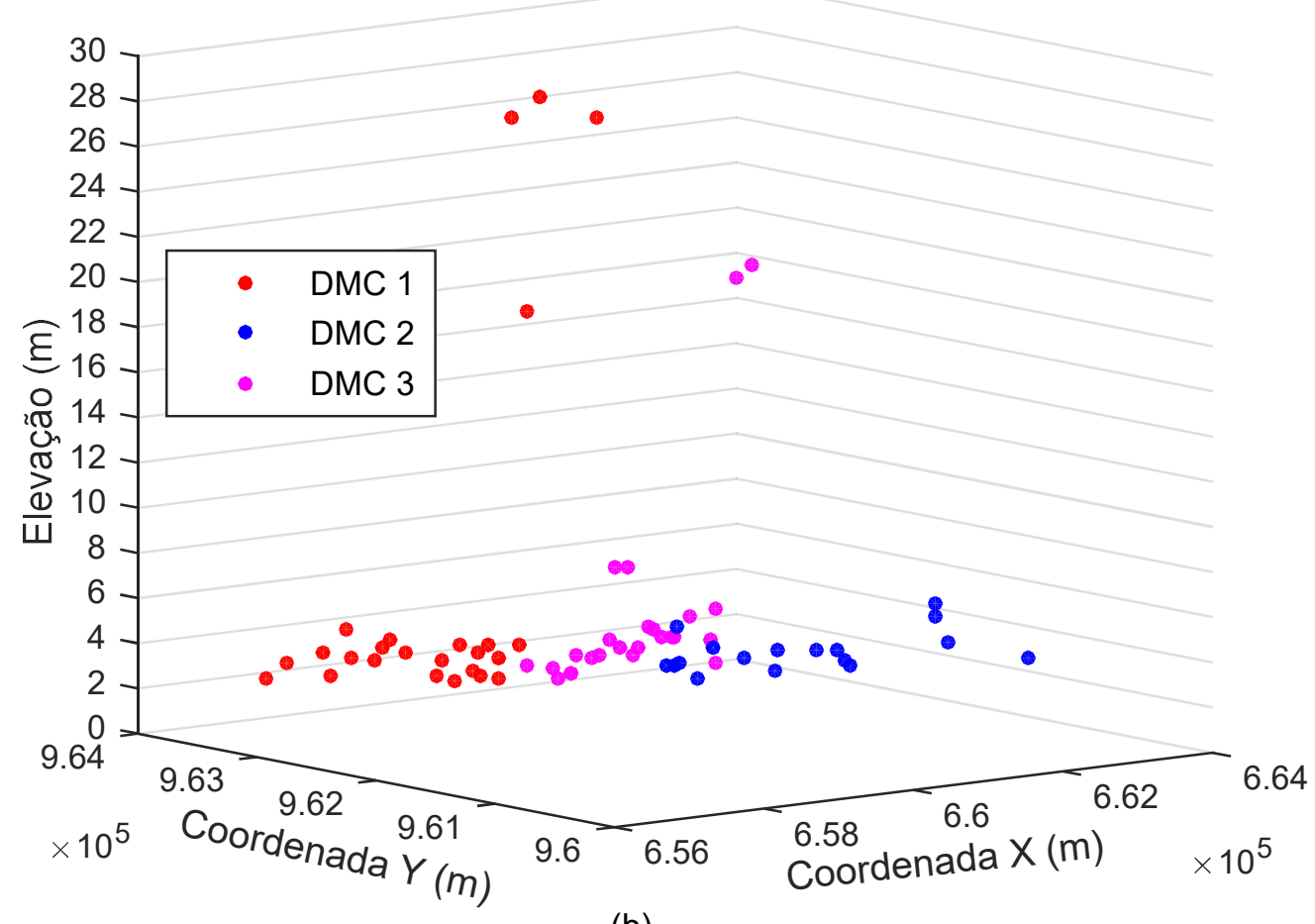

(b)

A Figura 22 apresenta a localização das válvulas de isolamento e a delimitação dos setores de abastecimento do sistema setorizado proposto. 
Figura 22 - Setorização da RDA de Pescara com posicionamento dos fechamentos de setor.

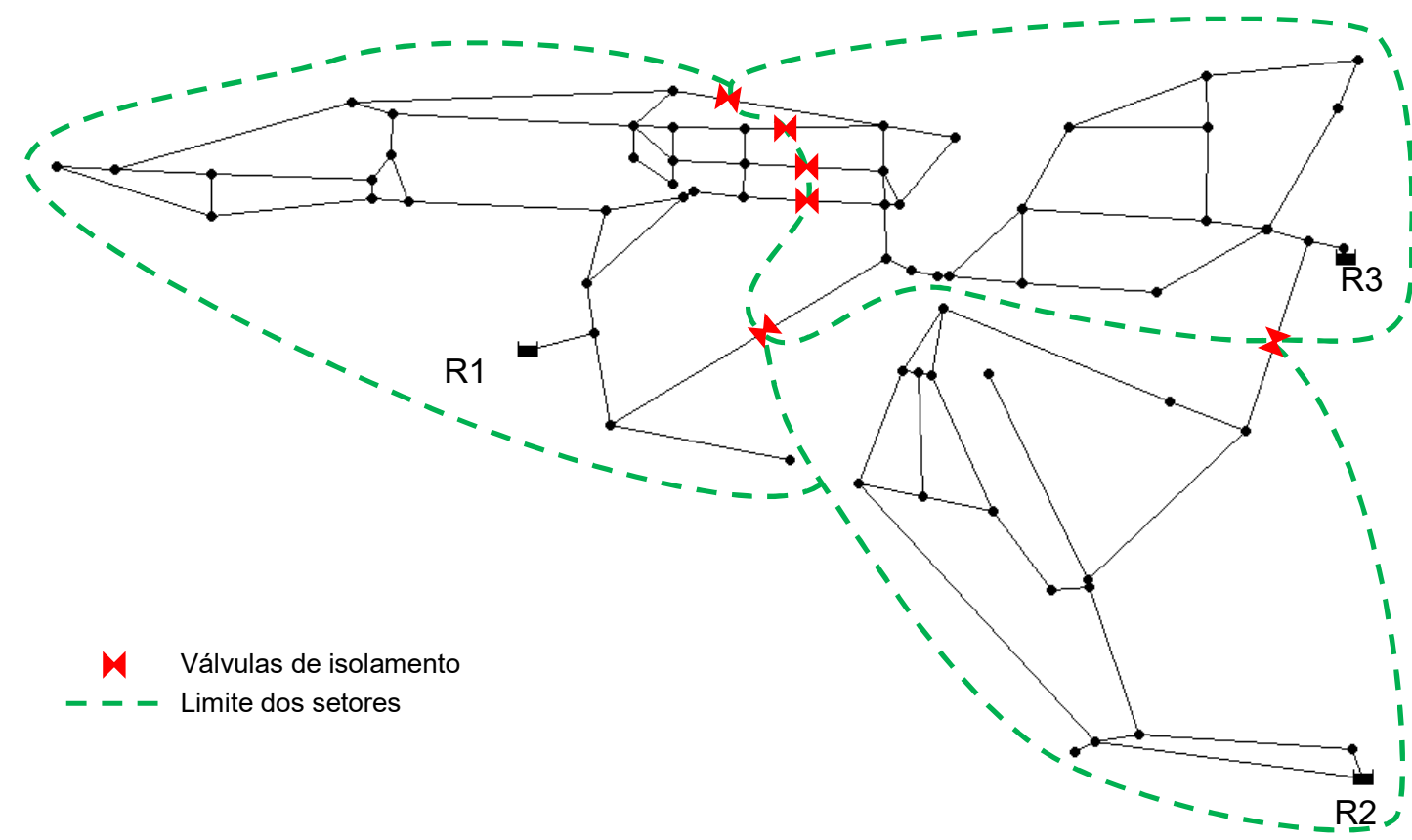

A setorização implantada apresentou impacto direto sobre as métricas de confiabilidade, como pode ser observado na Tabela 10.

Tabela 10 - Valores das métricas de confiabilidade para o sistema original e o sistema após definição da setorização para o Estudo de caso 1 - RDA de Pescara.

\begin{tabular}{|c|c|c|c|c|c|}
\hline & \multicolumn{2}{|c|}{ Confiabilidade Hidráulica } & \multicolumn{2}{|c|}{ Resiliência } & \multirow[b]{2}{*}{$\begin{array}{c}\text { Entropia } \\
\text { (S) }\end{array}$} \\
\hline & $\begin{array}{l}\text { Estado zero } \\
\qquad\left(R^{0}\right)\end{array}$ & $\begin{array}{c}1^{\circ} \text { estado } \\
\left(\mathrm{R}^{1}\right)\end{array}$ & $\begin{array}{l}\text { Resiliência da } \\
\text { rede }\left(I_{n r}\right)\end{array}$ & $\begin{array}{c}\text { Índice de } \\
\text { Resiliência }\left(I_{r}\right)\end{array}$ & \\
\hline RDA de Pescara Original & 0,998 & 0,525 & 0,36 & 0,42 & 3,54 \\
\hline RDA de Pescara Setorizada & 0,873 & 0,518 & 0,32 & 0,37 & 3,41 \\
\hline
\end{tabular}

A RDA de Pescara original apresenta confiabilidade hidráulica no estado zero muito próxima a um enquanto a RDA setorizada é igual a 0,873. É possível observar a grande influência do déficit de abastecimento do sistema em condições normais (ausência de falha) para determinação de $R^{0}$. A relação entre a vazão efetivamente distribuída e a vazão demanda para a RDA setorizada é de 0,87 , numericamente igual à métrica calculada.

O impacto da setorização sobre o valor obtido para a confiabilidade hidráulica é maior para $R^{0}$ do que para $R^{1}$, apresentando redução mais acentuada para $R^{0}$, que se justifica pelo isolamento dos setores e consequente redução das pressões no sistema. A RDA original não apresenta déficit de abastecimento, com todos os nós do sistema 
exibindo pressões acima da desejável com pressão mínima no sistema igual a 20,7 mca, enquanto a rede setorizada apresenta pressão mínima igual a 12,7 mca.

A redução do valor obtido para a entropia entre a RDA original e a setorizado também pode ser explicado pela redução na vazão total distribuída. Apesar de a rede original já apresentar os índices $I_{n r}$ e $I_{r}$ baixos, a setorização proposta foi possível apresentando desvio considerado pequeno para estas métricas, de 12,40 e 12,95\%, respectivamente.

Da mesma forma que para a RDA de Pescara, devido ao porte da RDA de Modena, foi utilizado o critério de número de reservatórios existentes para a definição da quantidade de clusters predefinidos na execução do algoritmo k-means. Portanto, a setorização segundo as quatro fontes de abastecimento (reservatórios) independentes resultante pode ser vista na Figura 23. 
Figura 23 - Setores definidos a partir do algoritmo k-means para o Estudo de caso 1 - RDA de Modena (a) nós da rede categorizados por DMC na localização geográfica e, (b) elevação dos nós da rede.

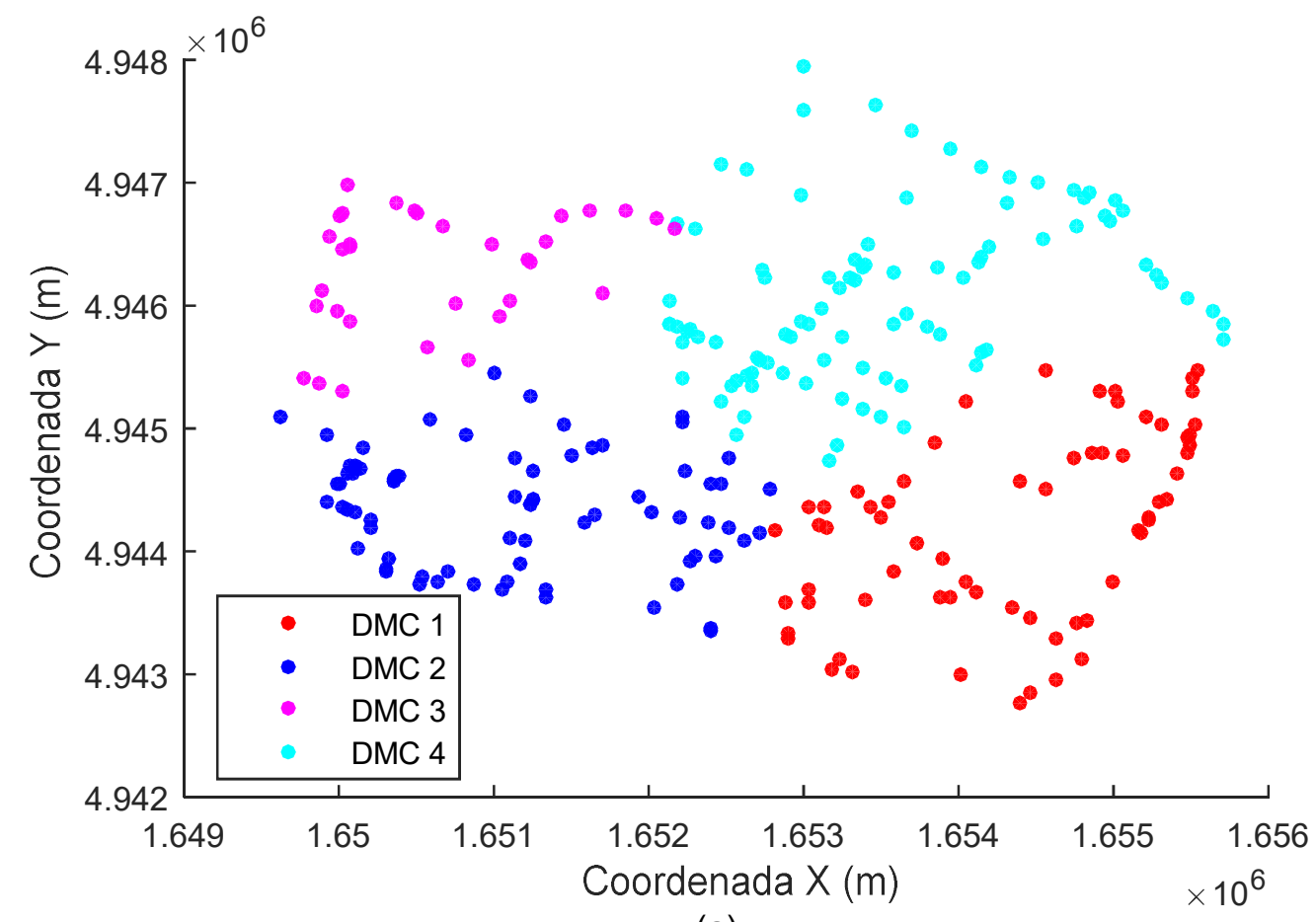

(a)

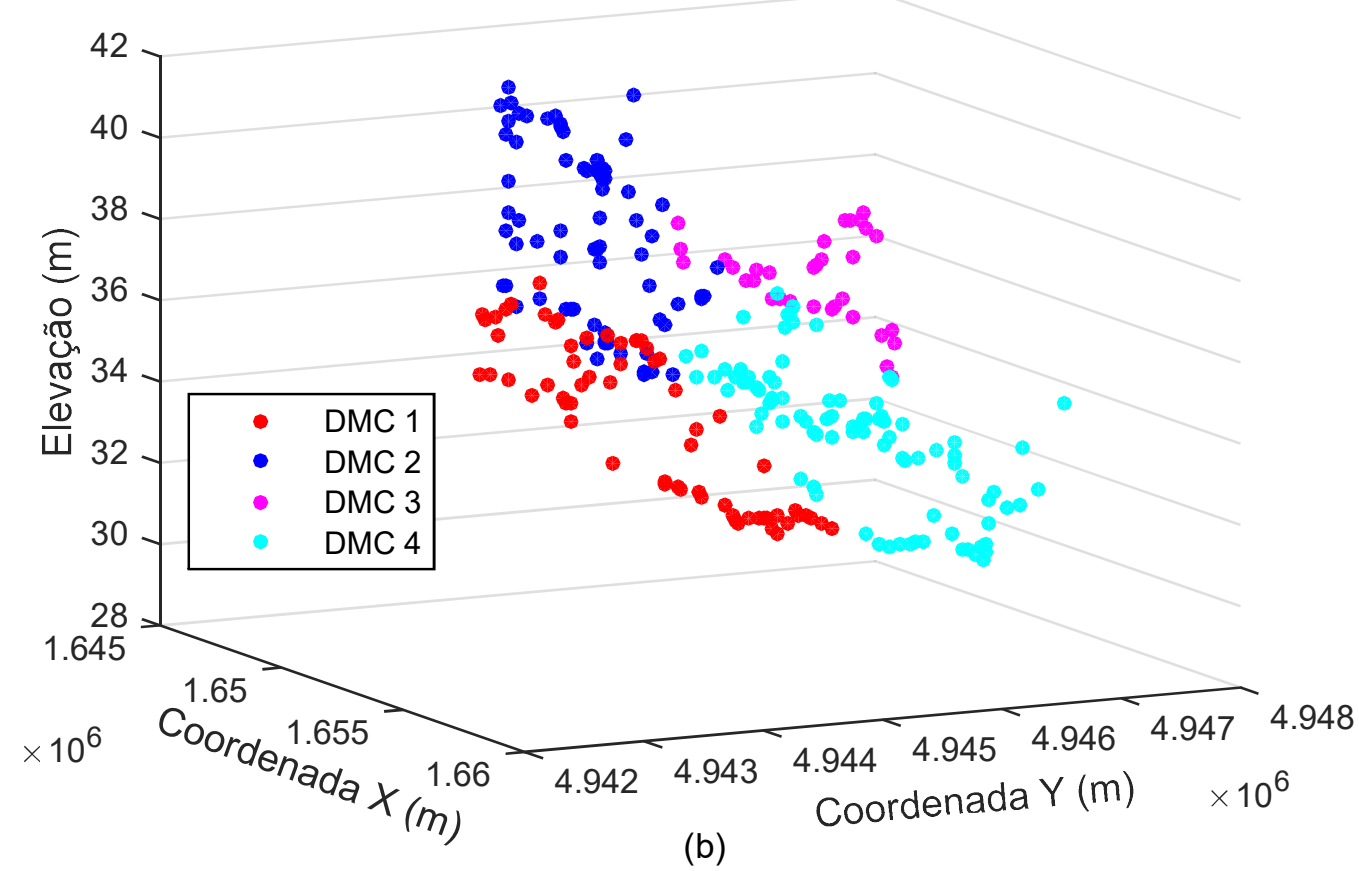

A Figura 24 apresenta a localização das válvulas de isolamento e a delimitação dos setores de abastecimento do sistema setorizado proposto. 
Figura 24 - Setorização da RDA de Modena com posicionamento dos fechamentos de setor.

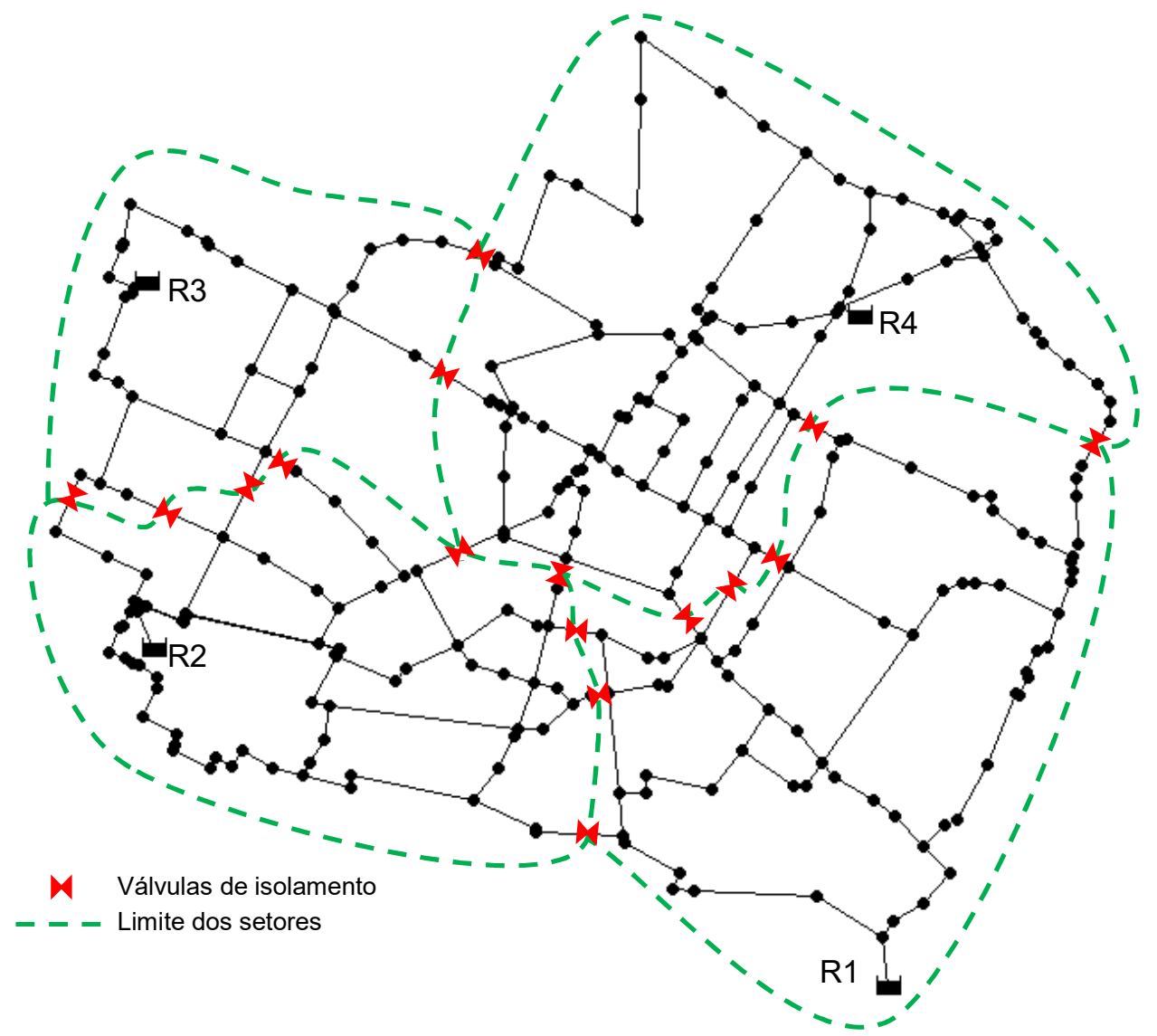

O resultado comparativo das métricas de confiabilidade hidráulica para a rede original e após a setorização proposta pode ser observado na Tabela 11.

Tabela 11 - Comparação entre as métricas de confiabilidade para o sistema original e o sistema após definição da setorização para o Estudo de caso 2 - RDA de Modena.

\begin{tabular}{|c|c|c|c|c|c|}
\hline & \multicolumn{2}{|c|}{ Confiabilidade Hidráulica } & \multicolumn{2}{|c|}{ Resiliência } & \multirow[b]{2}{*}{$\begin{array}{c}\text { Entropia } \\
\text { (S) }\end{array}$} \\
\hline & $\begin{array}{l}\text { Estado zero } \\
\qquad\left(R^{0}\right)\end{array}$ & $\begin{array}{c}1^{\circ} \text { estado } \\
\left(R^{1}\right)\end{array}$ & $\begin{array}{l}\text { Resiliência da } \\
\text { rede }\left(I_{n r}\right)\end{array}$ & $\begin{array}{c}\text { Índice de } \\
\text { Resiliência }\left(\mathrm{I}_{\mathrm{r}}\right)\end{array}$ & \\
\hline RDA de Modena Original & 0,992 & 0,575 & 0,41 & 0,43 & 4,92 \\
\hline RDA de Modena Setorizada & 0,779 & 0,540 & 0,37 & 0,39 & 4,84 \\
\hline
\end{tabular}

A RDA de Modena, assim como observado para a RDA de Pescara, a presenta impacto da setorização mais significativo para a confiabilidade hidráulica em $\mathrm{R}^{0}$ do que para $R^{1}$, apresentando redução mais acentuada para $R^{0}$, que se justifica devido ao isolamento dos setores e consequente redução das pressões no sistema.

A RDA de Modena, não apresenta déficit de abastecimento na rede original, com pressão mínima igual a 20,1 mca, enquanto a rede setorizada apresentou pressão mínima de 6,4 mca e uma relação entre a vazão efetivamente distribuída e a vazão demanda é igual a 0,78 , numericamente igual à métrica $R^{0}$ calculada. 
Os desvios para as métricas $I_{n r}$ e $I_{r}$ foram de $9,74 \%$ e $9,83 \%$, respectivamente, ainda menores do que os verificados para RDA de Pescara. Também foi observada pequena redução da entropia para a RDA setorizada em relação à original.

A RDA de Exeter é a mais complexa dentre as analisadas neste trabalho, uma vez que possui maior quantidade de tubulações e maior demanda requerida. Além disso, na Figura 19, foi possível observar que a mesma apresenta pressões inferiores à desejável mesmo em condições normais de operação.

Este sistema apresenta dois reservatórios de abastecimento e cinco outras interligações conhecidas que recebem contribuição de sistemas vizinhos. Devido à sua complexidade, a definição de setores completamente isolados uns dos outros é inviável e para tanto, foi considerado o particionamento deste sistema.

Para definição das partições, bem como o número ótimo das mesmas, foi executado o algoritmo k-means considerando os quatro índices de validação explicitados no subitem 4.2.4, cujos resultados são resumidos nos gráficos da Figura 25.

Figura 25 - Resultados do número ótimo de clusters para cada um dos índices avaliados para o Estudo de caso 3 - RDA de Exeter.
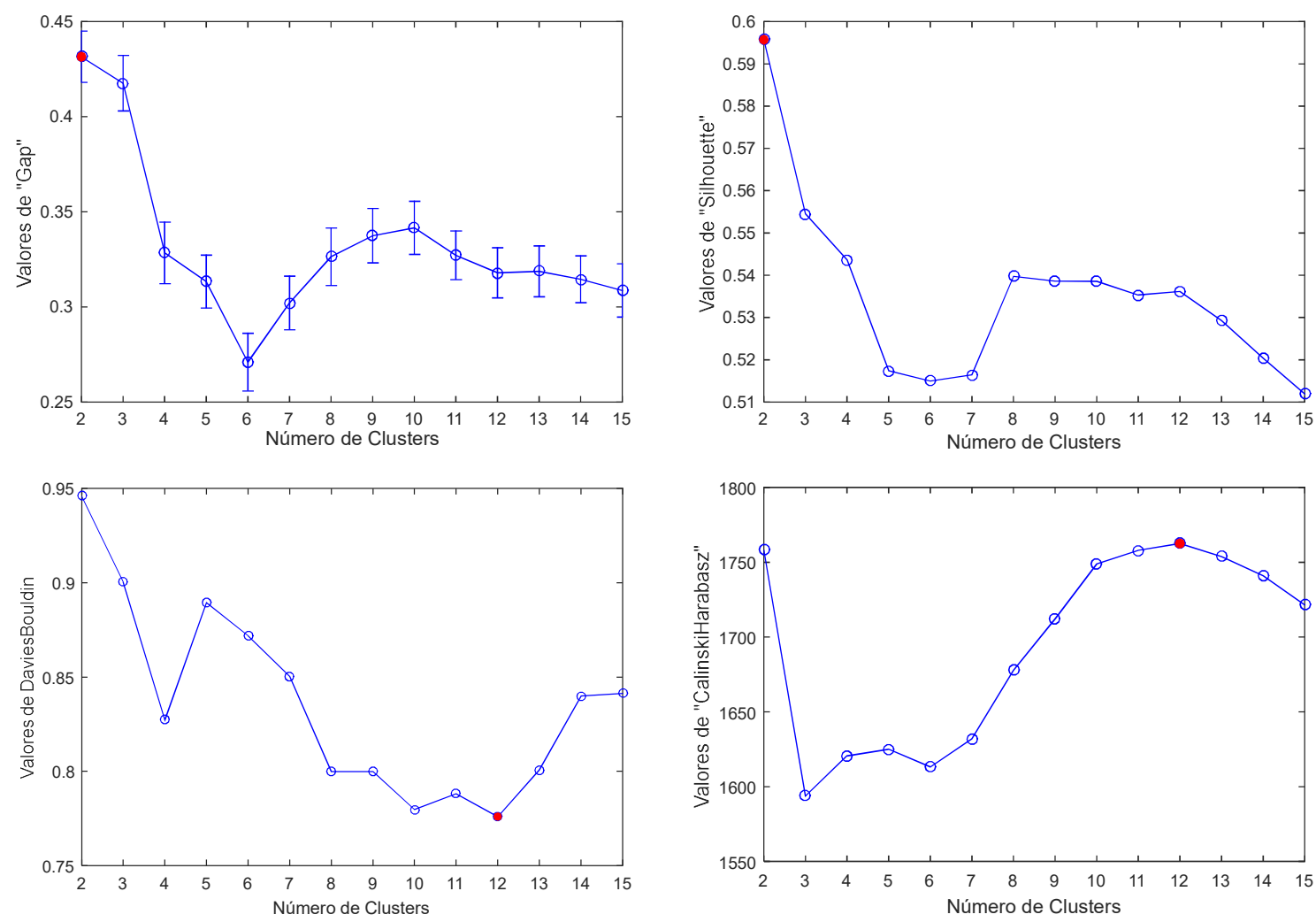
Observa-se que dois resultados distintos foram produzidos para o número ótimo de clusters segundo os índices utilizados. Os índices GAP e Silhouette alcançaram como resultado o número de partições igual a dois (2). Já os índices Calinski-Harabasz, Davies-Bouldin produziram doze (12) partições para o sistema.

Ambas as proposições foram avaliadas em termos das métricas de confiabilidade e a configuração das partições para cada uma delas, conforme indicações da Figura $26 \mathrm{e}$ da Figura 27. 
Figura 26 - Setores definidos a partir do algoritmo k-means utilizando os índices GAP e Silhouette para o Estudo de caso 3 - RDA de Exeter (a) nós da rede categorizados por DMC na localização geográfica e, (b) elevação dos nós da rede.

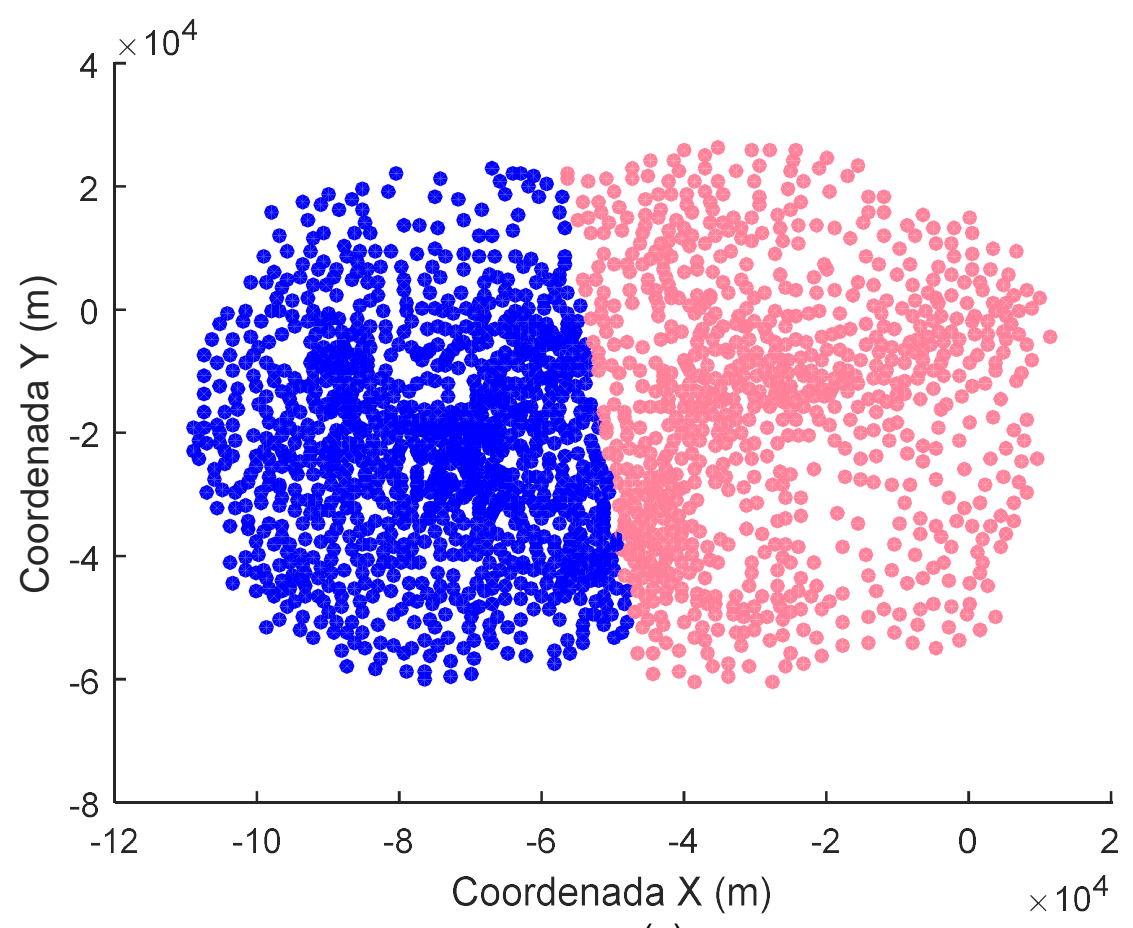

(a)

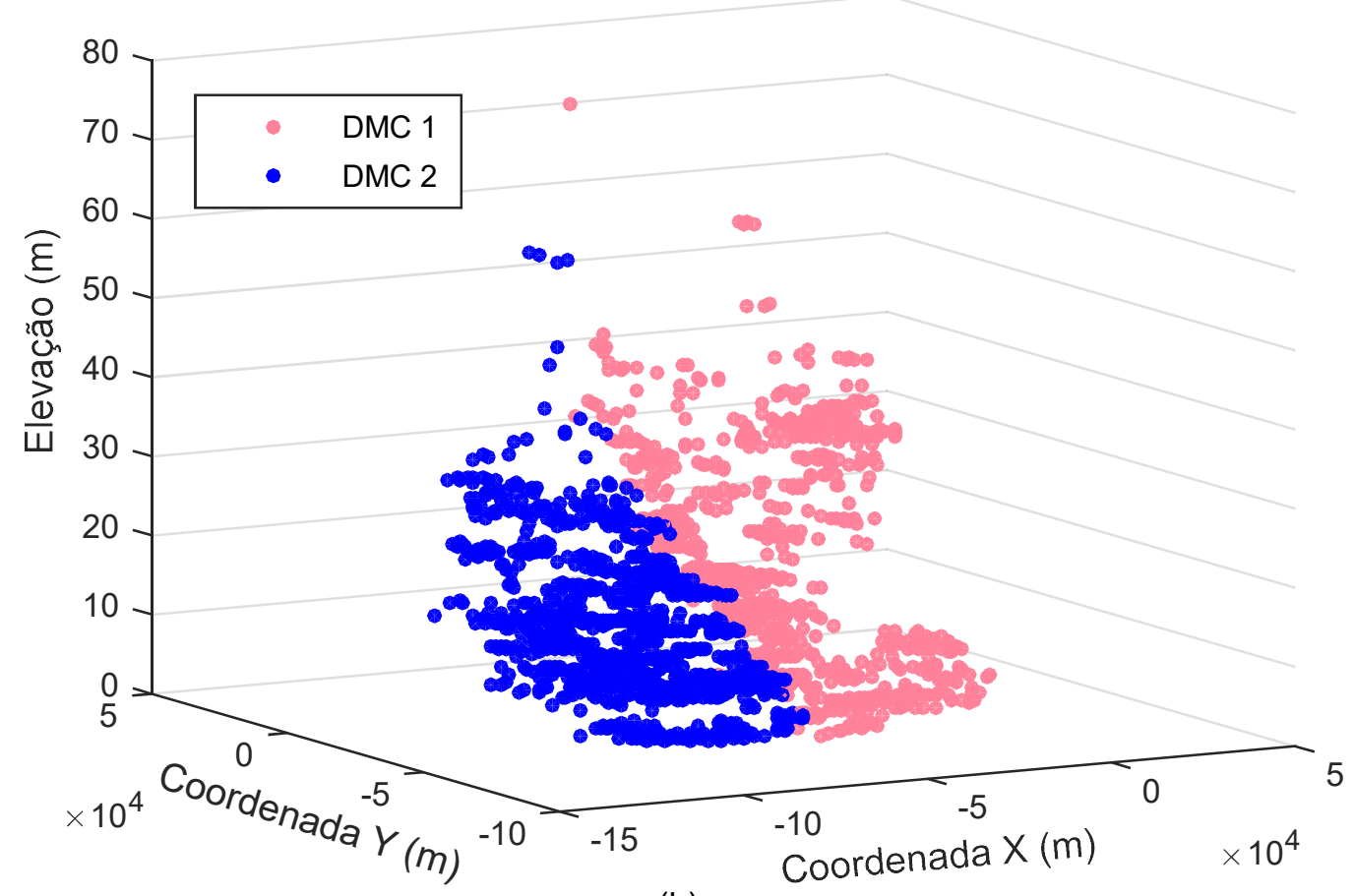

(b) 
Figura 27 - Setores definidos a partir do algoritmo k-means utilizando os índices CalinskiHarabasz e Davies-Bouldin para o Estudo de caso 3 - RDA de Exeter (a) nós da rede categorizados por DMC na localização geográfica e, (b) elevação dos nós da rede.

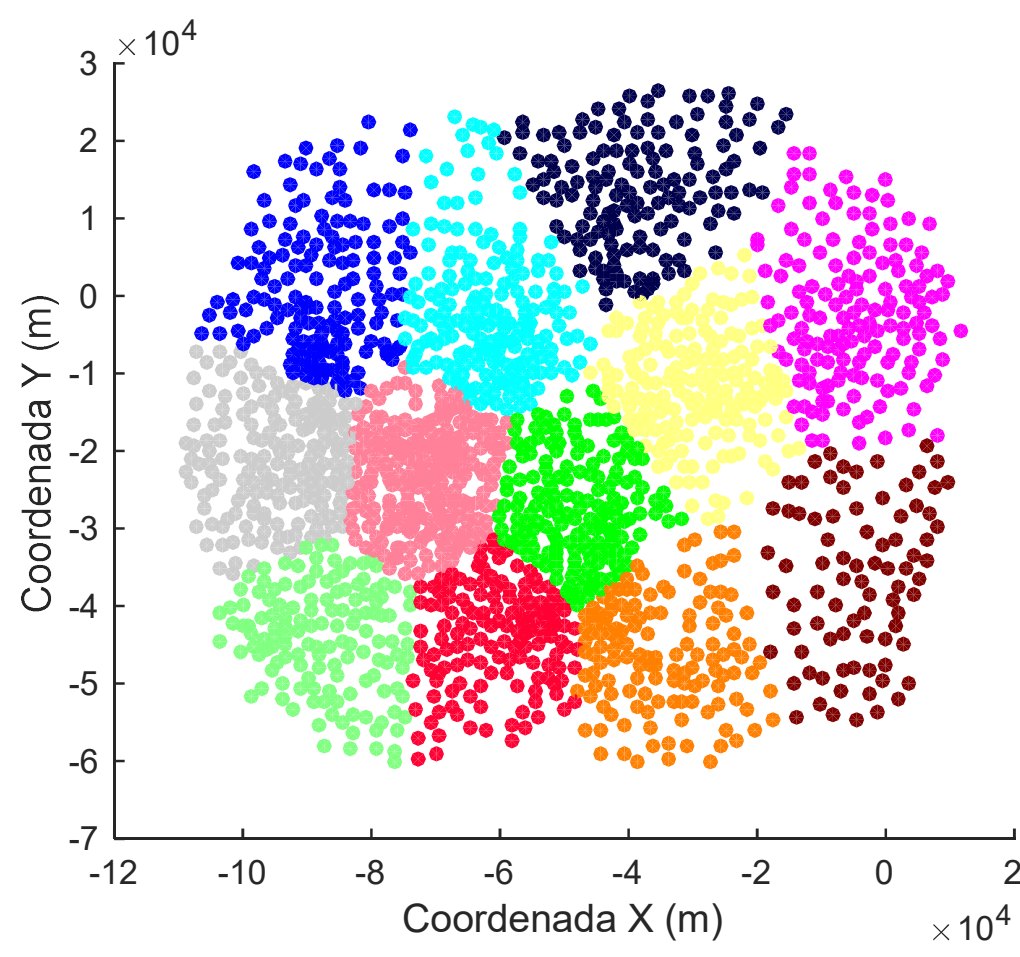

\begin{tabular}{|c|c|}
\hline - & DMC 1 \\
\hline - & DMC 2 \\
\hline - & DMC 3 \\
\hline - & DMC 4 \\
\hline - & DMC 5 \\
\hline - & DMC 6 \\
\hline - & DMC 7 \\
\hline & DMC 8 \\
\hline - & DMC 9 \\
\hline - & DMC 10 \\
\hline - & DMC 11 \\
\hline - & DMC 12 \\
\hline
\end{tabular}

(a)

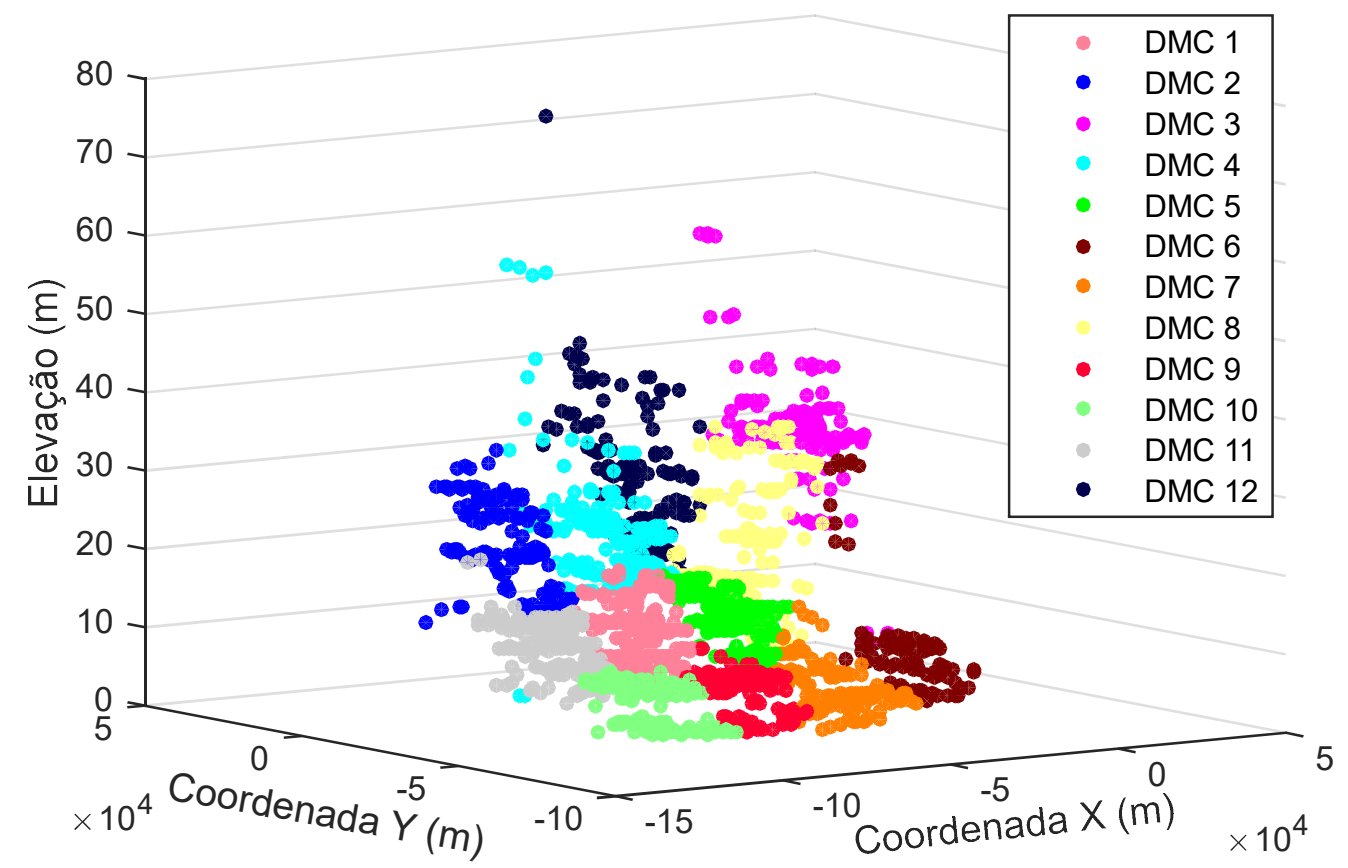

(b)

A Figura 28 e a Figura 29 apresentam a localização das válvulas de isolamento necessárias para a delimitação dos setores, bem como o posicionamento das entradas em cada um deles. 
Figura 28 - Setorização da RDA de Exeter (2 setores) com posicionamento dos fechamentos de setor.

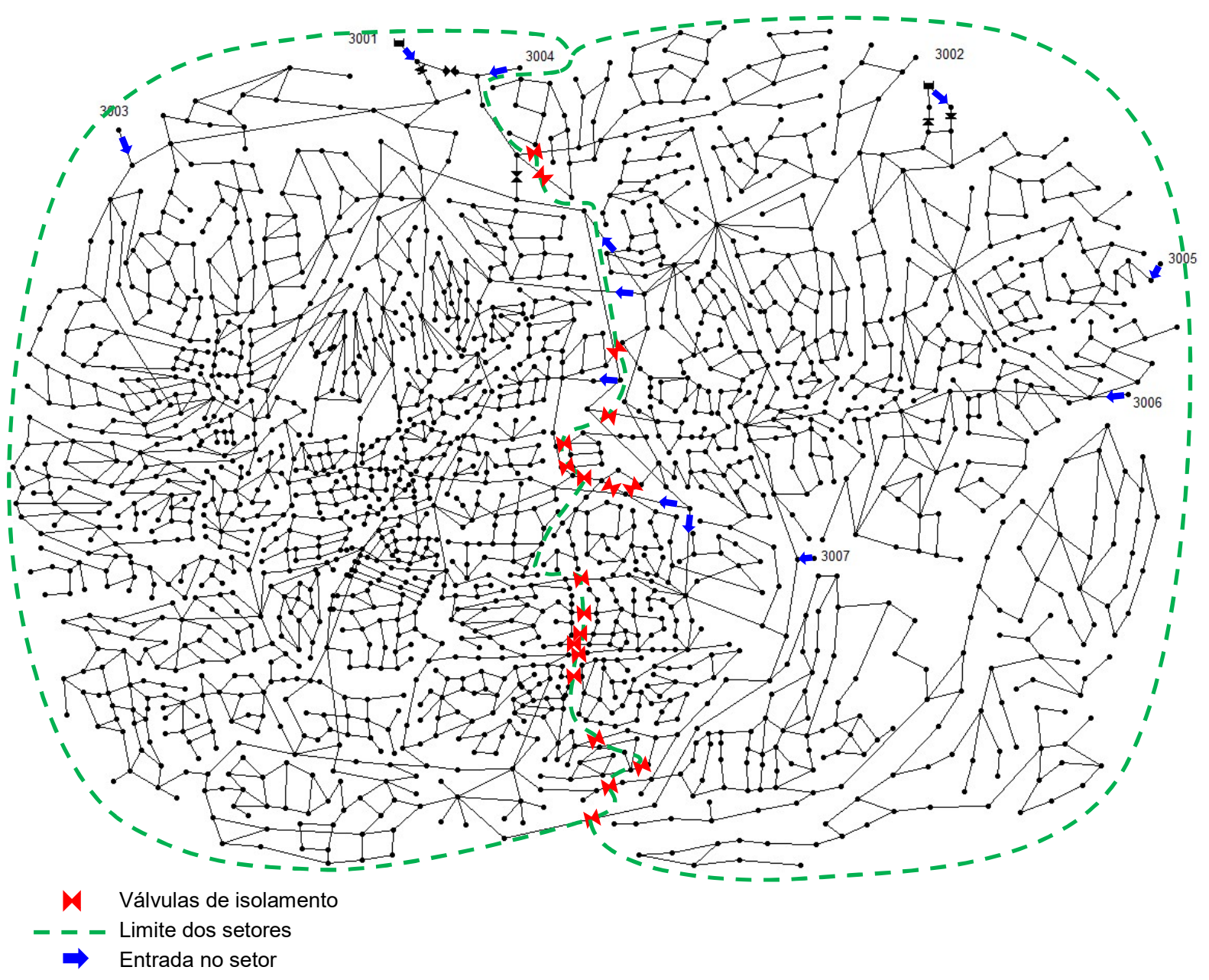


Figura 29 - Setorização da RDA de Exeter (12 setores) com posicionamento dos fechamentos de setor.

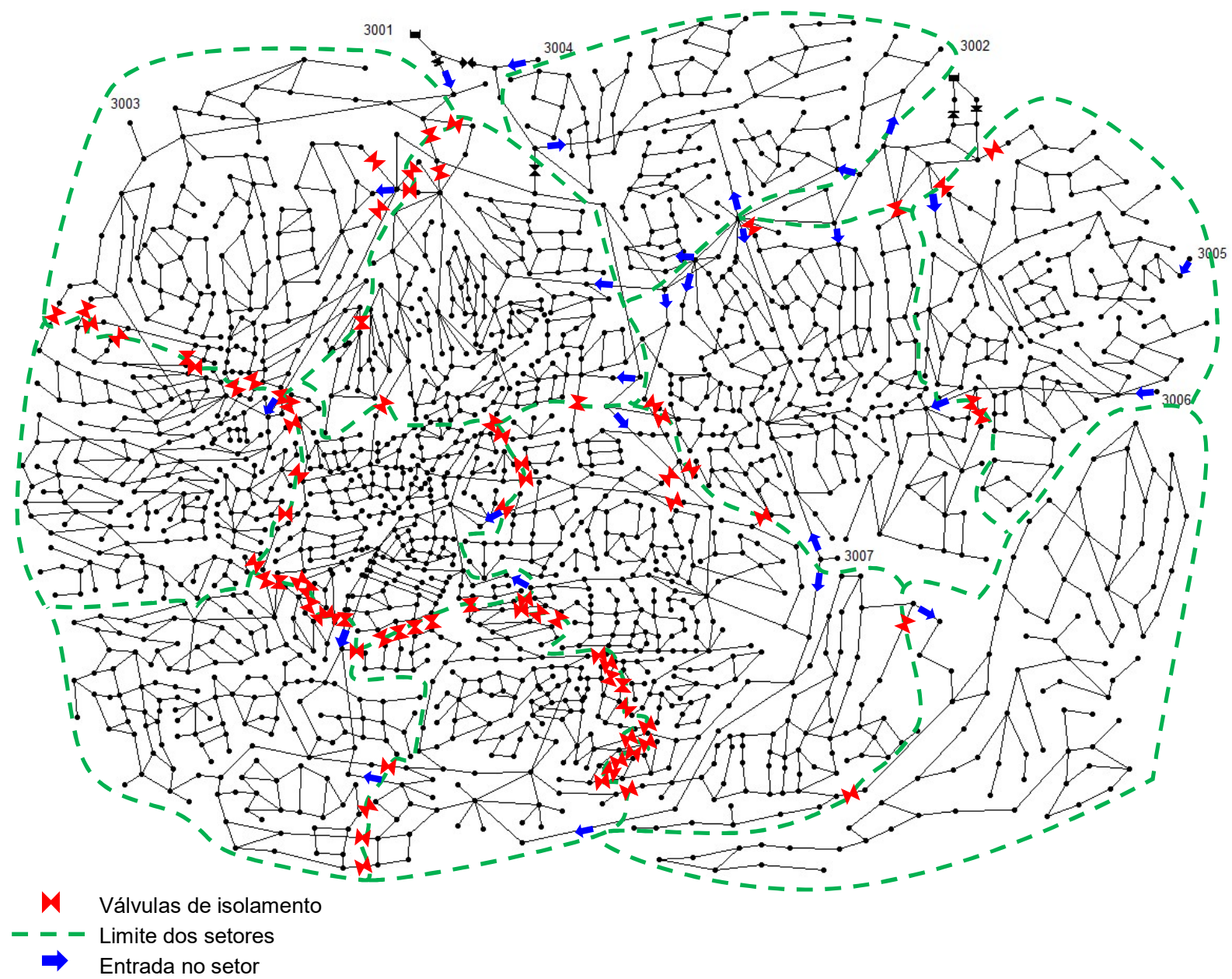

O resultado comparativo das métricas de confiabilidade hidráulica para a rede original e após a setorização proposta pode ser observado na Tabela 12.

Tabela 12 - Comparação entre as métricas de confiabilidade para o sistema original e o sistema após definição da setorização para o Estudo de caso 3 - RDA de Exeter.

\begin{tabular}{|c|c|c|c|c|c|}
\hline & \multicolumn{2}{|c|}{ Confiabilidade Hidráulica } & \multicolumn{2}{|c|}{ Resiliência } & \multirow[b]{2}{*}{ Entropia (S) } \\
\hline & $\begin{array}{l}\text { Estado zero } \\
\qquad\left(\mathrm{R}^{0}\right)\end{array}$ & $\begin{array}{c}1^{\circ} \text { estado } \\
\left(R^{1}\right)\end{array}$ & $\begin{array}{c}\text { Resiliência } \\
\text { da rede } \\
\left(I_{n r}\right)\end{array}$ & $\begin{array}{l}\text { Índice de } \\
\text { Resiliência } \\
\left(I_{r}\right)\end{array}$ & \\
\hline RDA de Exeter Original & 0,800 & 0,654 & 0,18 & 0,19 & 6,77 \\
\hline RDA de Exeter Setorizada (2 setores) & 0,611 & 0,561 & 0,09 & 0,06 & 6,54 \\
\hline RDA de Exeter Particionada (12 setores) & 0,591 & 0,547 & 0,04 & 0,05 & 6,52 \\
\hline
\end{tabular}

Para a RDA original a relação entre a vazão efetivamente distribuída e a vazão demanda é de 0,95. Este resultado não é numericamente igual a $\mathrm{R}^{0}$, como ocorreu para RDA de Pescara e para RDA de Modena. 
O valor mais baixo da confiabilidade estado zero, mesmo com o abastecimento quase pleno do sistema, está relacionado principalmente à probabilidade de falha atribuída às tubulações, que mostra aderência ao que foi observado por Gheisi e Naser (2013) no que diz respeito à influência da disponibilidade dos trechos no calculo da confiabilidade hidráulica para RDA de maior porte.

Observa-se a queda dos índices de confiabilidade com o aumento do número de partições no sistema. Com fechamento de diversas entradas para os setores, a pressão cai drasticamente e o modelo apresenta dificuldades de convergência.

A relação entre a vazão efetivamente distribuída e a vazão demanda para a RDA com dois setores e com doze setores, respectivamente, é igual a 0,64 e 0,62. Ressalta-se aqui a pequena diferença entre os resultados obtidos para os diferentes particionamentos comparado à discrepância na quantidade de setores formados em cada configuração.

As métricas de resiliência da RDA original já são consideravelmente baixas, e o particionamento do sistema fez com que estas caíssem drasticamente. Os desvios para as métricas $I_{n r}$ e $I_{r}$ foram, respectivamente, de $51,03 \%$ e $67,10 \%$, para a RDA com dois setores e $78,67 \%$ e $73,68 \%$, para a RDA com doze setores.

Esta elevada variação das métricas de resiliência se relaciona com o fato de a RDA original já apresentar pressão média muito próxima da desejada (18,8 mca). Para a resiliência, o excedente de pressão na rede é o que promove a capacidade de desta em suportar as elevadas perdas de carga observadas no sistema dada falha em seus componentes.

A entropia apresentou pequena redução entre o valor obtido para a RDA original e as RDA particionadas, diferente do comportamento observado até então para as demais métricas.

O estudo de caso da RDA de Aracy é ligeiramente diferente dos demais, uma vez que se trata de um sistema que já apresenta uma setorização, com três reservatórios abastecendo seus setores de maneira independente. Ressalta-se que os setores não possuem interligações, mesmo que com válvulas de isolamento fechadas, entre si. 
Para este caso foram propostas novas partições e, assim como apresentado para a RDA de Exeter, devido à complexidade do sistema, foi executado o algoritmo $k$-means considerando os quatro índices de validação explicitados no subitem 4.2.4. Os resultados podem ser observados da Figura 30.

Figura 30 - Resultados do número ótimo de clusters para cada um dos índices avaliados para o Estudo de caso 4 - RDA de Aracy.
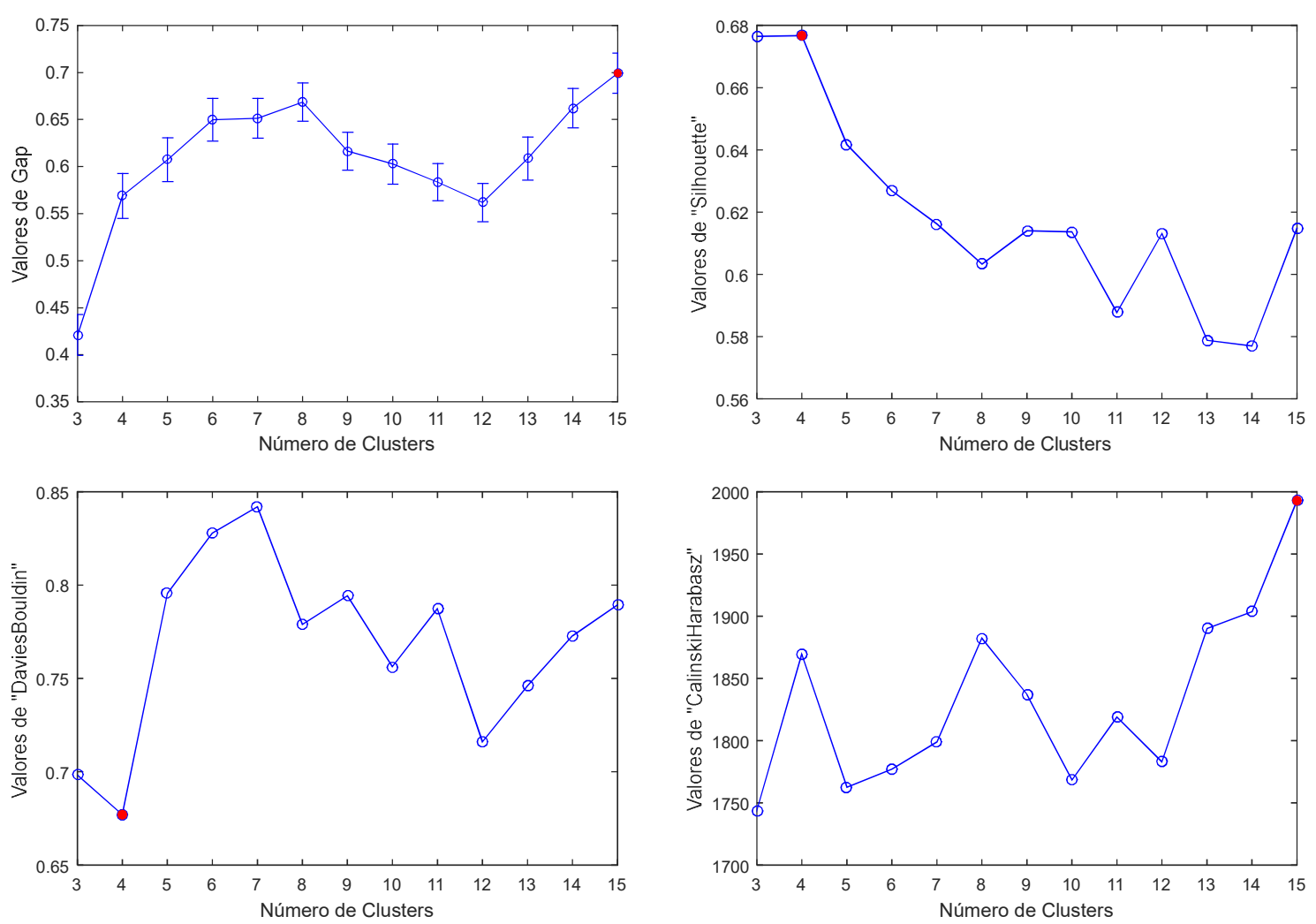

Foram obtidos dois resultados distintos como número ótimo de clusters para este sistema na avaliação dos índices utilizados. Os índices Davies-Bouldin e Silhouette produziram como resposta o número ótimo de partições igual a quatro. Já os índices GAP e Calinski-Harabasz apontaram quinze partições. As partições produzidas como resposta podem ser observadas na Figura 31 e na Figura 32. 
Figura 31 - Setores definidos a partir do algoritmo k-means utilizando os índices Silhouette e Davies-Bouldin para o Estudo de caso 4 -RDA de Aracy (a) nós da rede categorizados por DMC na localização geográfica e, (b) elevação dos nós da rede.

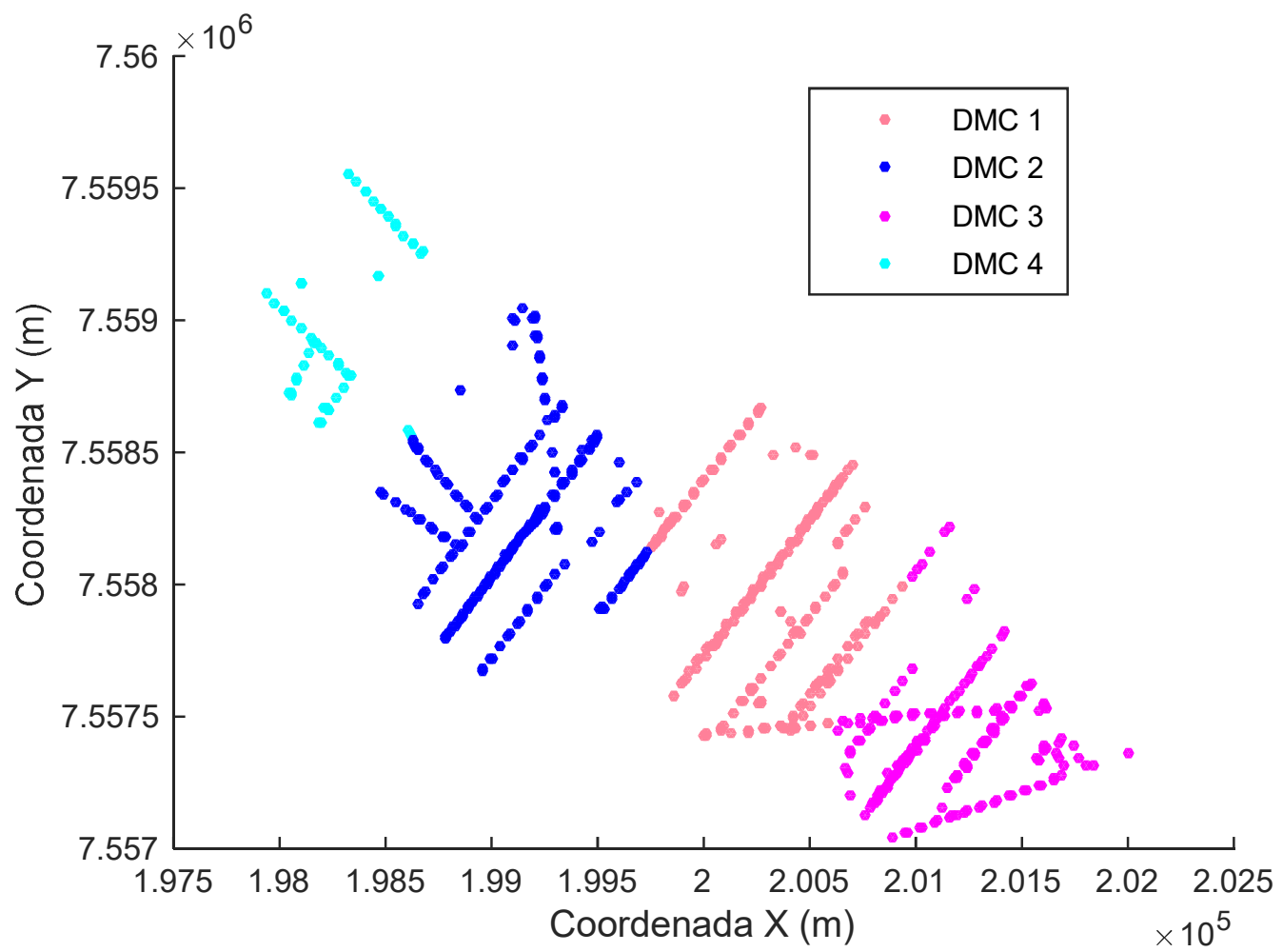

(a)

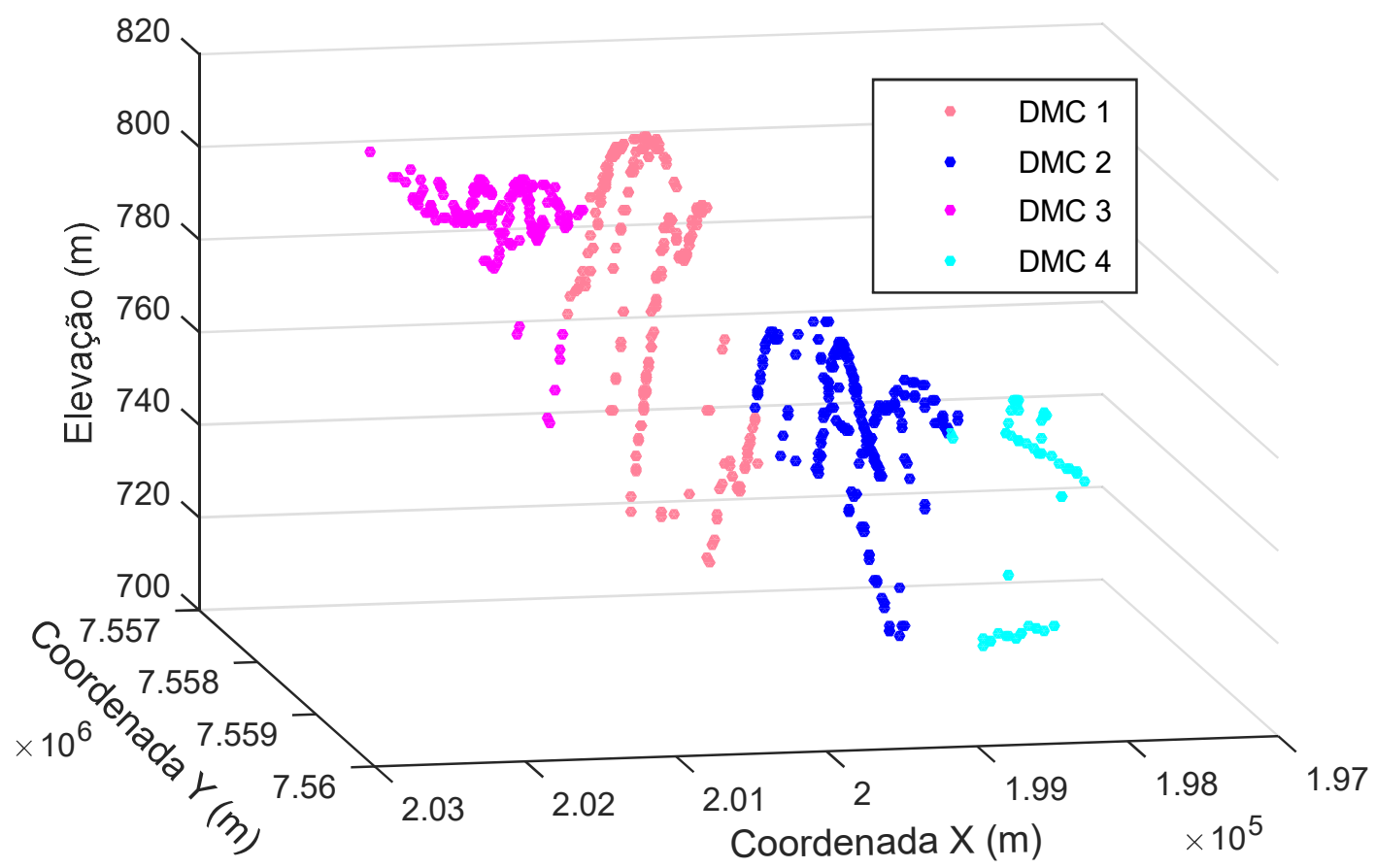

(b) 
Figura 32 - Setores definidos a partir do algoritmo k-means utilizando os índices GAP e Calinski-Harabasz para o Estudo de caso 4 - RDA de Aracy (a) nós da rede categorizados por DMC na localização geográfica e, (b) elevação dos nós da rede.

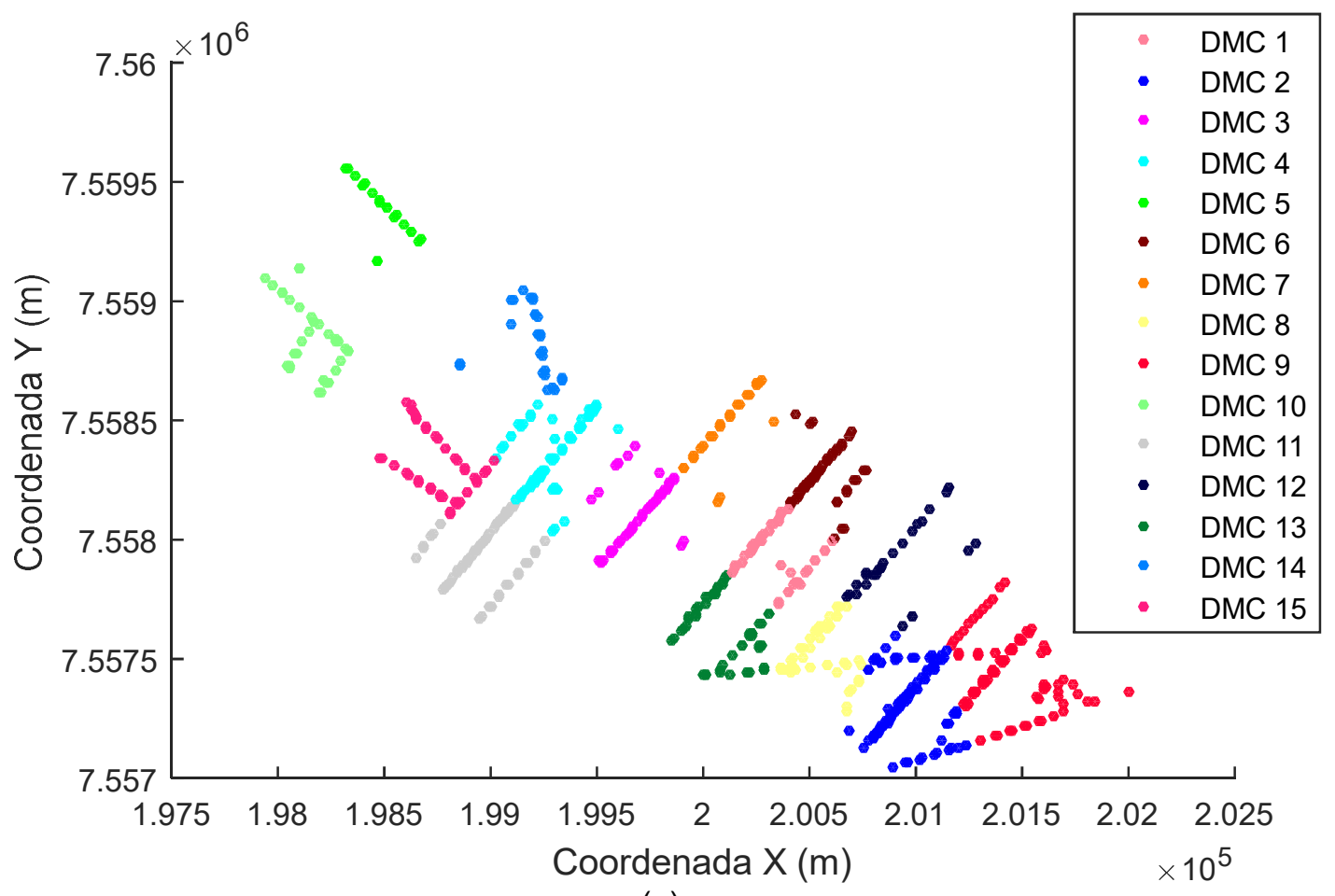

(a)

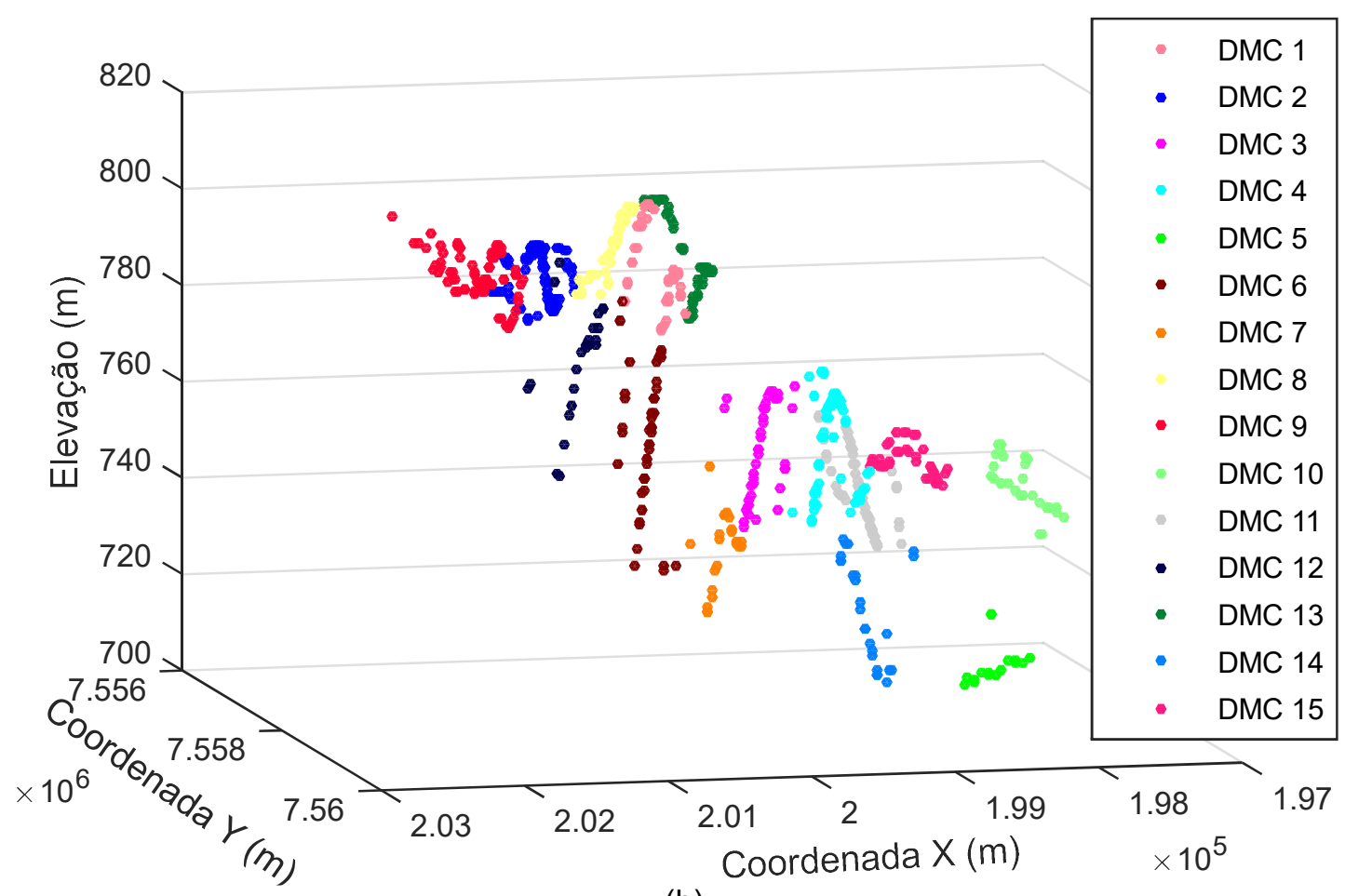

(b)

A Figura 33 e a Figura 34 apresentam a localização das válvulas de isolamento necessárias para a delimitação dos setores, bem como o posicionamento das entradas em cada um deles. 
Figura 33 - Setorização da RDA de Aracy (4 setores) com posicionamento dos fechamentos de setor.

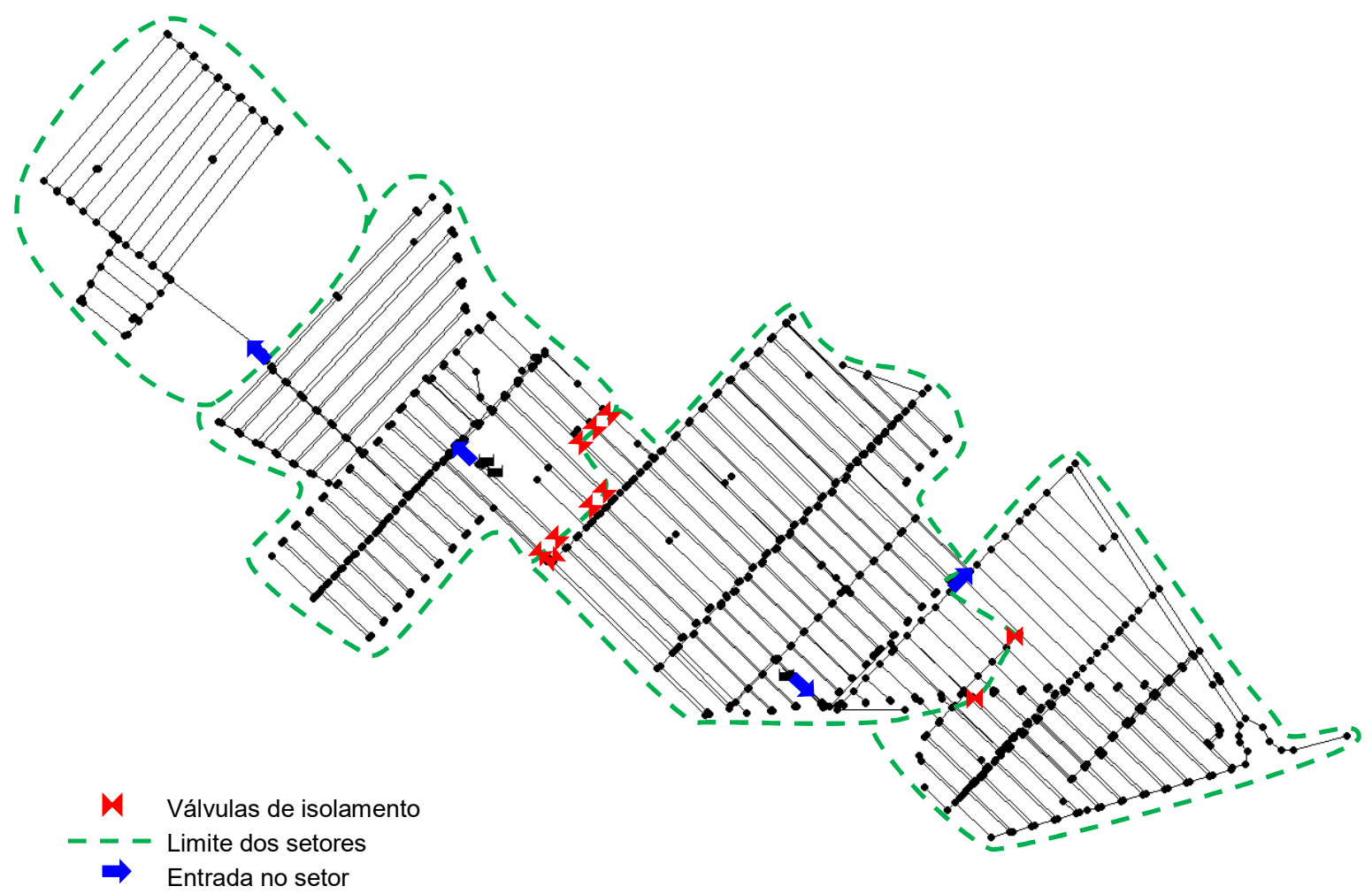


Figura 34 - Setorização da RDA de Aracy (15 setores) com posicionamento dos fechamentos de setor.

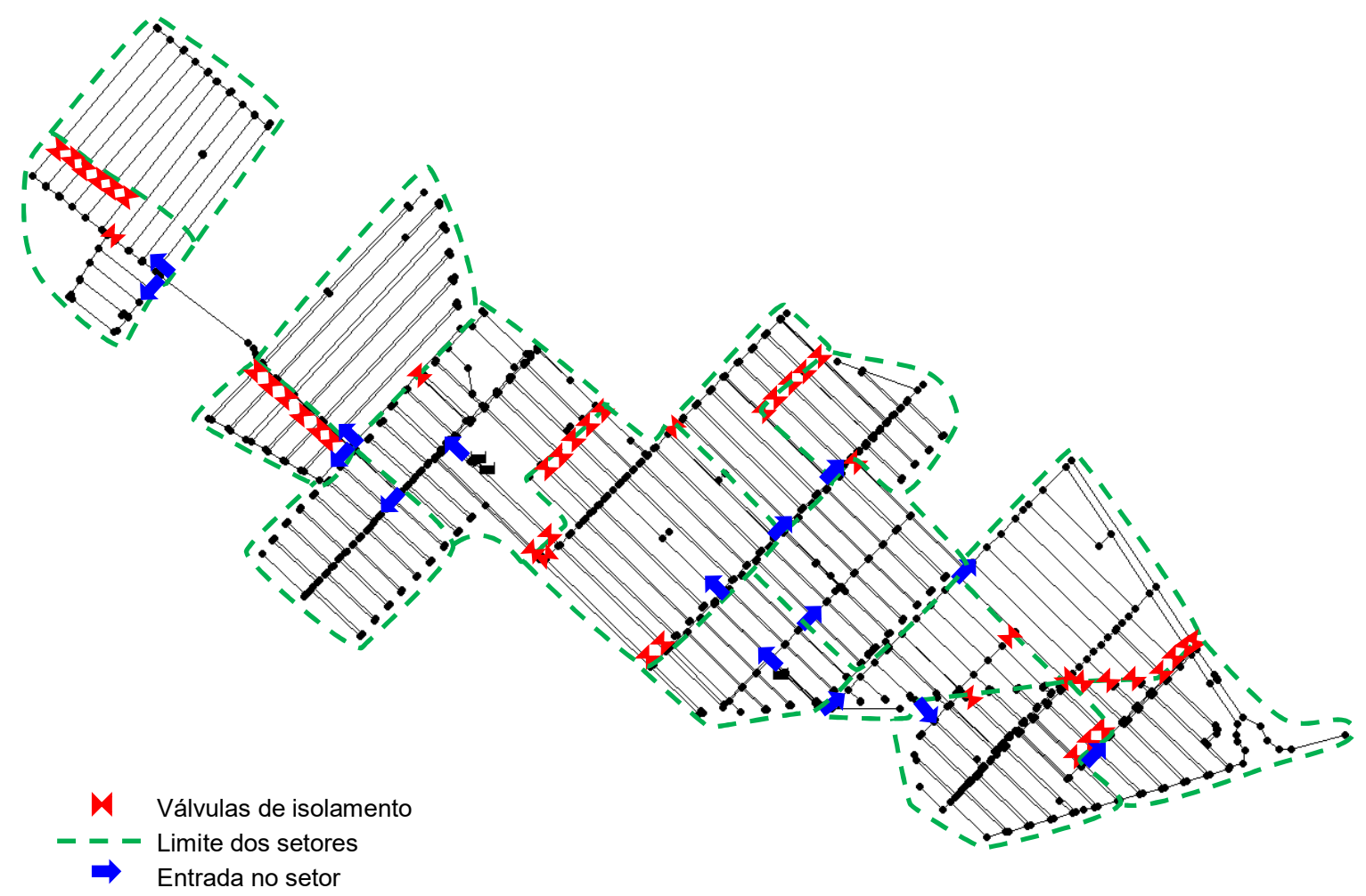

O resultado comparativo das métricas de confiabilidade hidráulica para a rede original e após a setorização proposta pode ser observado na Tabela 13.

Tabela 13 - Comparação entre as métricas de confiabilidade para o sistema original e o sistema após definição da setorização para o Estudo de caso 4 - RDA de Aracy.

\begin{tabular}{lccccc}
\hline & \multicolumn{3}{c}{ Confiabilidade Hidráulica } & \multicolumn{3}{c}{ Resiliência } \\
& $\begin{array}{c}\text { Estado zero } \\
\left(\mathrm{R}^{0}\right)\end{array}$ & $\begin{array}{c}1^{\circ} \text { estado } \\
\left(\mathrm{R}^{1}\right)\end{array}$ & $\begin{array}{c}\text { Resiliência } \\
\text { da rede } \\
\left(\mathrm{I}_{\mathrm{nr}}\right)\end{array}$ & $\begin{array}{c}\text { Resice de } \\
\left(\mathrm{I}_{\mathrm{r}}\right)\end{array}$ & $\begin{array}{c}\text { Entropia } \\
(\mathrm{S})\end{array}$ \\
\hline RDA de Aracy Original (3 setores existentes) $)$ & 0,841 & 0,673 & 0,67 & 0,72 & 6,14 \\
RDA de Aracy Particionada (4 setores) & 0,858 & 0,682 & 0,70 & 0,76 & 6,16 \\
RDA de Aracy Particionada (15 setores) & 0,852 & 0,677 & 0,61 & 0,69 & 6,22 \\
\hline
\end{tabular}

Observa-se que, em se tratando dos índices de confiabilidade hidráulica, houve um aumento entre o valor obtido para a RDA original comparado ao resultado para a RDA particionada.

Para a RDA original a relação entre a vazão efetivamente distribuída e a vazão demanda é de 0,97. Assim como observado para a RDA de Exeter, este valor não é numericamente igual a $\mathrm{R}^{0}$. 
Da mesma forma, esse comportamento se deve à influência da disponibilidade dos trechos no cálculo da confiabilidade hidráulica para RDA de maior porte, como observado por observado por Gheisi e Naser (2013)

Os valores das métricas $\mathrm{NR}$ e $\mathrm{I}_{\mathrm{r}}$, no entanto, apresentaram comportamentos distintos para os dois particionamentos propostos. A RDA com quatro DMC apresentou desvio de $5 \%$ e $6,6 \%$ negativos, devido ao aumento do resultado de ambas as métricas.

Tal aumento é fruto de uma melhoria nas pressões do sistema uma vez que a nova setorização promoveu uma mudança na área de influência do reservatório 3 que apresentava pressões baixas. Com isso, a vazão efetivamente distribuída também aumentou, e por consequência, também os índices $R^{0}$ e $R^{1}$.

Ressalta-se que promover alteração na área de influência dos reservatórios do Sistema Aracy implica em realizar uma interligação inexistente a partir do reservatório 2, uma vez que como explicitado anteriormente, setores originais não possuem interligação entre si.

Na RDA com quinze DMC observa-se uma melhoraria no atendendo às demandas através do aumento da confiabilidade hidráulica. Esta concepção apresenta pressão mínima de 1,3 mca, enquanto a RDA original a pressão mínima era igual a 0,1 mca.

O desvio positivo das métricas $I_{n r}$ e $I_{r}$, de $8 \%$ e $3,4 \%$, respectivamente, está relacionado com os isolamentos de rede necessários, que promovem a redução da pressão média (ainda acima da desejável e atendendo às demandas), diminuindo o resultado dessas métricas que se baseiam do excedente de pressão da rede.

A entropia apresentou aumento em ambas as RDA particionadas, quando comparada à RDA original, seguindo o comportamento do aumento da confiabilidade hidráulica, tanto em $\mathrm{R}^{0}$ quanto em $\mathrm{R}^{1}$.

Ressalta-se que as partições propostas promoveram alteração da área de influência dos reservatórios do sistema. A demanda inicialmente atribuída a cada nó foi mantida mesmo em casos em que determinado nó da rede passou a ser abastecido por um reservatório diferente. Uma vez que não se tem os dados medidos no hidrômetro do cliente, o consumo de cada nó é proporcional à vazão medida na saída do reservatório. 
Com vistas a avaliar a relação existente entre as métricas alternativas e a confiabilidade, a Figura 35 apresenta os coeficientes de determinação encontrados.

Figura 35 - Relação entre a Confiabilidade Hidráulica e as métricas alternativas $I_{n r}$ e $I_{r}$ e $S$.
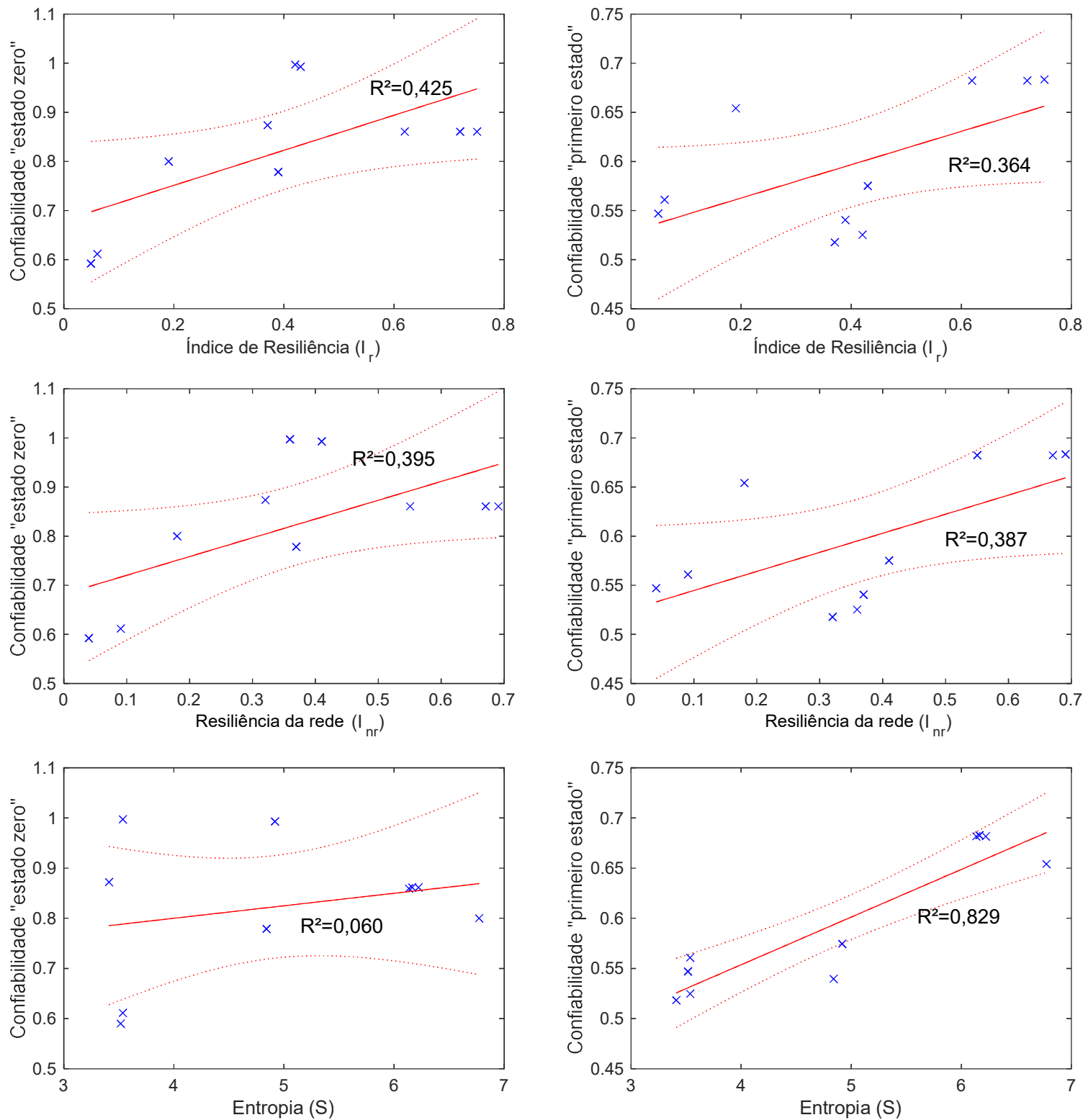

Todas as métricas aqui investigadas apresentaram correlações positivas entre si para os sistemas estudados.

O Índice de Resiliência (Ir) apresentou coeficiente maior quando avaliada sua correlação com a Confiabilidade "estado zero" (Ro), igual a 0,425. Para sua correlação com a Confiabilidade "primeiro estado" foi encontrado coeficiente igual a 0,364. 
A Resiliência da rede $(\ln r)$ apresentou comportamento similar ao observado para o Índice de Resiliência ( $\mathrm{I}_{\mathrm{r}}$ ), correspondendo a uma diminuição menos acentuada no coeficiente com o aumento do estado da Confiabilidade.

De modo geral, ambas as métricas apresentaram correlação positiva com os estados da Confiabilidade, sugerindo que podem ser métricas representativas para a caracterização da confiabilidade hidráulica em RDA.

Já a entropia apresentou coeficiente muito baixo, próxima a zero, quando analisada sua relação com a Confiabilidade "estado zero" ( $\left.R_{0}\right)$, igual6 a 0,060 . No entanto, observa-se um resultado muito maior quando analisada sua relação com a Confiabilidade "primeiro estado", igual a 0,829.

O resultado da entropia é coerente com o notado por Gheise e Naser (2015), que observou crescimento significativo no coeficiente de determinação da entropia quando comparados os diferentes estados da confiabilidade. Isso implica em dizer que a entropia tem melhor representatividade para estados superiores da confiabilidade. 


\section{CONCLUSÕES}

O presente trabalho teve como objetivo analisar e identificar métodos de avaliação da setorização de RDA. Nesse sentido, a literatura apresenta métricas alternativas de confiabilidade que contemplem critérios tais como resiliência e entropia. Resumidamente, a entropia avalia a possibilidade de a água desenvolver trajetórias alternativas no interior dos condutos da rede, visando o atendimento dos consumos, enquanto a resiliência quantifica a capacidade de superação de condições adversas a que a rede pode ser submetida, garantindo níveis de pressão para atendimento dos consumos. Algumas das métricas propostas como índices de avaliação desses dois critérios foram eleitas para o desenvolvimento deste trabalho, denominadas índice de resiliência, a resiliência da rede e a entropia. Os valores obtidos para tais métricas foram comparados ainda com os valores produzidos para a confiabilidade "estado zero" e para a confiabilidade "primeiro estado", que quantificam o atendimento dos consumos, considerando a probabilidade de falhas dos componentes do sistema. Nota-se que, no presente estudo, foi considerada uma falha por vez para os componentes dos sistemas para o cálculo dos índices de confiabilidade hidráulica.

Para a quantificação dessas métricas foi necessário que as RDA fossem simuladas hidraulicamente fazendo uso de modelos mais realistas do ponto de vista do atendimento dos consumos, ou seja, modelos de demanda dirigida pela pressão e de vazamentos. Assim, o trabalho desenvolvido incluiu a análise e a escolha de modelos a serem adotados para a simulação hidráulica dos sistemas estudados.

O algoritmo k-means, recentemente proposto para a setorização de SDA, foi aplicado à setorização das redes de Pescara (Itália), Modena (Itália), Exeter (Inglaterra) e Aracy (São Carlos, SP), considerando como critérios para estabelecer similaridade a proximidade espacial, a elevação e a carga de pressão dos nós das redes.

Os sistemas de Pescara e Modena foram setorizados de fato, ou seja, foram subdivididos em três e quatro setores, respectivamente, em conformidade com o número de reservatórios de tais sistemas. O sistema de Exeter foi setorizado e particionado (níveis maiores de subdivisão) e Aracy foi particionado de duas maneiras (níveis). 
Para efeito de comparação e avaliação dos níveis de setorização assim produzidos, para cada qual desses quatro sistemas, foi avaliado o comportamento das métricas de confiabilidade hidráulica. Pode-se dizer, que, de uma forma geral a setorização implicou na redução dos valores das métricas, com exceção do sistema Aracy, cujas partições promoveram melhoria no atendimento aos consumos, de maneira a produzir valores mais elevados para os indicadores.

O sistema que apresentou maior redução nos valores das métricas devido ao particionamento foi a RDA de Exeter, o que demonstra coerência, uma vez que a RDA original, não particionada, já apresenta pressões abaixo da desejada e com a subdivisão em duas e em doze partições os níveis de pressão diminuíram consideravelmente, gerando o pior resultado em termos de confiabilidade hidráulica para o sistema com doze partições. A RDA de Pescara foi o sistema que apresentou menor redução dos indicadores com o particionamento, o que é coerente com as pressões mínimas observadas no sistema, muito próximas da desejável.

As correlações das métricas alternativas com os índices de confiabilidade hidráulica foram avaliadas. O Índice de Resiliência $\left(I_{r}\right)$ e a Resiliência da rede ( $\left.I_{n r}\right)$ apresentaram boa correlação para ambos "estado zero" e "primeiro estado" da confiabilidade hidráulica, sendo que para o "estado zero" maior coeficiente de determinação foi produzido. Já a entropia apresentou maior correlação com a confiabilidade do "primeiro estado".

Os resultados sugerem a viabilidade de utilização das métricas de confiabilidade como forma de avaliar diferentes níveis de setorização, no que diz respeito à vulnerabilidade do sistema. Recomenda-se, porém que os modelos sejam exaustivamente testados para que maior confiança seja atribuída aos resultados produzidos.

Ressalta-se que, para a RDA de Aracy, foram atribuídos consumos nos nós da rede de acordo com as medições de vazão nas saídas dos reservatórios e, ao reagrupar os nós de consumo em novas partições, estas demandas inicialmente estabelecidas foram mantidas, mesmo quando se alterou a área de influência de cada reservatório.

Acredita-se que a maior fragilidade dos resultados obtidos com o suporte das simulações hidráulicas esteja no fato de que, ao reagrupar nós de consumo, os valores representativos dos consumos máximos podem sofrer alterações significativas. 
Sugere-se a utilização de dados mais precisos de demanda nos nós uma vez que o consumo na rede não é homogêneo, podendo vir a apresentar resultados irreais em termos de demanda para cada setor gerado.

Recomenda-se que em trabalhos de pesquisa futuros o isolamento ótimo dos setores seja considerado, do ponto de vista da implantação e operação, usando válvulas de isolamento ou mesmo de abertura controlada. 


\section{REFERÊNCIAS}

ALPEROVITS, E.; SHAMIR, U. Design of Optimal Water Distribution Systems. Wather Resources Research, v. 13, n. 6, p. 885-900, 1977.

AWUMAH, K.; GOULTER, I.; BHATT, S. K. Entropy-based redundancy measures in water-distribution networks. Journal of Hydraulic Engineering, v. 117, n. 5, p. 595614, 1991.

CALIÑSKI, T.; HARABASZ, J. A Dendrite Method Foe Cluster Analysis. Communications in Statistics, v. 3, n. 1, p. 1-27, 1974.

CAMPBELL, E. et al. A flexible methodology to sectorize water supply networks based on social network theory concepts and multi-objective optimization. Journal of Hydroinformatics, p. jh2015146, 2015.

CESARIO, L. Modeling, Analysis and Design of Water Distribution Systems. Denver, CO: American Water Works Association, 1995.

CHEUNG, P. B.; VAN ZYL, J. E.; REIS, L. F. R. Extension of epanet for pressure driven demand modeling in water distribution system. 8th International Conference on Computing and Control for the Water Industry. Anais...Exeter: 2005

CIAPONI, C.; MURARI, E.; TODESCHINI, S. Modularity-Based Procedure for Partitioning Water Distribution Systems into Independent Districts. Water Resources Management, v. 30, n. 6, p. 2021-2036, 2016.

CIMORELLI, L. et al. Comparison Among Resilience and Entropy Index in the Optimal Rehabilitation of Water Distribution Networks Under Limited-Budgets. Water Resources Management, p. 3997-4011, 2018.

CONEJOS, M. P.; ALZAMORA, F. M.; ALONSO, J. C. A Water Distribution System Model to Simulate Critical Scenarios by Considering Both Leakage and Pressure Dependent Demands. Procedia Engineering, v. 186, n. May, p. 380-387, 2017.

CREACO, E.; FRANCHINI, M.; TODINI, E. The combined use of resilience and loop diameter uniformity as a good indirect measure of network reliability. Urban Water Journal, v. 13, n. 2, p. 167-181, 2016.

CULLINANE, B. M. J.; LANSEY, K. E.; MAYS, L. W. Optimization-availability-based design of water-distribution networks. v. 118, n. 3, p. 420-441, 1992.

DAVIES, D. L.; BOULDIN, D. W. A Cluster Separation Measure. IEEE Transactions on Pattern Analysis and Machine Intelligence, v. PAMI-1, n. 2, p. 224-227, 1979.

DI NARDO, A. et al. An Automated Tool for Smart Water Network Partitioning. Water Resources Management, v. 27, n. 13, p. 4493-4508, 2013.

DI NARDO, A. et al. Performance indices for water network partitioning and sectorization. Water Science and Technology: Water Supply, v. 15, n. 3, p. 499509, 2015.

DI NARDO, A. et al. Water Distribution Network Clustering: Graph Partitioning or Spectral Algorithms? v. 3, p. 1197-1209, 2018. 
DI NARDO, A.; DI NATALE, M. A heuristic design support methodology based on graph theory for district metering of water supply networks. Engineering Optimization, v. 43, n. 2, p. 193-211, 2011.

DI NARDO, A.; DI NATALE, M.; SANTONASTASO, G. F. A comparison between different techniques for water network sectorizationWater Science and Technology: Water Supply, 2014.

FARMANI, R.; SAVIC, D. A.; WALTERS, G. A. Evolutionary multi-objective optimization in water distribution network design. Engineering Optimization, v. 37, n. 2, p. 167-183, 2005.

FERRARI, G.; SAVIC, D.; BECCIU, G. Graph-Theoretic Approach and Sound Engineering Principles for Design of District Metered Areas. Journal of Water Resources Planning and Management, v. 140, n. 12, p. 04014036, 2014.

FORMIGA, K. T. M.; CHAUDHRY, F. H. Modelos de análise hidráulica de redes de distribuição de água considerando demanda dirigida pela pressão e vazamentos. Engenharia Sanitaria e Ambiental, v. 13, n. 2, p. 153-162, 2008.

FORMIGA, K. T. M.; CHAUDHRY, F. H.; VIERIA, M. E. A. G. Otimização Multiobjetivo De Redes De Abastecimento De Água. VI SEREA - Seminário Iberoamericano sobre Sistemas de Abastecimento Urbano de Água. Anais...João Pessoa: 2006

FUJIWARA, O.; LI, J. Reliability analysis of water distribution networks in consideration of equity, redistribution, and pressure-dependent demand. Water Resources Research, v. 34, n. 7, p. 1843-1850, jul. 1998.

FUJIWARA, O.; TUNG, H. D. Reliability improvement for water distribution networks through increasing pipe size. Water Resources Research, v. 27, n. 7, p. 1395-1402, 1991.

GARGANO, R.; PIANESE, D. Influence of Hydraulic and Mechanical Reliability of Water Networks. 26th Convegno di Idraulica e Costruzioni Idrauliche. Anais...Catania: 1998

GARGANO, R.; PIANESE, D. Reliability as Tool for Hydraulic Network Planning. Journal of Hydraulic Engineering, v. 126, n. 5, p. 354-364, 2000.

GERMANOPOULOS, G. A technical note on the inclusion of pressure dependent demand and leakage terms in water supply network models. Civil Engineering Systems, v. 2, n. September, p. 171-179, 1985.

GHEISI, A; NASER, G. Multistate Reliability of Water-Distribution Systems: Comparison of Surrogate Measures. Journal of Water Resources Planning and Management, v. 141, n. 10, p. 04015018, 2015.

GHEISI, A.; FORSYTH, M.; NASER, G. Water Distribution Systems Reliability: A Review of Research Literature. Journal of Water Resources Planning and Management, v. 142, 2016.

GHEISI, A.; NASER, G. Water distribution system reliability under simultaneous multicomponent failure scenario. Journal - American Water Works Association, v. 
106, n. 7, p. 83-84, 2014a.

GHEISI, A.; NASER, G. A surrogate measure for multi-component failure based reliability analysis of water distribution systems. Procedia Engineering, v. 89, p. 333$338,2014 b$.

GHEISI, A. R.; NASER, G. On the significance of maximum number of components failures in reliability analysis of water distribution systems. Urban Water Journal, v. 10, n. 1, p. 10-25, 2013.

GHORBANIAN, V.; KARNEY, B. W.; GUO, Y. Minimum Pressure Criterion in Water Distribution Systems: Challenges and Consequences. World Environmental and Water Resources Congress 2015, n. Lambert 2000, p. 777-791, 2015.

GIUSTOLISI, O.; RIDOLFI, L. New Modularity-Based Approach to Segmentation of Water Distribution Networks. Journal of Hydraulic Engineering, v. 140, n. 10, p. 04014049, 2014.

GIUSTOLISI, O.; WALSKI, T. M. Demand Components in Water Distribution Network Analysis. Journal of Water Resources Planning and Management, v. 138, n. 4, p. 356-367, 2012.

GOULTER, I. Analytical and simulation models for reliability analysis in water distribution systems. In: CABRERA, E.; VELA, A. (Eds.). . Improving efficiency and reliability in water distribution systems. Dordrecht: Kluwer Academic Publishers, 1995.

GOULTER, I. et al. Reliability Analysis for Design. In: MAYS, L. W. (Ed.). . Water Distribution Systems Handbook. New York: McGraw Hill, 2000.

GÜNTER, S.; BUNKE, H. Validation indices for graph clustering. Pattern Recognition Letters, v. 24, n. 8, p. 1107-1113, 2003.

JAYARAM, N.; SRINIVASAN, K. Performance-based optimal design and rehabilitation of water distribution networks using life cycle costing. Water Resources Research, v. 44 , n. 1, p. 1-15, 2008.

JOWITT, P. W.; XU, C. Optimal Valve Control in Water-Distribution Networks. Journal of Water Resources Planning and Management, v. 116, n. 4, p. 455-472, 1990.

JUN, L.; GUOPING, Y. Iterative Methodology of Pressure-Dependent Demand Based on EPANET for Pressure-Deficient Water Distribution Analysis. v. 139, n. 2, p. 34-44, 2013.

JUNG, D. et al. Linear Model for Estimating Water Distribution System Reliability. Journal of Water Resources Planning and Management, v. 142, n. 8, 2016.

LANSEY, K.; MAYS, L. W.; TUNG, Y. K. Reliability and Availability Analysis od Water Distribution Systems. In: MAYS, L. W. (Ed.). . Urban water supply handbook. New York: McGraw Hill, 2002.

LAUCELLI, D. B. et al. Optimal Design of District Metering Areas for the Reduction of Leakages. Journal of Water Resources Planning and Management, v. 143, n. 6, p. 04017017, jun. 2017. 
LIU, H. et al. A diameter-sensitive flow entropy method for reliability consideration in water distribution system design. Water Resources Research, v. 50, n. 7, p. 55975610, 2014.

LIU, H. et al. Comparing topological partitioning methods for district metered areas in the water distribution network. Water (Switzerland), v. 10, n. 4, 2018.

MAHMOUD, H. A.; SAVIC, D.; KAPELAN, Z. New Pressure-Driven Approach for Modeling Water Distribution Networks. Journal of Water Resources Planning and Management, v. 143, n. 8, p. 1-11, 2017.

MAULIK, U.; BANDYOPADHYAY, S. Performance evaluation of some clustering algorithms and validity indices. IEEE Transactions on Pattern Analysis and Machine Intelligence, v. 24, n. 12, p. 1650-1654, 2002.

MURANHO, J. et al. Pressure-dependent demand and leakage modelling with an EPANET extension - WaterNetGen. Procedia Engineering, v. 89, p. 632-639, 2014.

NOVARINI, B. et al. Mixed Computational and Hydraulic Criteria for DMA Creation Using Hybrid SOM + k-Means Algorithms. Congreso de Métodos Numéricos en Ingeniería, n. June, p. 1-14, 2017.

PACCHIN, E.; ALVISI, S.; FRANCHINI, M. Analysis of Non-Iterative Methods and Proposal of a New One for Pressure-Driven Snapshot Simulations with EPANET. Water Resources Management, v. 31, n. 1, p. 75-91, 2017.

PRASAD, T. D.; PARK, N.-S. Multiobjective Genetic Algorithms for Design of Water Distribution Networks. Journal of Water Resources Planning and Management, v. 130, n. 1, p. 73-82, 2004.

RAAD, D. N.; SINSKE, A. N.; VAN VUUREN, J. H. Comparison of four reliability surrogate measures for water distribution systems design. Water Resources Research, v. 46, n. 5, p. 1-11, 2010.

ROSSMAN, L. A. Computer Models/EPANET. In: MAYS, L. W. (Ed.). . Water Distribution Systems Handbook. New York: McGraw Hill, 2000a.

ROSSMAN, L. A. EPANET 2: Users Manual. Cincinnati, Ohio: U.S. Environmental Protection Agency, 2000b.

ROUSSEEUW, P. J. Silhouettes: A graphical aid to the interpretation and validation of cluster analysis. Journal of Computational and Applied Mathematics, v. 20, p. 5365, nov. 1987.

SCARPA, F.; LOBBA, A.; BECCIU, G. Elementary DMA Design of Looped Water Distribution Networks with Multiple Sources. Journal of Water Resources Planning and Management, v. 142, n. 6, p. 1-9, 2016.

SELA PERELMAN, L. et al. Automated sub-zoning of water distribution systems. Environmental Modelling \& Software, v. 65, p. 1-14, mar. 2015.

SHANNON, C. E. A Mathematical Theory of Communication. Bell System Technical Journal, v. 27, n. 3, p. 379-423, 1948. 
TANYIMBOH, T. T. et al. Comparison of Surrogate Measures for the Reliability and Redundancy of Water Distribution Systems. Water Resources Management, v. 30, n. 10 , p. 3535-3552, 2016.

TANYIMBOH, T. T.; TABESH, M.; BURROWS, R. Appraisal of Source Head Methods for Calculating Reliability of Water Distribution Networks. Journal of Water Resources Planning and Management, v. 127, n. 4, p. 206-213, ago. 2001.

TANYIMBOH, T. T.; TEMPLEMAN, A. B. Optimum Design of Flexible Water Distribution Networks. Civil Engineering Systems, v. 10, n. 3, p. 243-258, 1993a.

TANYIMBOH, T. T.; TEMPLEMAN, A. B. Maximum Entropy Flows for Single-Source Networks. Engineering Optimization, v. 22, n. 1, p. 49-63, $1993 \mathrm{~b}$.

TANYIMBOH, T. T.; TEMPLEMAN, A. B. A New Method for Calculating the Reliability of Single-Source Networks. 6th International Conference on Computing in Civil and Structural Engineering. Anais...Cambridge: 1995

TANYIMBOH, T. T.; TEMPLEMAN, A. B. Calculating the reliability of single-source networks by the source head method. Advances in Engineering Software, v. 29, n. 7-9, p. 499-505, 1998.

TANYIMBOH, T. T.; TEMPLEMAN, A. B. Seamless pressure-deficient water distribution system model. Institution of Civil Engineers: Water Management. Anais...2010

TANYIMBOH, T.; TAHAR, B.; TEMPLEMAN, A. Pressure-driven modelling of water distribution systems. 3rd World Water Congress. Anais...Melbourne: 2002

TIBSHIRANI, R.; WALTHER, G.; HASTIE, T. Estimating the number of clusters in a data set via the gap statistic. Journal of the Royal Statistical Society. Series B: Statistical Methodology, v. 63, n. 2, p. 411-423, 2001.

TODINI, E. Looped water distribution networks design using a resilience index based heuristic approach. Urban Water, v. 2, n. 2, p. 115-122, 2000.

TODINI, E.; PILATI, S. A gradient method for the analysis of pipe networks. In: COULBECK, B.; CHUN-HOU, O. (Eds.). . Computer Application in Water Supply. Vol. I - System Analysis and Simulation. London: John Wiley \& Sons, 1987.

TUCCIARELLI, T.; CRIMINISI, A.; TERMINI, D. Leak Analysis in Pipeline Systems by means of Optimal Valve Regulation. Journal of Hydraulic Engineering, v. 125, n. 3, p. 277-285, 1999.

WAGNER, J. M.; SHAMIR, U.; MARKS, D. H. Water Distribution Reliability: Simulation Methods. Journal of Water Resources Planning and Management, v. 114, n. 3, p. 276-294, 1988.

WANG, H.; CHEN, X. Optimization of Maintenance Planning for Water Distribution Networks under Random Failures. Journal of Water Resources Planning and Management, v. 142, n. 2, 2016.

WANG, Q. et al. Two-Objective Design of Benchmark Problems of a Water Distribution System via MOEAs: Towards the Best-Known Approximation of the True Pareto Front. 
Journal of Water Resources Planning and Management, v. 141, n. 3, p. 04014060 , mar. 2015.

WU, Z. Y. et al. Extended Global-Gradient Algorithm for Pressure-Dependent Water Distribution Analysis. Journal of Water Resources Planning and Management, $v$. 135, n. February, p. 13-22, 2009.

XU, C.; GOULTER, I. C. Reliability-Based Optimal Design of Water Distribution Networks. Journal of Water Resources Planning and Management, v. 125, n. 6, p. 352-362, 1999. 